\title{
Universiteit
}

Leiden

The Netherlands

\section{Complement in health and disease}

Seelen, Marc A.

\section{Citation}

Seelen, M. A. (2005, June 23). Complement in health and disease. Retrieved from https://hdl.handle.net/1887/3738

Version: $\quad$ Corrected Publisher's Version

Licence agreement concerning inclusion of doctoral

License: $\quad$ thesis in the Institutional Repository of the University of Leiden

Downloaded from: $\quad$ https://hdl.handle.net/1887/3738

Note: To cite this publication please use the final published version (if applicable). 
Complement in health and disease 



\section{Complement in health and disease}

\section{Proefschrift}

ter verkrijging van

de graad van Doctor aan de Universiteit Leiden, op gezag van de Rector Magnificus Dr. D.D. Breimer,

hoogleraar in de faculteit der Wiskunde en Natuurwetenschappen en die der Geneeskunde, volgens besluit van het College voor Promoties te verdedigen op donderdag 23 juni 2005

klokke 16:15 uur

door

Marcus Antonius Johannes Seelen geboren te Delft in 1967 


\section{Promotiecommissie}

Promotor $\quad$ Prof. Dr. M.R. Daha

Co-promotor Dr. A. Roos

Referent Prof. Dr. C.E. Hack (Crucell BV/VV, Amsterdam)

Overige leden Prof. Dr. B.A.C. Dijkmans (VU, Amsterdam)

Dr. C. van Kooten

Prof. Dr. P.S. Hiemstra

Prof. Dr. C.G.M. Kallenberg (UMCG, Groningen)

Prof. Dr. T.W.J. Huizinga

Prof. Dr. J.M.J.J. Vossen

The studies described in this thesis were supported by grants of the European Union (EU-QLGI-CT2001-01039), the Dutch Kidney Foundation and Wieslab IDEON.

Additional financial support from Dutch Arthritis Association, 3A-out foundation, Roche, Genzyme, Pfizer, Fujisawa, MSD, Novartis, Wyeth, Amgen, Servier, Nycomed and AstraZeneca is also gratefully acknowledged.

ISBN: 9036723000

(C) Marc Seelen

Printing by: Stichting Drukkerij C. Regenboog, Groningen 
"To read well is to be read by that which we read"

(Jean Baptiste Siméon)

Aan Mariken, Dominique en Wouter Aan mijn ouders 


\section{Table of contents}

$\begin{array}{lll}\text { Chapter } 1 & \text { Introduction }\end{array}$

Chapter $2 \quad$ Activation of the lectin pathway in murine lupus nephritis 33

Chapter 3 Autoantibodies against mannose binding lectin (MBL)

in systemic lupus erythematosus

Chapter 4 A role for mannose-binding lectin dysfunction in generation of autoantibodies in systemic lupus erythematosus

Chapter 5 Functional analysis of the classical, alternative, and MBL pathway of the complement system: standardization and validation of a simple ELISA

Chapter 6 Age and gender-associated changes of complement activity in a healthy Caucasian population

General discussion

Summary

Nederlandse samenvatting

Nawoord

Curriculum Vitae

Publications 


\section{Chapter 1}

\section{INTRODUCTION}




\section{Systemic lupus erythematosus}

Clinical features

Pathogenesis

Lupus nephritis and the role of autoantibodies and complement

The complement system

Pathways of complement activation

Mannose-binding lectin, the recognition protein of the MBL pathway of complement activation

Function of mannose-binding lectin

Mannose-binding lectin in disease

Infectious diseases

Non-infectious diseases

\section{Complement deficiencies and disease}

Assessment of the functional activity of the complement pathways

Scope of the thesis

\section{References}




\section{Systemic lupus erythematosus}

\section{Clinical features}

SLE is a typical systemic autoimmune disease characterised by widespread involvement of organs including serosa, joints, central nervous system, skin and kidneys. The incidence of SLE varies between geographic areas, genders and ages. Women during their childbearing years and black Americans and Hispanics have the highest incidence. The incidence for northern Europe is about 40 per 100,000 ${ }^{1 ; 2}$. Diagnostic criteria for SLE are based on the classification criteria for SLE introduced by the American College of Rheumatologists. Although these criteria were meant for research purposes, to categorise patients for clinical trials, they are also used in clinical practise. On the bases of these clinical trials new drug therapies were developed for treatment of the disease and for supportive care. With the introduction of steroids and cytotoxic agents the 5year survival rate of patients with SLE dramatically increased from $50 \%$ in the fifties to over $90 \%$ in the nineties ${ }^{3 ; 4}$. However, with the improved results for treatment of active disease after introduction of aggressive immunosuppressive drugs, undesirable side effects became also more apparent. Therefore, treatment of a patient with SLE is a challenging quest for every doctor working in this field.

\section{Pathogenesis}

Multiple factors are involved in the pathogenesis of SLE i.e., genetic, immunological, hormonal, viral and environmental factors. The precise aetiology of SLE, however, is unknown. An important role for genetic predisposition is suggested by the concordance of SLE in identical twins (20-50\%) and dizygotic twins (5\%) ${ }^{5}$. Many different genes have been demonstrated to contribute to disease susceptibility. However, in some patients a single gene may be responsible, as been reported for homozygous deficiency of $\mathrm{C} 1 \mathrm{q}$, the first component of the classical pathway of complement activation ${ }^{6}$.

Numerous immunologic abnormalities have been distinguished in patients with SLE, all concerning immune dysregulation related to loss of self-tolerance, as characterized by $\mathrm{B}$ cell hyperactivity, autoantibody production, and immune complex formation ${ }^{7}$. The central immunological disturbance in patients with SLE is autoantibody production. Autoantibodies against a variety of self-antigens can be detected in sera of patients with SLE. An important group of autoantibodies is directed against nucleosomes and their different elements. Anti-nuclear antibodies occur in more than 95 percent of SLE patients and anti-dsDNA antibodies are the characteristic autoantibodies found in patients with SLE ${ }^{8}$. Specific autoantibodies in serum from patients with SLE are associated with certain disease characteristics. Anti-SSA and anti-SSB antibodies are associated with cardiac involvement in SLE and anti-cardiolipin antibodies are associated with thrombotic events, whereas anti-DNA and anti-C1q antibodies are associated with lupus nephritis ${ }^{9-14}$. In patients with SLE antibodies directed against other components of the complement system have also been reported (Table 1). The clinical significance of these autoantibodies, however, is not always clear. Furthermore, most of these autoantibodies are also found in sera from patients with other diseases 
Table 1. Autoantibodies against complement components, convertases, complement receptors and complement regulatory proteins in patients with SLE

\begin{tabular}{|c|c|c|}
\hline Antibody & Disease association & References \\
\hline \multirow[t]{12}{*}{ Anti-C1q } & SLE & 12 \\
\hline & Hypocomplementaemic urticarial & 122 \\
\hline & vasculitis syndrome & \\
\hline & $\begin{array}{l}\text { Felty's syndrome } \\
\text { Rheumatoid arthritis }\end{array}$ & 123 \\
\hline & Rheumatoid vasculitis & 123 \\
\hline & Classic polyarthritis nodosa & 123 \\
\hline & Sjögren's syndrome & 124 \\
\hline & Mixed connective tissue disease & 123 \\
\hline & Polychondritis & 123 \\
\hline & Temporal artritis & 123 \\
\hline & Mixed cryoglobulinaemia & 123 \\
\hline & Glomerulonephritis & $123 ; 125-127$ \\
\hline Anti-C1s & SLE & 128 \\
\hline Anti-MBL & SLE & 129 \\
\hline Anti-C4 & SLE & 130 \\
\hline \multirow[t]{5}{*}{ C3NeF } & SLE & 131 \\
\hline & Post streptococcal & 132 \\
\hline & glomerulonephritis & 133 \\
\hline & MPGN & 134 \\
\hline & Partial lipodystrophy & \\
\hline \multirow[t]{4}{*}{ Immunoconglutinins } & SLE & 135 \\
\hline & Rheumatoid arthritis & 135 \\
\hline & PNH & 136 \\
\hline & Chronic liver disease & 137 \\
\hline \multirow[t]{3}{*}{ Anti-CR1 } & SLE & 138 \\
\hline & Colitis & 139 \\
\hline & Liver cirrhosis & 140 \\
\hline \multirow{6}{*}{ Anti-Calreticulin } & SLE & 141 \\
\hline & Multiple sclerosis & 142 \\
\hline & Sjogrens Syndrome & 143 \\
\hline & Primary billiary cirrhosis & 144 \\
\hline & Coeliac disease & 145 \\
\hline & Congenital heart block & 146 \\
\hline
\end{tabular}


than SLE and the presence of some of these autoantibodies has been reported in healthy individuals ${ }^{15}$. It has recently been suggested that autoantibodies are present and accumulate many years before patients develop the clinical characteristics of SLE ${ }^{16}$. Therefore, apparently healthy individuals with circulating autoantibodies might develop the clinical characteristics of SLE later on.

\section{Lupus nephritis and the role of autoantibodies and complement}

Lupus nephritis (LN) is a frequent complication of SLE with major influence on morbidity and mortality ${ }^{17: 18}$. In contrast to the female predominance in acquiring SLE the incidence of renal disease for patients with SLE is equal between males and females ${ }^{19}$ The incidence of LN is higher in younger patients and those from African-American origin ${ }^{19 ; 20}$. Although treatment of lupus nephritis with new immune-suppressive drugs has improved renal outcome, progression towards end-stage renal disease is still an important complication for patients with LN. For diagnostic, therapeutic and prognostic purposes the pathology of lupus nephritis has been classified according to the criteria of the Word Health Organisation (WHO). Recently a revised version of the WHO lupus nephritis classification has been developed to improve treatment strategy and research quality in $\mathrm{LN}^{21}$. One of the important criteria for the histological diagnosis of LN is the presence of antibodies and complement assessed by immunofluorescent staining of renal biopsies.

The original model proposed to explain the presence of autoantibodies and complement deposited in inflammatory lesions in glomeruli of patients with SLE and renal involvement, was that immune complexes consisting of autoantigens and autoantibodies activate complement and their subsequent deposition in renal tissue causes local inflammatory injury. Patients with SLE and lupus nephritis show decreased serum complement levels of the classical and the alternative pathway during active phases of disease which is associated with organ damage ${ }^{22-24}$. Both anti-DNA and anti-C1q antibodies are present in renal tissue demonstrated by elution of these antibodies from kidneys from patients with lupus nephritis ${ }^{25-27}$. Increased serum levels of both antiDNA and anti-C1q autoantibodies are present in patients with lupus nephritis and a rise of serum levels of these autoantibodies can predict a flare of disease activity ${ }^{28,29}$. A rise in anti-DNA antibodies is most sensitive for predicting all kinds of disease exacerbations, whereas a rise in anti-C1q has the highest specificity for predicting a renal relapse ${ }^{28}$. A potentially pathogenic mechanism for renal injury by anti-C1q antibodies has been suggested by showing stabilization of deposited C1q in renal capillaries by anti-C1q antibodies ${ }^{30}$. Recently it has been demonstrated that deposition of IgG in the kidney is essential for $\mathrm{C} 1 \mathrm{q}$ deposition and subsequent binding of anti-C1q antibodies. Enhanced activation of neutrophils triggered by binding of the Fc-fragments from IgG augmented by the presence of anti-C1q antibodies and activation of the complement system, leads to tissue damage ${ }^{31}$.

Besides a detrimental role of complement in the effector-phase of the disease, when locally activated, increasing evidence is presented of an protective role of complement 
in the induction-phase of the disease. As mentioned above autoantibodies are present in the induction phase, before clinical onset, of the disease. Different hypotheses for linking complement to the generation of autoantibodies are currently under investigation. One of the hypotheses proposes that complement plays a role in determining the threshold of activation of $\mathrm{B}$ and $\mathrm{T}$ lymphocytes and that complement deficiency causes autoantibody production and subsequently tissue damage by impairing the normal mechanism of tolerance induction and maintenance ${ }^{32}$. Another hypothesis involves the role of complement in physiological waste-disposal mechanisms, in particular the clearance of dying cells and immune complexes. Complement deficiency has therefore been suggested to impair normal mechanisms of waste disposal and consequently this material can be a source of autoantigens ${ }^{33 ; 34} . \mathrm{C} 1 \mathrm{q}$ has been shown to bind to late apoptotic material and to play an important role in their clearance via $\mathrm{C} 1 \mathrm{q}$ receptors present on cells of the mononuclearphagocyte system ${ }^{35 ; 36}$. The important role of C1q has been most clearly shown in studies with C1q-deficient mice ${ }^{37}$. These mice develop a proliferative glomerulonephritis characterized by the presence of apoptotic cells. Not only C1q has been shown to be involved in uptake of apoptotic cells, this has also been demonstrated for MBL and other molecules that can activate the complement system, such as human C-reactive protein (CRP) and IgM ${ }^{36 ; 38-40}$. In patients with SLE, defective uptake of apoptotic cells, for other reasons than C1q deficiency, might trigger an autoimmune response against $\mathrm{C} 1 \mathrm{q}$ leading to production of anti-C1q autoantibodies. Hypothetically a similar mechanism of defective uptake of apoptotic cells might generate other autoantibodies directed against proteins playing a role in clearance of apoptotic material, such as antibodies directed against MBL.

\section{The Complement system}

\section{Pathways of complement activation}

The complement system is a major constituent of the innate immune defence system and is involved in initiation of adaptive immunity ${ }^{22 ; 23}$. Activation of different complement components in an enzymatic cascade reveals three different pathways of complement activation, the classical pathway, the alternative pathway and the lectin pathway, each with its own recognition mechanism. These pathways converge at the central component of the complement system, C3. The final common pathway leads to the formation of a protein complex on a complement-activating surface, named the membrane attack complex (MAC) (Fig. 1).

Of the three initiating pathways the classical pathway $(\mathrm{CP})$ is activated via binding of its recognition molecule $\mathrm{C} 1 \mathrm{q}$ to immunoglobulins i.e., IgG and IgM, acute phase proteins, charged molecules, and apoptotic or necrotic cell debris. A conformational change of the $\mathrm{C} 1 \mathrm{q}$ molecule, when bound to its substrate, results in activation of the serine proteases $\mathrm{C} 1 \mathrm{r}$ and $\mathrm{C} 1 \mathrm{~s}$, which are associated with the collagen-like tail of the C1q molecule. C1s activate C4 and C2 leading to the formation of the C4b2a complex. This complex or convertase leads to activation of the central complement component C3. 


\section{Classical Pathway Lectin Pathway}

Immune complexes

$\lg G \lg M$
Carbohydrates

$\lg \mathrm{A}$
Alternative Pathway

Bacterial surfaces

LPS IgA

MBL
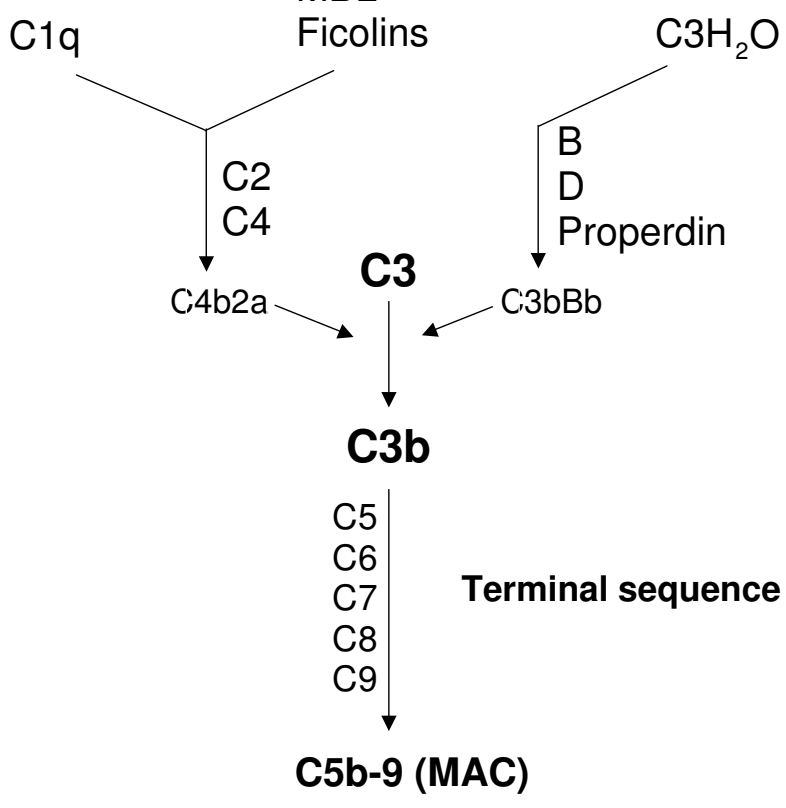

Figure 1. The three activation pathways of the complement system (MAC= membrane attack complex)

The alternative pathway (AP) is activated by $\mathrm{C}_{3}\left(\mathrm{H}_{2} \mathrm{O}\right)$ which is continuously formed by hydrolysis of $\mathrm{C} 3$. Activated $\mathrm{C} 3$ binds factor $\mathrm{B}$ and a $\mathrm{C} 3$ convertase, $\mathrm{C} 3\left(\mathrm{H}_{2} \mathrm{O}\right) \mathrm{Bb}$, is formed after cleavage and activation of factor $\mathrm{B}$ by factor $\mathrm{D}$. This convertase is stabilized by properdin and can subsequently activate C3. Activated C3 can bind factor B and subsequent activation of factor $\mathrm{B}$ leads to formation of a more active $\mathrm{C} 3$ converta$\mathrm{se}, \mathrm{C} 3 \mathrm{bBb}$. Activation of the alternative pathway is controlled by regulatory proteins such as factor $\mathrm{H}$ and $\mathrm{I}$.

Activation of the lectin pathway occurs in response to recognition of mannose-binding lectin (MBL) and ficolins (L-ficolin and $\mathrm{H}$-ficolin) of various carbohydrate ligands. Complement activation and formation of the lectin pathway $\mathrm{C} 3$ convertase via MBL and ficolins resemble the classical pathway, but MASP-2 appears to be responsible for mediating the activation as a substitute for C1s. After activation of $\mathrm{C} 2$ and $\mathrm{C} 4$, the same complement components as in the classical pathway cascade, the $\mathrm{C} 3$ convertase of the lectin pathway, C4b2a, is formed.

The terminal pathway is similar for all three initiating pathways. Incorporation of a $\mathrm{C} 3 \mathrm{~b}$ molecule in the $\mathrm{C} 3$ convertases leads to the formation of a C 5 convertase. C5 is 
activated and subsequent binding of $\mathrm{C} 6, \mathrm{C} 7, \mathrm{C} 8$, and $\mathrm{C} 9$ results in the formation of the membrane attack complex C5b-9.

During the activation of complement, cleavage fragments of complement components are generated which are chemotactic factors such as C5a. Furthermore, C4b and C3b can opsonize particles by binding to the surface leading to recognition of these particles by phagocytes.

The major source of most circulating complement components is the liver. In contrast to the components generated in the liver, C1q production is mainly extra-hepatic by bone marrow-derived cells like macrophages and dendritic cells ${ }^{41}$. However, many other organs are capable of synthesizing complement components. There is increasing evidence that this locally generated complement is biologically active and exerts powerful effects within the local environment. For instance, it has been shown that local production complement components is involved in immune mediated damage and allograft rejection ${ }^{42}$.

Soon after birth the serum complement levels reach adult levels under normal physiological circumstances. Much less is known about differences in complement activity in adults. Increase in classical pathway activity during age has been described with increasing levels of C1q, C4, C3 and C9 ${ }^{43}$. For the alternative pathway reduced levels of factor B with increasing age has been reported ${ }^{43}$. Recently Ip et al. ${ }^{44}$ reported a tendency to lower MBL concentrations in the elderly. Also differences between complement levels and gender have been reported ${ }^{45 ; 4}$. The clinical relevance of the difference in complement level between genders and during ageing remains to be established.

\section{Mannose binding lectin, one of the recognition proteins of the lectin pathway of complement activation}

\section{Mannose-binding lectin}

Mannose-binding lectin is one of the members of the human plasma lectins. Other members are the pulmonary surfactant proteins SP-A and SP-D 47. These proteins, also termed "collectins", belong to the C-type or $\mathrm{CA}^{2+}$-dependent lectin superfamily 48. Characteristic features of the collectins is that they contain a collagenous region and a lectin domain (carbohydrate recognition domain, CRD) through which they can bind various saccharides, a quality that enables the collectins to interact with different microbial pathogens. MBL binding to sugar moieties involves hydrogen bonds of four amino acid residues. The orientation of the hydroxyl groups determines the selectivity of MBL binding, N-acetyl glucosamine > L-fucose, mannose, N-acetyl mannosamine $>$ maltose $>$ glucose $>>$ galactose, $\mathrm{N}$-acetyl galactosamine. The weak affinity of the CRD for one monosaccharide makes multiple binding sites through clustering of CRD and many repeating sugar groups on the microbial surface necessary. Because most carbohydrate structures in animals are terminated by sugar moieties not recognised by the collectins, such as galactose and sialic acid, MBL discriminates between self and non-self. 
Circulating MBL as well as other collectins comprise structural subunits each composed of three identical polypeptide chains of $32 \mathrm{kDa}$ assembled to higher-order oligomeric structure containing two up to six of these trimeric subunits. Each chain consists of a lectin domain, a hydrophobic neck region, a collagenous region and an $\mathrm{N}$-terminal region. Disulphide bridges and non-covalent bonds create stability between these subunits. By electron microscopy the structure of MBL resembles a bouquet-like shape similar to that of C1q (Fig. 2).
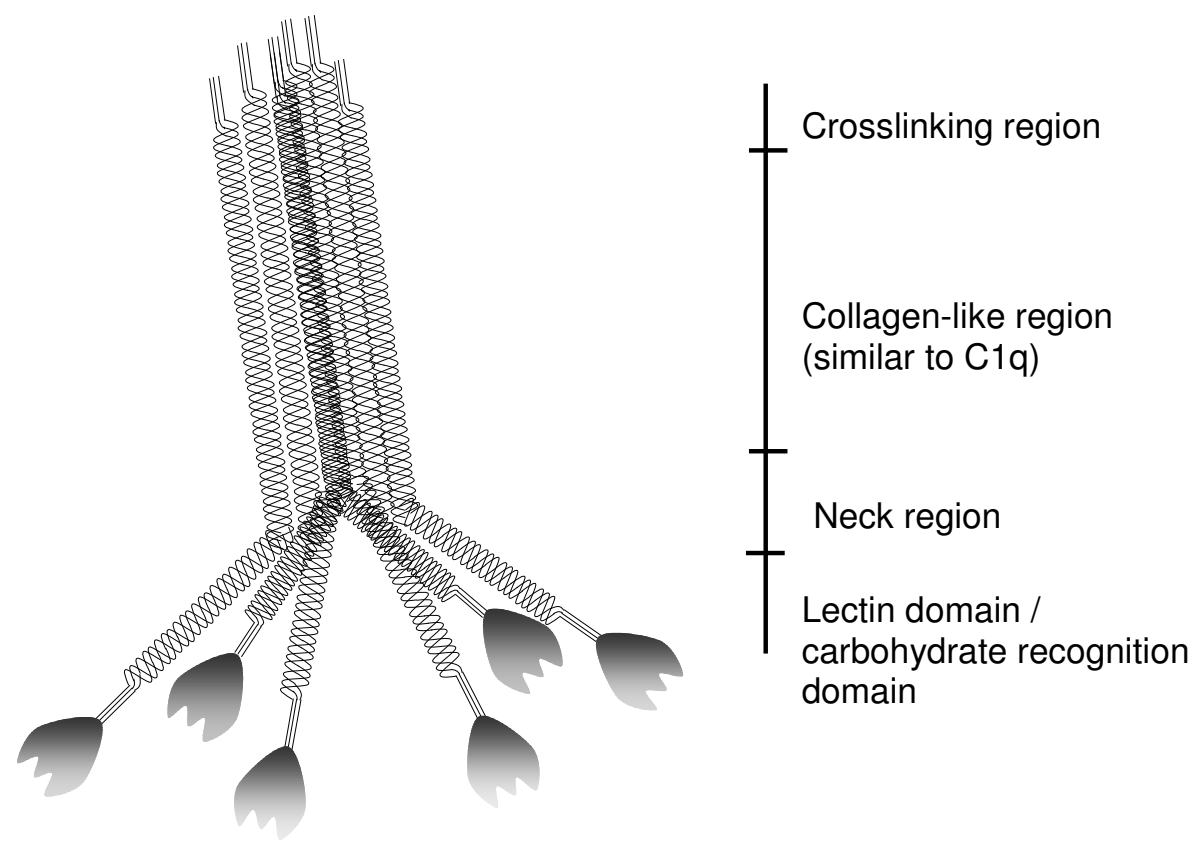

Figure 2. Schematic model of $M B L$.

MBL is mainly produced in the liver by hepatocytes and the rate of synthesis is to some extent influenced by stress. Therefore MBL is reported as an acute phase protein ${ }^{49}$. At birth MBL plasma levels are about two thirds of adult levels. Within a few weeks after delivery the adult plasma levels are reached ${ }^{50}$. The plasma concentration of MBL varies very much within the population from as low as a $10 \mathrm{ng} / \mathrm{ml}$ to $10 \mu \mathrm{g} / \mathrm{ml}$. This variation is largely genetically determined. The amount of MBL increases only up to three-fold during an acute phase response. In contrast to one serum form of MBL in man, in rodents two serum forms of MBL have been described ${ }^{51}$. Both mouse MBL-A and MBL-C are present in serum and are able to activate the MBL pathway of the complement system ${ }^{52}$.

The proteins of the collectin family are encoded by a cluster of genes on the long arm of chromosome $10^{53}$ apart from CL-P1 and CL-L1 which are located on chromosome 8 and 18, respectively. In man MBL is encoded by a single gene consisting of four exons in contrast to rat and mice which have two functional MBL genes encoding the two 
MBL serum forms ${ }^{54}$. Exon 1 encodes the $\mathrm{N}$ terminal region, a cysteine rich-region and part of the collagenous region. Exon 2 encodes the remainder of the collagenous region. Exon 3 encodes the hydrophobic neck region and exon 4 the C-terminal carbohydrate recognition domain. Upstream of the structural MBL gene the promoter region of $\mathrm{MBL}$ is located ${ }^{55}$. Four allelic forms of the MBL gene, i.e. the normal $\mathrm{A}$ allele and three variant alleles, B, C and D have been reported. These SNP are found in the collagen-like region and are considered to prevent the correct formation of a triple helix. The first report on MBL deficiency due to a structural mutation in codon ${ }^{54}$ of exon 1 of the MBL gene (allel B) was in 1991 by Sumiya et al ${ }^{56}$. This single nucleotide polymorphism (SNP) at base 230 of exon 1 caused a change of codon ${ }^{54}$ from GGC to GAC. Substitution of an aspartic acid for a glycine in the translated protein affects the secondary structural stability in the collagenous region of the molecule. This mutation showed an autosomal dominant co-inheritance with low MBL levels. Also a SNP at codon ${ }^{57}$ (allele C), frequently found in sub-Saharan Africans, results in a replacement of a glycine by a glutamic acid and disruption of the secondary structure ${ }^{57}$. A third mutation in exon one at codon ${ }^{52}$ (allele D) of the MBL gene causes a replacement of a cysteine for an arginine but with less effect on protein levels ${ }^{58}$. SNPs have also been described in the promoter region of the MBL gene influencing the gene expression and thereby the MBL plasma concentration. This could explain the wide variation of serum MBL concentrations found in A/A genotype individuals ${ }^{55,59}$.

\section{Function of mannose-binding lectin}

Mannose-binding lectin as an element of the innate immune system plays an important role in the first line of defence before the adaptive systems become active. Crucial for innate as well as for adaptive defence is the central concept of distinguishing between self and non-self, from potentially injurious and non-injurious microorganisms. The innate immune system discriminates between self and non-self via pathogen-associated molecular patterns (PAMPs). These PAMPs are unique components of the surface of infectious agents and are recognised by pattern-recognition receptors. Mannose-binding lectin, as well as CRP and SAP are members of secreted pattern recognition molecules ${ }^{60}$. Other pattern recognition receptors are present as cell surface receptors expressed on macrophages mediating phagocytosis of microorganisms. For example, Macrophage mannose receptor (MMR) is a member of the C-type lectin family and interacts with a variety of gram-positive and gram-negative bacteria and fungal pathogens.

A wide variety of bacteria, viruses and fungi are bound by MBL ${ }^{61}$. Once MBL recognizes a microbial surface complement is activated via MASP-2, which leads to opsonization of microorganisms with $\mathrm{C} 4 \mathrm{~b}$ and $\mathrm{C} 3 \mathrm{~b}$. Opsonized microorganisms can subsequently be cleared via complement receptors expressed on phagocytic cells ${ }^{62}$. In addition, further activation of the complement system on the microbial surface may results in the formation of the membrane attack complex and cell lysis. The clinical consequence of MBL deficiency in relation to infectious diseases is discussed below.

The importance of innate immunity in host defence against invading microorganisms is well established. In recent years it has become clear that the innate immune system 
also plays an important role in non-inflammatory handling of dying host cells. Binding of MBL and other collectins to apoptotic material has been demonstrated ${ }^{38}$. Furthermore, enhanced uptake of apoptotic cells via MBL by macrophages is mediated by calreticulin and CD91. Also uptake of apoptotic cells by DC is facilitated by $\mathrm{MBL}^{63}$. The ligand for MBL on apoptotic material has not been identified yet. Recently, DNA present on apoptotic material has been proposed as possible ligand for MBL on apoptotic material ${ }^{64}$.

\section{Mannose-binding lectin in disease}

\section{Infectious diseases}

The importance of MBL for host defence in early childhood is well established and has led to the suggestion that the role for MBL is particularly important after the decay of passively acquired maternal antibodies and before the maturation of own antibodies ${ }^{65}$. Furthermore, MBL has been hypothesised to act in the first line of defence at the time of primary contact with invading microorganism and therefore called "ante-antibody" ${ }^{166}$. The importance of MBL in childhood is well illustrated in two large-scale studies on MBL deficiency and infections ${ }^{6768}$. In both studies an increased susceptibility to infections was identified in heterozygous and homozygous MBL deficiency. Preliminary results of a prospective study also confirmed the higher prevalence of MBL mutant genotype in children with infectious diseases ${ }^{69}$. More recently, association of MBL polymorphisms with sepsis and fatal outcome in patients with systemic inflammatory response syndrome was reported ${ }^{70}$. Also associations of MBL deficiencies with infections as complications in underlying diseases such as asthma, COPD, cystic fibrosis and SLE have been demonstrated ${ }^{71-74}$. On the other hand for some infectious diseases one might benefit from an MBL deficiency as has been described for intracellular infections with $\mathrm{M}$. tuberculosis and $\mathrm{M}$. leprae ${ }^{75,76}$.

Association of MBL deficiency with viral infections has also been investigated. MBL deficiency predisposes to susceptibility to HIV infection ${ }^{77-79}$. Reports on the progression of HIV in relation to MBL deficiency are conflicting ${ }^{7779: 80}$. Also findings on the association of MBL deficiency with hepatitis $C$ are controversial ${ }^{81,82}$. MBL deficiency has been shown to be associated with susceptibility and progression of hepatitis $B{ }^{83,84}$. Furthermore, MBL deficiency is found to be associated with the recurrence of candidiasis ${ }^{85,86}$.

\section{Non-infectious diseases}

\section{Rheumatoid arthritis}

Inconsistent results have been reported on MBL insufficiency and predisposition to rheumatoid arthritis ${ }^{87-92}$. Some reports have suggested that MBL insufficiency might be a progression factor in RA. However, other groups do not show an association between MBL insufficiency and progression of disease ${ }^{87}$. The mechanism by which 
MBL could influence inflammation in patients with RA has not been established. Interaction of MBL with aggregated IgG-G0 has been demonstrated and might be imported in RA ${ }^{93}$. MBL has a binding affinity for IgG from patients with RA because IgG from RA patients expose more $\mathrm{N}$-acetylglucosamine, since the Fc-portion contains less terminal galactose molecules (agalactosyl IgG or IgG-G0) ${ }^{94}$. Binding of MBL to IgG-G0 results in complement activation and therefore, might enhance clearance of IgG-G0 immune complexes in patients with RA. On the other hand complement activation on IgG-G0 immune complexes present in the joints of RA patients might aggravate joint destruction. Furthermore, enhanced risk for infections because of an MBL insufficiency might also participate in the development of the disease in RA patients ${ }^{90}$. In mouse models it has been demonstrated using different complement knockout and Fc-receptor knockout strains that activation of the alternative pathway and possibly the MBL pathway of complement plays an important role in the pathogenesis of RA. It has been hypothesised that the damage in RA is not caused by formation of the membrane attack complex but by the chemotactic effect of C5a on neutrophils ${ }^{95}$

\section{IgA nephropathy}

Primary IgA nephropathy is the most common form of glomerulonephritis worldwide ${ }^{96}$. Deposition of predominantly polymeric IgA of the IgA1-subclass and complement components are found in the glomerular mesangium ${ }^{97}$. In rats complement activation by dimeric and polymeric IgA and subsequent glomerular damage has been demonstrated ${ }^{98}$. Abnormal glycosylation of IgA molecules has been proposed to play a role in the pathological mechanism leading to renal deposition ${ }^{98 ; 9}$. The presence of C3 in mesangium from patients with IgA nephropathy has been suggested to result from alternative pathway activation because it is generally accepted that the classical pathway of complement is not activated by $\operatorname{IgA}{ }^{100}$. However, in $30 \%$ of biopsies from IgA nephropathy kidney also deposition of $C 4$ is found ${ }^{98 ; 101}$ and only in $6 \%$ deposition of C1q. Therefore, complement activation via the MBL pathway has been suggested. Co-deposition of IgA with MBL in kidney biopsies form IgA nephropathy patients has been demonstrated ${ }^{98 ; 102}$. Furthermore, it has been shown that MBL binds to IgA via its lectin domain resulting in activation of the complement system ${ }^{103}$. Generation of the C5b-9 complex in sublytic concentrations can activate the mesangium to produce proinflammatory mediators as well as matrix proteins ${ }^{98 ; 104}$.

\section{Systemic lupus erythematosus}

From clinical studies in SLE patients it seems that MBL could play a role both in the induction and in the effector-phase of the disease. MBL gene polymorphisms have been shown to be associated with the onset and clinical presentation of SLE ${ }^{72 ; 105-108}$. Although there are some conflicting results reported on this association ${ }^{109}$, when including only studies with patients fulfilling at least four criteria for a proper diagnosis of SLE, this association was recently confirmed in a meta-analysis ${ }^{72}$. Disease severity and complications are associated with MBL gene polymorphisms and suggest a possible protective role for MBL in the effector-phase of the disease. Patients with an MBL gene polymorphism tend to have a more severe disease expression and more frequent com- 
plications during their disease. A possible pathogenic role for MBL in lupus nephritis has also been suggested, showing the deposition of MBL and co-localisation of other complement components in renal biopsies of lupus nephritis patients ${ }^{110}$.

\section{Vascular disease}

Increasing evidence supports the hypothesis that MBL activation on endothelial cells might play an important role in the pathogenesis of different diseases. Complement activation via MBL on (hypoxic) endothelial cells has been demonstrated in in vitro studies. In vivo studies have shown that MBL-dependent complement activation after ischaemia/reperfusion injury can cause tissue damage. Furthermore, inhibition of mannose binding lectin pathway has been shown to reduce post-ischaemic myocardial reperfusion injury in rats ${ }^{111}$. A potential aggravating effect of the MBL pathway of complement activation in humans at the level of endothelial cells subjected to oxidative stress has been hypothesised. Supporting this theory are results on MBL-mediated inflammatory response found after surgery for thoracoabdominal aortic aneurysm ${ }^{112}$. Furthermore, an association between mannose-binding lectin and vascular complications in type 1 diabetes has been demonstrated ${ }^{13 ; 1114}$. In contrast, other studies have demonstrated that diminished levels of MBL are predictive for coronary artery disease ${ }^{115}$.

The function of MBL in diseases, as described above, appears to be on the one hand protective while on the other had harmful. In infectious diseases MBL is most often supportive in the defence against invading microorganisms, although some intracellular pathogens profit from the presence of MBL. For many inflammatory diseases MBL protects against development or progression of the disease. However, for some diseases activation of the complement system via MBL can induce an inflammatory response on tissue level.

\section{Complement deficiencies and disease}

Complement deficiencies can be divided in primary or genetic complement deficiencies and secondary deficiencies due to complement consumption. For most complement components genetic deficiencies are described ${ }^{116}$. SLE and SLE-like disease are associated with deficiencies of early complement components of the classical pathway, whereas bacterial infections are associated with C3 deficiencies and deficiencies of components of the alternative pathway and the terminal pathway.

Complement activation is a response of the innate immune system on invading microorganisms, circulating immune complexes and apoptotic material. However, inappropriate activation of complement has been implicated in a number of diseases. In some diseases autoantibodies against complement components interfere with complement function and cause secondary complement deficiencies. In patients with recurrent infections or systemic diseases where a complement deficiency is suspected, serum can be screened for deficiencies by functional complement assays. 


\section{Assessment of the functional activity of the complement pathways}

To assess the functional activity of the classical and the alternative pathway of complement activation, haemolytic assays are available. For assessment of classical pathway (CH50) complement activation, sheep red blood cells (SRBC) are sensitised using rabbit anti-SRBC antibodies. For analysis of alternative pathway activity (AP50) rabbit erythrocytes are used. Serum from patients is added to these erythrocytes and the amount of erythrocyte lysis is used as a marker for complement activity of the classical and alternative pathway. Deficiency of complement components, decreased concentration or function of any component between the initiating component of the pathway and the terminal complex, results in a decreased functional activity.

Different assays have been developed to assess the functional activity of the lectin pathway of complement. Some of the assays measure directly the functional activity of the MBL/MASP complex by assessing the binding of this complex to a solid-phase ligand and determining the activation of $\mathrm{C} 4{ }^{117}$. To circumvent in these assays classical pathway activation via $\mathrm{C} 1 \mathrm{q}$ binding to anti-mannan antibodies, sera are incubation in high sodium chloride buffers. At this tonicity, however, activation of C4 is also inhibited and therefore the activity of the MBL complex is assessed in a second step with exogenously added purified C4. These assays do not assess the functional activity of the whole MBL pathway up to the final common pathway of complement activation. Measurement of full-length complement pathway activation leading to formation of the membrane attack complex is performed for the classical and alternative pathway by assessing the lysis of sensitised erythrocytes. Similar assays are developed for the MBL pathway using mannan coated erythrocytes or by indirect lysis of erythrocytes but these are only useful for experimental purposes ${ }^{118 ; 119}$.

Other assays are developed to assess the functional activity of the lectin pathway up to the formation of $\mathrm{C} 5 \mathrm{~b}-9$ with autologous complement components ${ }^{120 ; 121}$. Activation of the classical pathway of complement is prevented by addition of an inhibitory antibody to C1q. Recently an ELISA-based assay has been developed to assess the functional activity of the three pathways of complement activation in one assay. 


\section{Scope of the thesis}

The scope of the first part of the present study is to assess the role of the MBL pathway as a two edged sword, in the pathogenesis of SLE. In the second part a new method to assess MBL pathway activity was evaluated for clinical practise.

The role for complement components from the classical and alternative pathway of the complement system in SLE has been demonstrated in clinical and experimental studies in mice and man. A role for MBL in the pathogenesis of SLE in man has been reported. The involvement of the MBL pathway of complement as a potential aggravating factor in a murine model for lupus nephritis has been investigated in the present study (Chapter 2).

Polyclonal B-cell hyper-reactivity resulting in the production of a wide variety of autoantibodies, of which many are directed against antigens present on apoptotic material, is a characteristic finding in patients with SLE. Therefore the prevalence of antibodies against two complement proteins present on apoptotic material, MBL and C1q, was studied in patients with SLE during active and inactive phases of disease. The clinical consequence of the presence of anti-MBL and anti-C1q antibodies was investigated (Chapter 3).

It has been demonstrated that polymorphisms of the MBL gene are associated with the development of SLE. Furthermore, impaired complement-mediated clearance of apoptotic material has been suggested to play a role in the pathogenesis of SLE. A possible mechanism by which MBL might play a role in the development of SLE was examined. Therefore, the production of autoantibodies against epitopes present on apoptotic material in patients with an MBL polymorphism has been investigated. Furthermore, MBL concentration, MBL-MASP complex activity and MBL pathway activity was studied in patients with SLE in association with the presence of autoantibodies and disease activity (Chapter 4 ).

To assess the functional activity of the classical and alternative pathway haemolytic assays are used. Until recently no such assay was available to assess the functional activity of the MBL pathway. In view of the clinical relevance of MBL deficiencies such an assay would be very valuable. Therefore, a new assay has been developed to enable the assessment of the functional activity of the whole MBL pathway and to determine the classical and the alternative pathway functional activity in a simple uniform design. Assessment of genetic complement deficiencies and secondary complement deficiencies leading to a dysfunction of complement activation has been studied in a standardised way (Chapter 5).

This novel assay was used to assess to functional activity of the three pathways of complement activation in healthy individuals in relation to age and gender (Chapter 6). Finally, a discussion and summary of the results of the present thesis are given. 


\section{References}

1. Mills, J. A. 1994. Systemic lupus erythematosus. N.Engl.J.Med. 330:1871-1879.

2. Ballou, S. P., M. A. Khan, and I. Kushner. 1982. Clinical features of systemic lupus erythematosus: differences related to race and age of onset. Arthritis Rheum. 25:55-60.

3. Ginzler, E. M. 1991. Clinical manifestations of disease activity, its measurement, and associated morbidity in systemic lupus erythematosus. Curr.Opin.Rheumatol. 3:780-788.

4. Mok, C. C., K. W. Lee, C. T. Ho, C. S. Lau, and R. W. Wong. 2000. A prospective study of survival and prognostic indicators of systemic lupus erythematosus in a southern Chinese population. Rheumatology.(Oxford) 39:399-406.

5. Mok, C. C. and C. S. Lau. 2003. Pathogenesis of systemic lupus erythematosus. J.Clin.Pathol. 56:481490.

6. Walport, M. J., K. A. Davies, and M. Botto. 1998. C1q and systemic lupus erythematosus. Immunobiology 199:265-285.

7. Oates, J. C. and G. S. Gilkeson. 2002. Mediators of injury in lupus nephritis. Curr.Opin.Rheumatol. 14:498-503.

8. Siegert, C. E., M. R. Daha, A. J. Swaak, E. A. van der Voort, and F. C. Breedveld. 1993. The relations hip between serum titers of autoantibodies to $\mathrm{C} 1 \mathrm{q}$ and age in the general population and in patients with systemic lupus erythematosus. Clin.Immunol.Immunopathol. 67:204-209.

9. Finkelstein, Y., Y. Adler, L. Harel, M. Nussinovitch, and P. Youinou. 1997. Anti-Ro (SSA) and anti-La (SSB) antibodies and complete congenital heart block. Ann.Med.Interne (Paris) 148:205-208.

10. Ginsberg, J. S., C. Demers, P. Brill-Edwards, M. Johnston, R. Bona, R. F. Burrows, J. Weitz, and J. A. Denburg. 1993. Increased thrombin generation and activity in patients with systemic lupus erythematosus and anticardiolipin antibodies: evidence for a prothrombotic state. Blood 81:2958-2963.

11. Siegert, C. E., M. R. Daha, C. M. Tseng, I. E. Coremans, L. A. van Es, and F. C. Breedveld. 1993. Predictive value of $\mathrm{IgG}$ autoantibodies against $\mathrm{C} 1 \mathrm{q}$ for nephritis in systemic lupus erythematosus. Ann.Rheum.Dis. 52:851-856.

12. Siegert, C., M. Daha, M. L. Westedt, d. van, V, and F. Breedveld. 1991. IgG autoantibodies against $\mathrm{C} 1 \mathrm{q}$ are correlated with nephritis, hypocomplementemia, and dsDNA antibodies in systemic lupus erythematosus. J.Rheumatol. 18:230-234.

13. Leung, W. H., K. L. Wong, C. P. Lau, C. K. Wong, and H. W. Liu. 1990. Association between antiphos pholipid antibodies and cardiac abnormalities in patients with systemic lupus erythematosus. Am.J.Med. 89:411-419.

14. Smeenk, R., K. Brinkman, B. H. van den, R. M. Termaat, J. Berden, H. Nossent, and T. Swaak. 1990. Antibodies to DNA in patients with systemic lupus erythematosus. Their role in the diagnosis, the follow-up and the pathogenesis of the disease. Clin.Rheumatol. 9:100-110.

15. Dighiero, G., P. Lymberi, B. Guilbert, T. Ternynck, and S. Avrameas. 1986. Natural autoantibodies constitute a substantial part of normal circulating immunoglobulins. Ann.N.Y.Acad.Sci. 475:135-145.

16. Arbuckle, M. R., M. T. McClain, M. V. Rubertone, R. H. Scofield, G. J. Dennis, J. A. James, and J. B. Harley. 2003. Development of autoantibodies before the clinical onset of systemic lupus erythematosus. N.Engl.J.Med. 349:1526-1533. 
17. Cameron, J. S. 1999. Lupus nephritis. J.Am.Soc.Nephrol. 10:413-424.

18. Berden, J. H. 1997. Lupus nephritis. Kidney Int. 52:538-558.

19. Cervera, R., M. A. Khamashta, J. Font, G. D. Sebastiani, A. Gil, P. Lavilla, I. Domenech, A. O. Aydintug, A. Jedryka-Goral, E. de Ramon, and . 1993. Systemic lupus erythematosus: clinical and immunologic patterns of disease expression in a cohort of 1,000 patients. The European Working Party on Systemic Lupus Erythematosus. Medicine (Baltimore) 72:113-124.

20. Ward, M. M. and S. Studenski. 1990. Clinical manifestations of systemic lupus erythematosus. Identification of racial and socioeconomic influences. Arch.Intern.Med. 150:849-853.

21. Weening, J. J., V. D. D'Agati, M. M. Schwartz, S. V. Seshan, C. E. Alpers, G. B. Appel, J. E. Balow, J. A. Bruijn, T. Cook, F. Ferrario, A. B. Fogo, E. M. Ginzler, L. Hebert, G. Hill, P. Hill, J. C. Jennette, N. C. Kong, P. Lesavre, M. Lockshin, L. M. Looi, H. Makino, L. A. Moura, and M. Nagata. 2004. The classification of glomerulonephritis in systemic lupus erythematosus revisited. J.Am.Soc.Nephrol. $15: 241-250$

22. Walport, M. J. 2001. Complement. First of two parts. N.Engl.J.Med. 344:1058-1066.

23. Walport, M. J. 2001. Complement. Second of two parts. N.Engl.J.Med. 344:1140-1144.

24. Gunnarsson, I., B. Sundelin, M. Heimburger, J. Forslid, R. van Vollenhoven, I. Lundberg, and S. H. Jacobson. 2002. Repeated renal biopsy in proliferative lupus nephritis--predictive role of serum C1q and albuminuria. J.Rheumatol. 29:693-699.

25. Mannik, M. and M. H. Wener. 1997. Deposition of antibodies to the collagen-like region of C1q in renal glomeruli of patients with proliferative lupus glomerulonephritis. Arthritis Rheum. 40:15041511.

26. Trouw, L. A., M. A. Seelen, R. Visseren, J. M. Duijs, H. Benediktsson, E. de Heer, A. Roos, C. van Kooten, and M. R. Daha. 2004. Anti-C1q autoantibodies in murine lupus nephritis.

Clin.Exp.Immunol. 135:41-48.

27. Winfield, J. B., I. Faiferman, and D. Koffler. 1977. Avidity of anti-DNA antibodies in serum and IgG glomerular eluates from patients with systemic lupus erythematosus. Association of high avidity antinative DNA antibody with glomerulonephritis. J.Clin.Invest 59:90-96.

28. Coremans, I. E., P. E. Spronk, H. Bootsma, M. R. Daha, E. A. van der Voort, L. Kater, F. C. Breedveld, and C. G. Kallenberg. 1995. Changes in antibodies to C1q predict renal relapses in systemic lupus erythematosus. Am.J.Kidney Dis. 26:595-601.

29. Forger, F., T. Matthias, M. Oppermann, H. Becker, and K. Helmke. 2004. Clinical significance of antidsDNA antibody isotypes: IgG/IgM ratio of anti-dsDNA antibodies as a prognostic marker for lupus nephritis. Lupus 13:36-44.

30. Coremans, I. E., J. A. Bruijn, E. de Heer, E. A. van der Voort, FC. Breedveld, and M. R. Daha. 1995. Stabilization of glomerular deposits of C1q antibodies against C1q in mice. J Clin Lab Immunol 44:47-61.

31. Trouw, L. A., T. W. Groeneveld, M. A. Seelen, J. M. Duijs, I. M. Bajema, F. A. Prins, U. Kishore, D. J. Salant, J. S. Verbeek, C. C. Kooten, and M. R. Daha. 2004. Anti-C1q autoantibodies deposit in glomeruli but are only pathogenic in combination with glomerular C1q-containing immune complexes. J.Clin.Invest 114:679-688. 
32. Manderson, A. P., M. Botto, and M. J. Walport. 2004. The Role of Complement in the Development of Systemic Lupus Erythematosus. Annu.Rev.Immunol. 22:431-456.

33. Botto, M. and M. J. Walport. 2002. C1q, autoimmunity and apoptosis. Immunobiology 205:395-406.

34. Casciola-Rosen, L. A., G. Anhalt, and A. Rosen. 1994. Autoantigens targeted in systemic lupus ery thematosus are clustered in two populations of surface structures on apoptotic keratinocytes. J.Exp.Med. 179:1317-1330.

35. Nauta, A. J., M. R. Daha, C. van Kooten, and A. Roos. 2003. Recognition and clearance of apoptotic cells: a role for complement and pentraxins. Trends Immunol. 24:148-154.

36. Ogden, C. A., A. deCathelineau, P. R. Hoffmann, D. Bratton, B. Ghebrehiwet, V. A. Fadok, and P. M. Henson. 2001. C1q and mannose binding lectin engagement of cell surface calreticulin and CD91 initiates macropinocytosis and uptake of apoptotic cells. J.Exp.Med. 194:781-795.

37. Botto, M., C. Dell'Agnola, A. E. Bygrave, E. M. Thompson, H. T. Cook, F. Petry, M. Loos, P. P. Pandolfi, and M. J. Walport. 1998. Homozygous C1q deficiency causes glomerulonephritis associated with multiple apoptotic bodies. Nat.Genet. 19:56-59.

38. Nauta, A. J., N. Raaschou-Jensen, A. Roos, M. R. Daha, H. O. Madsen, M. C. Borrias-Essers, L. P. Ryder, C. Koch, and P. Garred. 2003. Mannose-binding lectin engagement with late apoptotic and necrotic cells. Eur.J.Immunol. 33:2853-2863.

39. Mold, C., R. Baca, and T. W. Du Clos. 2002. Serum amyloid P component and C-reactive protein opsonize apoptotic cells for phagocytosis through Fcgamma receptors. J.Autoimmun. 19:147-154.

40. Shaw, P. X., S. Horkko, M. K. Chang, L. K. Curtiss, W. Palinski, G. J. Silverman, and J. L. Witztum. 2000. Natural antibodies with the T15 idiotype may act in atherosclerosis, apoptotic clearance, and protective immunity. J.Clin.Invest 105:1731-1740.

41. Castellano, G., A. M. Woltman, A. J. Nauta, A. Roos, L. A. Trouw, M. A. Seelen, F. P. Schena, M. R. Daha, and C. van Kooten. 2004. Maturation of dendritic cells abrogates C1q production in vivo and in vitro. Blood 103:3813-3820.

42. Pratt, J. R., S. A. Basheer, and S. H. Sacks. 2002. Local synthesis of complement component C3 regu lates acute renal transplant rejection. Nat.Med. 8:582-587.

43. Nagaki, K., S. Hiramatsu, S. Inai, and A. Sasaki. 1980. The effect of aging on complement activity (CH50) and complement protein levels. J.Clin.Lab Immunol. 3:45-50.

44. Ip, W. K., Y. F. To, S. K. Cheng, and Y. L. Lau. 2004. Serum mannose-binding lectin levels and mbl2 gene polymorphisms in different age and gender groups of southern Chinese adults. Scand.J.Immunol. 59:310-314.

45. Spath, P. J., A. G. Sjoholm, G. N. Fredrikson, G. Misiano, R. Scherz, U. B. Schaad, B. Uhring-Lambert, G. Hauptmann, J. Westberg, M. Uhlen, C. Wadelius, and L. Truedsson. 1999. Properdin deficiency in a large Swiss family: identification of a stop codon in the properdin gene, and association of meningococcal disease with lack of the IgG2 allotype marker G2m(n). Clin.Exp.Immunol. 118:278284.

46. Ritchie, R. F., G. E. Palomaki, L. M. Neveux, and O. Navolotskaia. 2004. Reference distributions for complement proteins C3 and C4: a comparison of a large cohort to the world's literature. J.Clin.Lab Anal. 18:9-13.

47. Holmskov, U., S. Thiel, and J. C. Jensenius. 2003. Collections and ficolins: humoral lectins of the innate immune defense. Annu.Rev.Immunol. 21:547-578. 
48. Holmskov, U., R. Malhotra, R. B. Sim, and J. C. Jensenius. 1994. Collectins: collagenous C-type lectins of the innate immune defense system. Immunol.Today 15:67-74.

49. Thiel, S., U. Holmskov, L. Hviid, S. B. Laursen, and J. C. Jensenius. 1992. The concentration of the Ctype lectin, mannan-binding protein, in human plasma increases during an acute phase response. Clin.Exp.Immunol. 90:31-35.

50. Aittoniemi, J., A. Miettinen, P. Laippala, E. Isolauri, J. Viikari, T. Ruuska, and E. Soppi. 1996. Agedependent variation in the serum concentration of mannan-binding protein. Acta Paediatr. 85:906909.

51. Hansen, S. and U. Holmskov. 1998. Structural aspects of collectins and receptors for collectins. Immunobiology 199:165-189.

52. Hansen, S., S. Thiel, A. Willis, U. Holmskov, and J. C. Jensenius. 2000. Purification and characterization of two mannan-binding lectins from mouse serum. J.Immunol. 164:2610-2618.

53. Sastry, K., G. A. Herman, L. Day, E. Deignan, G. Bruns, C. C. Morton, and R. A. Ezekowitz. 1989. The human mannose-binding protein gene. Exon structure reveals its evolutionary relationship to a human pulmonary surfactant gene and localization to chromosome 10. J.Exp.Med. 170:1175-1189.

54. Sastry, K., K. Zahedi, J. M. Lelias, A. S. Whitehead, and R. A. Ezekowitz. 1991. Molecular characterization of the mouse mannose-binding proteins. The mannose-binding protein A but not $\mathrm{C}$ is an acute phase reactant. J.Immunol. 147:692-697.

55. Madsen, H. O., P. Garred, S. Thiel, J. A. Kurtzhals, L. U. Lamm, L. P. Ryder, and A. Svejgaard. 1995. Interplay between promoter and structural gene variants control basal serum level of mannan-binding protein. J.Immunol. 155:3013-3020.

56. Sumiya, M., M. Super, P. Tabona, R. J. Levinsky, T. Arai, M. W. Turner, and J. A. Summerfield. 1991. Molecular basis of opsonic defect in immunodeficient children. Lancet 337:1569-1570.

57. Lipscombe, R. J., M. Sumiya, A. V. Hill, Y. L. Lau, R. J. Levinsky, J. A. Summerfield, and M. W. Turner. 1992. High frequencies in African and non-African populations of independent mutations in the mannose binding protein gene. Hum.Mol.Genet. 1:709-715.

58. Madsen, H. O., P. Garred, J. A. Kurtzhals, L. U. Lamm, L. P. Ryder, S. Thiel, and A. Svejgaard. 1994. A new frequent allele is the missing link in the structural polymorphism of the human mannan-binding protein. Immunogenetics 40:37-44.

59. Madsen, H. O., M. L. Satz, B. Hogh, A. Svejgaard, and P. Garred. 1998. Different molecular events result in low protein levels of mannan-binding lectin in populations from southeast Africa and South America. J.Immunol. 161:3169-3175.

60. Fraser, I. P., H. Koziel, and R. A. Ezekowitz. 1998. The serum mannose-binding protein and the macrophage mannose receptor are pattern recognition molecules that link innate and adaptive immunity. Semin.Immunol. 10:363-372.

61. Eisen, D. P. and R. M. Minchinton. 2003. Impact of mannose-binding lectin on susceptibility to infectious diseases. Clin.Infect.Dis. 37:1496-1505.

62. Kuhlman, M., K. Joiner, and R. A. Ezekowitz. 1989. The human mannose-binding protein functions as an opsonin. J.Exp.Med. 169:1733-1745.

63. Nauta, A. J., G. Castellano, W. Xu, A. M. Woltman, M. C. Borrias, M. R. Daha, C. van Kooten, and A. Roos. 2004. Opsonization with $\mathrm{C} 1 \mathrm{q}$ and mannose-binding lectin targets apoptotic cells to dendritic cells. J.Immunol. 173:3044-3050. 
64. Palaniyar, N., J. Nadesalingam, H. Clark, M. J. Shih, A. W. Dodds, and K. B. Reid. 2004. Nucleic acid is a novel ligand for innate, immune pattern recognition collectins surfactant proteins $\mathrm{A}$ and $\mathrm{D}$ and mannose-binding lectin. J.Biol.Chem. 279:32728-32736.

65. Super, M., S. Thiel, J. Lu, R. J. Levinsky, and M. W. Turner. 1989. Association of low levels of mannan-binding protein with a common defect of opsonisation. Lancet 2:1236-1239.

66. Ezekowitz, R. A. 2003. Role of the mannose-binding lectin in innate immunity. J.Infect.Dis. 187 Suppl 2:S335-S339.

67. Garred, P., H. O. Madsen, B. Hofmann, and A. Svejgaard. 1995. Increased frequency of homozygosity of abnormal mannan-binding-protein alleles in patients with suspected immunodeficiency. Lancet 346:941-943.

68. Summerfield, J. A., M. Sumiya, M. Levin, and M. W. Turner. 1997. Association of mutations in mannose binding protein gene with childhood infection in consecutive hospital series. BMJ 314:12291232.

69. Mead, R., D. Jack, M. Pembrey, L. Tyfield, and M. Turner. 1997. Mannose-binding lectin alleles in a prospectively recruited UK population. The ALSPAC Study Team. Avon Longitudinal Study of Pregnancy and Childhood. Lancet 349:1669-1670.

70. Garred, P., J. Strom, L. Quist, E. Taaning, and H. O. Madsen. 2003. Association of mannose-binding lectin polymorphisms with sepsis and fatal outcome, in patients with systemic inflammatory response syndrome. J.Infect.Dis. 188:1394-1403.

71. Garred, P., T. Pressler, H. O. Madsen, B. Frederiksen, A. Svejgaard, N. Hoiby, M. Schwartz, and C. Koch. 1999. Association of mannose-binding lectin gene heterogeneity with severity of lung disease and survival in cystic fibrosis. J.Clin.Invest 104:431-437.

72. Garred, P., A. Voss, H. O. Madsen, and P. Junker. 2001. Association of mannose-binding lectin gene variation with disease severity and infections in a population-based cohort of systemic lupus ery thematosus patients. Genes Immun. 2:442-450.

73. Nagy, A., G. T. Kozma, M. Keszei, A. Treszl, A. Falus, and C. Szalai. 2003. The development of asthma in children infected with Chlamydia pneumoniae is dependent on the modifying effect of mannose-binding lectin. J.Allergy Clin.Immunol. 112:729-734.

74. Yang, I. A., S. L. Seeney, J. M. Wolter, E. M. Anders, J. G. McCormack, A. M. Tunnicliffe, G. C. Rabnott, J. G. Shaw, A. G. Dent, S. T. Kim, P. V. Zimmerman, and K. M. Fong. 2003. Mannose-binding lectin gene polymorphism predicts hospital admissions for COPD infections. Genes Immun. 4:269-274.

75. Garred, P., M. Harboe, T. Oettinger, C. Koch, and A. Svejgaard. 1994. Dual role of mannan-binding protein in infections: another case of heterosis? Eur.J.Immunogenet. 21:125-131.

76. Soborg, C., H. O. Madsen, A. B. Andersen, T. Lillebaek, A. Kok-Jensen, and P. Garred. 2003.

Mannose-binding lectin polymorphisms in clinical tuberculosis. J.Infect.Dis. 188:777-782.

77. Boniotto, M., L. Braida, D. Pirulli, L. Arraes, A. Amoroso, and S. Crovella. 2003. MBL2 polymorphisms are involved in HIV-1 infection in Brazilian perinatally infected children. AIDS 17:779-780.

78. Garred, P., H. O. Madsen, U. Balslev, B. Hofmann, C. Pedersen, J. Gerstoft, and A. Svejgaard. 1997. Susceptibility to HIV infection and progression of AIDS in relation to variant alleles of mannose-binding lectin. Lancet 349:236-240. 
79. Garred, P., C. Richter, A. B. Andersen, H. O. Madsen, I. Mtoni, A. Svejgaard, and J. Shao. 1997. Mannan-binding lectin in the sub-Saharan HIV and tuberculosis epidemics. Scand.J.Immunol. 46:204-208.

80. Amoroso, A., M. Berrino, M. Boniotto, S. Crovella, E. Palomba, G. Scarlatti, C. Serra, P. A. Tovo, and S. Vatta. 1999. Polymorphism at codon 54 of mannose-binding protein gene influences AIDS progression but not HIV infection in exposed children. AIDS 13:863-864.

81. Kilpatrick, D. C., L. A. McLintock, E. K. Allan, M. Copland, T. Fujita, N. E. Jordanides, C. Koch, M. Matsushita, H. Shiraki, K. Stewart, M. Tsujimura, M. L. Turner, I. M. Franklin, and T. L. Holyoake. 2003. No strong relationship between mannan binding lectin or plasma ficolins and chemotherapyrelated infections. Clin.Exp.Immunol. 134:279-284.

82. Sasaki, K., A. Tsutsumi, N. Wakamiya, K. Ohtani, Y. Suzuki, Y. Watanabe, N. Nakayama, and T. Koike. 2000. Mannose-binding lectin polymorphisms in patients with hepatitis $C$ virus infection. Scand.J.Gastroenterol. 35:960-965.

83. Thomas, H. C., G. R. Foster, M. Sumiya, D. McIntosh, D. L. Jack, M. W. Turner, and J. A. Summerfield. 1996. Mutation of gene of mannose-binding protein associated with chronic hepatitis B viral infection. Lancet 348:1417-1419.

84. Yuen, M. F., C. S. Lau, Y. L. Lau, W. M. Wong, C. C. Cheng, and C. L. Lai. 1999. Mannose binding lectin gene mutations are associated with progression of liver disease in chronic hepatitis B infection. Hepatology 29:1248-1251.

85. Babula, O., G. Lazdane, J. Kroica, W. J. Ledger, and S. S. Witkin. 2003. Relation between recurrent vulvovaginal candidiasis, vaginal concentrations of mannose-binding lectin, and a mannose-binding lectin gene polymorphism in Latvian women. Clin.Infect.Dis. 37:733-737.

86. Ip, W. K. and Y. L. Lau. 2004. Role of mannose-binding lectin in the innate defense against Candida albicans: enhancement of complement activation, but lack of opsonic function, in phagocytosis by human dendritic cells. J.Infect.Dis. 190:632-640.

87. Barton, A., H. Platt, F. Salway, D. Symmons, M. Lunt, J. Worthington, and A. Silman. 2004. Polymorphisms in the mannose binding lectin (MBL) gene are not associated with radiographic erosions in rheumatoid or inflammatory polyarthritis. J.Rheumatol. 31:442-447.

88. Garred, P., H. O. Madsen, H. Marquart, T. M. Hansen, S. F. Sorensen, J. Petersen, B. Volck, A. Svejgaard, N. A. Graudal, P. M. Rudd, R. A. Dwek, R. B. Sim, and V. Andersen. 2000. Two edged role of mannose binding lectin in rheumatoid arthritis: a cross sectional study. J.Rheumatol. 27:2634 .

89. Graudal, N. A., C. Homann, H. O. Madsen, A. Svejgaard, A. G. Jurik, H. K. Graudal, and P. Garred. 1998. Mannan binding lectin in rheumatoid arthritis. A longitudinal study. J.Rheumatol. 25:629-635.

90. Graudal, N. A., C. Homann, H. O. Madsen, A. Svejgaard, A. G. Jurik, H. K. Graudal, and P. Garred. 1998. Mannan binding lectin in rheumatoid arthritis. A longitudinal study. J.Rheumatol. 25:629-635.

91. Kilpatrick, D. C. 1997. Mannan binding protein in sera positive for rheumatoid factor. Br.J.Rheumatol. 36:207-209.

92. Stanworth, S. J., R. P. Donn, A. Hassall, P. Dawes, W. Ollier, and N. Snowden. 1998. Absence of an association between mannose-binding lectin polymorphism and rheumatoid arthritis.

Br.J.Rheumatol. 37:186-188. 
93. Malhotra, R., M. R. Wormald, P. M. Rudd, P. B. Fischer, R. A. Dwek, and R. B. Sim. 1995.

Glycosylation changes of IgG associated with rheumatoid arthritis can activate complement via the mannose-binding protein. Nat.Med. 1:237-243.

94. Parekh, R. B., R. A. Dwek, B. J. Sutton, D. L. Fernandes, A. Leung, D. Stanworth, T. W. Rademacher, T. Mizuochi, T. Taniguchi, K. Matsuta, and . 1985. Association of rheumatoid arthritis and primary osteoarthritis with changes in the glycosylation pattern of total serum IgG. Nature 316:452-457.

95. Ji, H., K. Ohmura, U. Mahmood, D. M. Lee, F. M. Hofhuis, S. A. Boackle, K. Takahashi, V. M. Holers, M. Walport, C. Gerard, A. Ezekowitz, M. C. Carroll, M. Brenner, R. Weissleder, J. S. Verbeek, V. Duchatelle, C. Degott, C. Benoist, and D. Mathis. 2002. Arthritis critically dependent on innate immune system players. Immunity. 16:157-168.

96. Schena, F. P. 1990. A retrospective analysis of the natural history of primary IgA nephropathy world wide. Am.J.Med. 89:209-215.

97. Conley, M. E., M. D. Cooper, and A. F. Michael. 1980. Selective deposition of immunoglobulin A1 in immunoglobulin A nephropathy, anaphylactoid purpura nephritis, and systemic lupus erythematosus. J.Clin.Invest 66:1432-1436.

98. Stad, R. K., J. A. Bruijn, D. J. Gijlswijk-Janssen, L. A. van Es, and M. R. Daha. 1993. An acute model for IgA-mediated glomerular inflammation in rats induced by monoclonal polymeric rat IgA antibodies. Clin.Exp.Immunol. 92:514-521.

99. Hiki, Y., H. Odani, M. Takahashi, Y. Yasuda, A. Nishimoto, H. Iwase, T. Shinzato, Y. Kobayashi, and K. Maeda. 2001. Mass spectrometry proves under-O-glycosylation of glomerular IgA1 in IgA nephropathy. Kidney Int. 59:1077-1085.

100. Russell MW, Kilian M, and Lamm ME. 1999. Biological activity of IgA. In Mucosal Immunology. Ogra PLO and Mestecky J, eds. Academic Press, San Diego, p. 225.

101. Miyazaki, R., M. Kuroda, T. Akiyama, I. Otani, Y. Tofuku, and R. Takeda. 1984. Glomerular deposition and serum levels of complement control proteins in patients with IgA nephropathy. Clin.Nephrol. 21:335-340.

102. Hisano, S., M. Matsushita, T. Fujita, Y. Endo, and S. Takebayashi. 2001. Mesangial IgA2 deposits and lectin pathway-mediated complement activation in IgA glomerulonephritis. Am.J.Kidney Dis. 38:1082-1088.

103. Roos, A., L. H. Bouwman, D. J. Gijlswijk-Janssen, M. C. Faber-Krol, G. L. Stahl, and M. R. Daha. 2001 Human IgA activates the complement system via the mannan-binding lectin pathway. J.Immunol. 167:2861-2868.

104. Hansch, G. M. 1993. The role of complement in mesangial cell damage. Nephrol.Dial.Transplant. 8:45.

105. Davies, E. J., N. Snowden, M. C. Hillarby, D. Carthy, D. M. Grennan, W. Thomson, and W. E. Ollier. 1995. Mannose-binding protein gene polymorphism in systemic lupus erythematosus. Arthritis Rheum. 38:110-114.

106. Davies, E. J., L. S. Teh, J. Ordi-Ros, N. Snowden, M. C. Hillarby, A. Hajeer, R. Donn, P. Perez-Pemen, M. Vilardell-Tarres, and W. E. Ollier. 1997. A dysfunctional allele of the mannose binding protein gene associates with systemic lupus erythematosus in a Spanish population. J.Rheumatol. 24:485488 .

107. Mok, M. Y., D. L. Jack, C. S. Lau, D. Y. Fong, M. W. Turner, D. A. Isenberg, and P. M. Lydyard. 2004. Antibodies to mannose binding lectin in patients with systemic lupus erythematosus. Lupus 13:522528. 
108. Sullivan, K. E., C. Wooten, D. Goldman, and M. Petri. 1996. Mannose-binding protein genetic poly morphisms in black patients with systemic lupus erythematosus. Arthritis Rheum. 39:2046-2051.

109. Horiuchi, T., H. Tsukamoto, C. Morita, T. Sawabe, S. Harashima, H. Nakashima, H. Miyahara, C. Hashimura, and M. Kondo. 2000. Mannose binding lectin (MBL) gene mutation is not a risk factor for systemic lupus erythematosus (SLE) and rheumatoid arthritis (RA) in Japanese. Genes Immun. 1:464-466.

110. Lhotta, K., R. Wurzner, and P. Konig. 1999. Glomerular deposition of mannose-binding lectin in human glomerulonephritis. Nephrol.Dial.Transplant. 14:881-886.

111. Jordan, J. E., M. C. Montalto, and G. L. Stahl. 2001. Inhibition of mannose-binding lectin reduces postischemic myocardial reperfusion injury. Circulation 104:1413-1418.

112. Sund, S., T. Hovig, A. V. Reisaeter, H. Scott, O. Bentdal, and T. E. Mollnes. 2003. Complement activation in early protocol kidney graft biopsies after living-donor transplantation. Transplantation 75:1204-1213.

113. Hansen, T. K., S. Thiel, S. T. Knudsen, C. H. Gravholt, J. S. Christiansen, C. E. Mogensen, and P. L. Poulsen. 2003. Elevated levels of mannan-binding lectin in patients with type 1 diabetes.

J.Clin.Endocrinol.Metab 88:4857-4861.

114. Hansen, T. K., L. Tarnow, S. Thiel, R. Steffensen, C. D. Stehouwer, C. G. Schalkwijk, H. H. Parving, and A. Flyvbjerg. 2004. Association between mannose-binding lectin and vascular complications in type 1 diabetes. Diabetes 53:1570-1576.

115. Best, L. G., M. Davidson, K. E. North, J. W. MacCluer, Y. Zhang, E. T. Lee, B. V. Howard, S. DeCroo, and R. E. Ferrell. 2004. Prospective analysis of mannose-binding lectin genotypes and coronary artery disease in American Indians: the Strong Heart Study. Circulation 109:471-475.

116. Roos, A., L. A. Trouw, Ioan-Facsinay A, M. R. Daha, and J. S. Verbeek. 2003. Complement system Fc receptors: Genetics. In Nature encyclopedia of the human genome., pp. 914-927.

117. Petersen, S. V., S. Thiel, L. Jensen, R. Steffensen, and J. C. Jensenius. 2001. An assay for the mannanbinding lectin pathway of complement activation. J.Immunol.Methods 257:107-116.

118. Ikeda, K., T. Sannoh, N. Kawasaki, T. Kawasaki, and I. Yamashina. 1987. Serum lectin with known structure activates complement through the classical pathway. J.Biol.Chem. 262:7451-7454.

119. Kuipers, S., P. C. Aerts, A. G. Sjoholm, T. Harmsen, and H. van Dijk. 2002. A hemolytic assay for the estimation of functional mannose-binding lectin levels in human serum. J.Immunol.Methods 268:149-157.

120. Roos, A., L. H. Bouwman, J. Munoz, T. Zuiverloon, M. C. Faber-Krol, Fallaux-van den Houten FC, N. Klar-Mohamad, C. E. Hack, M. G. Tilanus, and M. R. Daha. 2003. Functional characterization of the lectin pathway of complement in human serum. Mol.Immunol. 39:655-668.

121. Super, M., R. J. Levinsky, and M. W. Turner. 1990. The level of mannan-binding protein regulates the binding of complement-derived opsonins to mannan and zymosan at low serum concentrations. Clin.Exp.Immunol. 79:144-150.

122. Wisnieski, J. J. and S. M. Jones. 1992. Comparison of autoantibodies to the collagen-like region of $\mathrm{C} 1 \mathrm{q}$ in hypocomplementemic urticarial vasculitis syndrome and systemic lupus erythematosus. J.Immunol. 148:1396-1403.

123. Siegert, C. E., M. R. Daha, C. Halma, E. A. van der Voort, and F. C. Breedveld. 1992. IgG and IgA autoantibodies to $\mathrm{C} 1 \mathrm{q}$ in systemic and renal diseases. Clin.Exp.Rheumatol. 10:19-23. 
124. Wener, M. H., S. Uwatoko, and M. Mannik. 1989. Antibodies to the collagen-like region of C1q in sera of patients with autoimmune rheumatic diseases. Arthritis Rheum. 32:544-551.

125. Strife, C. F., A. E. Leahy, and C. D. West. 1989. Antibody to a cryptic, solid phase C1Q antigen in membranoproliferative nephritis. Kidney Int. 35:836-842.

126. Gunnarsson, I., J. Ronnelid, I. Lundberg, and S. H. Jacobson. 1997. Occurrence of anti-C1q antibodies in IgA nephropathy. Nephrol.Dial.Transplant. 12:2263-2268.

127. Coremans, I. E., M. R. Daha, E. A. van der Voort, Y. Muizert, C. Halma, and F. C. Breedveld. 1992. Antibodies against C1q in anti-glomerular basement membrane nephritis. Clin.Exp.Immunol. 87:256-260.

128. He, S. and Y. L. Lin. 1998. In vitro stimulation of C1s proteolytic activities by C1s-presenting auto antibodies from patients with systemic lupus erythematosus. J.Immunol. 160:4641-4647.

129. Seelen, M. A., L. A. Trouw, J. W. van der Hoorn, Fallaux-van den Houten FC, T. W. Huizinga, M. R. Daha, and A. Roos. 2003. Autoantibodies against mannose-binding lectin in systemic lupus erythematosus. Clin.Exp.Immunol. 134:335-343.

130. Giles, C. M. and J. L. Swanson. 1984. Anti-C4 in the serum of a transfused C4-deficient patient with systemic lupus erythematosus. Vox Sang. 46:291-299.

131. Daha, M. R., H. M. Hazevoet, L. A. Vanes, and A. Cats. 1980. Stabilization of the classical pathway C3 convertase C42, by a factor F-42, isolated from serum of patients with systemic lupus erythematosus. Immunology 40:417-424.

132. Fremeaux-Bacchi, V., L. Weiss, C. Demouchy, A. May, S. Palomera, and M. D. Kazatchkine. 1994. Hypocomplementaemia of poststreptococcal acute glomerulonephritis is associated with C3 nephritic factor (C3NeF) IgG autoantibody activity. Nephrol.Dial.Transplant. 9:1747-1750.

133. Ohi, H. and T. Yasugi. 1994. Occurrence of C3 nephritic factor and C4 nephritic factor in membran oproliferative glomerulonephritis (MPGN). Clin.Exp.Immunol. 95:316-321.

134. Levy, Y., J. George, E. Yona, and Y. Shoenfeld. 1998. Partial lipodystrophy, mesangiocapillary glomerulonephritis, and complement dysregulation. An autoimmune phenomenon. Immunol.Res. 18:5560.

135. Ronnelid, J., I. Gunnarsson, K. Nilsson-Ekdahl, and B. Nilsson. 1997. Correlation between anti-C1q and immune conglutinin levels, but not between levels of antibodies to the structurally related auto antigens C1q and type II collagen in SLE or RA. J.Autoimmun. 10:415-423.

136. Villaescusa, R., M. N. Santos, Y. Garcia, Y. Trujillo, B. Bernal, J. M. Ballester, and P. Hernandez. 1982. Circulating immune complexes in paroxysmal nocturnal hemoglobinuria. Acta Haematol. 68:136141.

137. Hautanen, A. and M. P. Salaspuro. 1981. Characteristics of C3b-binding in chronic liver diseases. Scand.J.Gastroenterol. 16:505-512.

138. Wilson, J. G., R. M. Jack, W. W. Wong, P. H. Schur, and D. T. Fearon. 1985. Autoantibody to the $\mathrm{C} 3 \mathrm{~b} / \mathrm{C} 4 \mathrm{~b}$ receptor and absence of this receptor from erythrocytes of a patient with systemic lupus erythematosus. J.Clin.Invest 76:182-190.

139. Potter, B. J., D. J. Brown, A. Watson, and D. P. Jewell. 1980. Complement inhibitors and immunocon glutinins in ulcerative colitis and Crohn's disease. Gut 21:1030-1034. 
140. Sadallah, S., C. Hess, M. Trendelenburg, C. Vedeler, M. Lopez-Trascasa, and J. A. Schifferli. 2003. Autoantibodies against complement receptor 1 (CD35) in SLE, liver cirrhosis and HIV-infected patients. Clin.Exp.Immunol. 131:174-181.

141. van den Berg, R. H., C. E. Siegert, M. C. Faber-Krol, T. W. Huizinga, L. A. van Es, and M. R. Daha. 1998. Anti-C1q receptor/calreticulin autoantibodies in patients with systemic lupus erythematosus (SLE). Clin.Exp.Immunol. 111:359-364.

142. Pinter, C., S. Beltrami, D. Caputo, P. Ferrante, and A. Clivio. 2000. Presence of autoantibodies against complement regulatory proteins in relapsing-remitting multiple sclerosis. J.Neurovirol. 6 Suppl 2:S42-S46.

143. Orth, T., T. Dorner, K. H. Meyer Zum Buschenfelde, and W. J. Mayet. 1996. Complete congenital heart block is associated with increased autoantibody titers against calreticulin. Eur.J.Clin.Invest 26:205-215.

144. Kreisel, W., A. Siegel, A. Bahler, C. Spamer, E. Schiltz, M. Kist, G. Seilnacht, R. Klein, P. A. Berg, and C. Heilmann. 1999. High prevalence of antibodies to calreticulin of the IgA class in primary biliary cirrhosis: a possible role of gut-derived bacterial antigens in its aetiology? Scand.J.Gastroenterol. 34:623-628.

145. Karska, K., L. Tuckova, L. Steiner, H. Tlaskalova-Hogenova, and M. Michalak. 1995. Calreticulin--the potential autoantigen in celiac disease. Biochem.Biophys.Res.Commun. 209:597-605.

146. Ben Chetrit, E. 1993. The molecular basis of the SSA/Ro antigens and the clinical significance of their autoantibodies. Br.J.Rheumatol. 32:396-402. 


\section{Chapter 2}

\section{Activation of the lectin pathway in murine lupus nephritis.}

Leendert A. Trouw, Marc A. Seelen, Jacques M.G.J. Duijs, Sven Wagner, Michael Loos, Ingeborg M. Bajema, Cees van Kooten, Anja Roos, Mohamed R. Daha

Department of Nephrology, and Pathology, Leiden University Medical Center, Leiden, The Netherlands. Johannes Gutenberg Universität, Mainz, Germany.

Mol Immunol. 42 (2005) 731-740 


\section{Abstract}

In Systemic Lupus Erythematosus (SLE), hypocomplementaemia and complement deposition have been described both in man and in experimental models. A major involvement of the classical pathway of complement activation has been demonstrated in this disease, however relatively little is known about the involvement of the lectin pathway. Therefore in the present study we have analyzed the activity of all three pathways of complement activation in murine models of SLE. In the mouse, MBL is expressed in two forms, namely MBL-A and MBL-C. In the present study young and old MRL-lpr and control MRL +/+ mice were compared for the levels of complement activity with specific attention for the lectin pathway. It was found that upon aging of both MRL-lpr and MRL+/+ mice, a marked decrease in the activity of the classical pathway (CP) occurs. Levels of alternative pathway (AP) and lectin pathway (LP) activity remain unchanged. Key-molecules of these pathways, C1q, C3, MBL-A and MBL$C$ were analyzed and were all found to be decreased in aged mice of both strains. The levels of MBL-A and MBL-C showed a high degree of correlation and decreased equally. In aged MRL-lpr mice in which autoimmunity is most pronounced, we observed high autoantibody titers and strong deposition of glomerular immune complexes in association with deposition of C1q, C3, MBL-A and MBL-C.

In conclusion, these data suggest that in addition to the classical pathway and the alternative pathway also the lectin pathway of complement activation is involved in murine lupus nephritis.

\section{Introduction}

The lectin pathway (LP) of complement activation is involved in the innate defense against pathogens (Petersen et al. 2001). However, the LP may also contribute to organ damage (Ohsawa et al. 2001). The LP of complement activation is initiated by the binding of its recognition molecule Mannose Binding Lectin (MBL) to one of its natural carbohydrate ligands (Petersen et al. 2001) as can be found on e.g. the surface of microorganisms, IgA (Roos et al. 2001a) or altered-self molecules (Nauta et al. 2003). Binding of MBL leads to the activation of MBL-associated serine proteases (MASP's). Activated MASP-2 cleaves C4 and C2 in a similar way as C1s do for the Classical Pathway (CP) leading to the formation of $\mathrm{C} 4 \mathrm{~b} 2 \mathrm{a}$, cleavage of $\mathrm{C} 3$, and complement activation up to the formation of the membrane attack complex (Petersen et al. 2001). MBL may also directly opsonize microorganisms for phagocytosis by interaction with several cellular receptors (Kuhlman et al. 1989).

MBL deficiency or low levels of MBL in serum are frequently observed in the general population due to single nucleotide polymorphisms in the structural region or the promotor of the MBL gene (Garred et al. 2003). Low serum levels of MBL and increased frequencies of MBL variant alleles have been described associated with a number of diseases e.g. recurrent infections (Garred et al. 2002;Mullighan et al. 2002;Peterslund et 
al. 2001), recurrent abortion (Baxter et al. 2001) and SLE (Garred et al. 2001;Christiansen et al. 1999;Kilpatrick et al. 1999). This indicates that the LP is involved in protection against a great number of pathological conditions (Garred et al. 2003). In addition, MBL deposition and LP activation have been observed in several renal diseases (Lhotta et al. 1999) such as IgA nephropathy (Endo et al. 1998) and lupus nephritis (Lhotta et al. 1999) as well as in ischaemia reperfusion injury (IRI) (Collard et al. 2000). On the other hand a protective role for MBL deficiency in relation to peritonitis (Takahashi et al. 2002) and inflammatory bowel disease (IBD) (Rector et al. 2001) has been described.

For humans, only one form of MBL has been described whereas for mice and several other species two forms of MBL have been identified (Hansen and Holmskov 1998). Initially MBL-A has been considered the serum form in rodents and MBL-C a liver form (Oka et al. 1988). However, recently both murine MBL-A and MBL-C have been purified and characterized from serum (Hansen et al. 2000;Liu et al. 2001). In order to be fully able to activate the complement system MBL needs to be in a proper oligomeric structure. Both mouse MBL-A and MBL-C have now been reported to be present in serum in high molecular weight forms, thus both allowing complement activation (Hansen et al. 2000).

MRL-lpr mice provide a well-accepted model of murine SLE (Andrews et al. 1978). These mice have a combination of an autoimmune-prone MRL background combined with a mutation in the apoptosis-promoting Fas gene (lpr) (Watanabe-Fukunaga et al. 1992). MRL-lpr mice have a more severe and accelerated autoimmune disease compared to MRL+/+ mice. Therefore comparing MRL-lpr and MRL +/+ mice of the same age provides an insight in slow development of SLE in MRL +/+ mice and a more rapid development of SLE in MRL-lpr mice.

In the present study we have investigated the contribution of complement with specific attention for the LP of complement activation in murine lupus nephritis. MBL-A and MBL-C concentrations in serum and depositions in the kidney were assessed in MRL-lpr and MRL +/+ mice at 6 weeks of age and 4 months of age. As markers of autoimmunity we have measured anti-Histone and anti-C1q autoantibodies (Trinder et al. 1995;Trouw L.A. et al. 2004b;Trouw L.A. et al. 2004a).

We observed that complement activity of the $\mathrm{CP}$ is decreased in old MRL-lpr mice compared to young mice. However, AP and LP activity remained unchanged. Serum levels of MBL-A and MBL-C were decreased in old MRL-lpr mice, as were C1q and C3. Concomitant with the decrease in serum levels, C1q, C3 and MBL-A and MBL-C deposited in the kidney, indicating that in addition to $\mathrm{CP}$ and $\mathrm{AP}$ also the $\mathrm{LP}$ is involved in murine lupus-nephritis. 


\section{Methods}

\section{Animals and experimental protocol}

MRL/MpJ lpr mice (MRL-lpr) and MRL/MpJ +/+ mice (MRL +/+), female, 4 weeks of age were obtained from the Jackson Laboratories (Bar Harbor, ME). All animals had free access to water and standard chow. Animal care and experimentation were performed in accordance with the National Institutes of Health Guidelines for the care and use of laboratory animals. Mice were divided in 2 groups of 12 MRL-lpr and 12 MRL $+/+$ mice. We sacrificed one group of $7 \mathrm{MRL}-1$ pr and $6 \mathrm{MRL}+/+$ mice at 6 weeks of age the other two groups of $6 \mathrm{MRL}-1 \mathrm{pr}$ and $7 \mathrm{MRL}+/+$ mice at 4 months of age. Prior to sacrifice urine was collected in metabolic cages for 18 hours. At the appropriate time, mice were anesthetized with urethane (Sigma-Aldrich, Zwijndrecht, The Netherlands) and sacrificed by heart puncture. Blood was collected and allowed to clot for 6 hours on ice. Serum was collected and stored in aliquots at $-80^{\circ} \mathrm{C}$ until use.

\section{Complement activity of the CP, AP and LP}

For the detection of CP activity Microlon F-shape plates (Greiner bio-one, Alphen aan de Rijn, The Netherlands) were coated with human IgM (Roos et al. 2003) at $3 \mu \mathrm{g} / \mathrm{ml}$ for 2 hours at $37^{\circ} \mathrm{C}$ in coating buffer $\left(100 \mathrm{mM} \mathrm{Na}_{2} \mathrm{CO}_{3} / \mathrm{NaHCO}_{3}, \mathrm{pH}\right.$ 9.6). After incubation, plates were washed three times with PBS containing 0.05\% Tween 20 (PBS-T). Residual binding sites were blocked by incubation with PBS containing 1 \% BSA (PBSBSA), for 1 hour at $37{ }^{\circ} \mathrm{C}$. Sera were incubated in serial dilutions starting from 1:40 in BVB++ (VBS containing $0.5 \mathrm{mM} \mathrm{MgCl}, 2 \mathrm{mM} \mathrm{CaCl}_{2}, 0.05 \%$ Tween-20 and $1 \% \mathrm{BSA}, \mathrm{pH}$ $7.5)$, for 1 hour at $37^{\circ} \mathrm{C}$. After washing, bound $\mathrm{C} 3$ was detected using rabbit anti-mouse C3 (generated in our laboratory) conjugated to digoxigenin (Dig) (Boehringer Mannheim, Mannheim, Germany) followed by HRP-conjugated sheep Fab anti-Dig Abs (Boehringer Mannheim) in PBS-T-BSA, for 1 hour at $37{ }^{\circ} \mathrm{C}$. Enzyme activity of HRP was developed using 2,2'-azino-bis(3-ethyl benzathioline-6-sulfonic acid) (SigmaAldrich). The optical density (OD) at $415 \mathrm{~nm}$ was measured using a microplate biokinetics reader (EL312e; Biotek instruments, Winooski, VT). For all complement activity ELISA's normal mouse serum (NMS) from 10 weeks old male Swiss mice (Harlan, Horst, The Netherlands), arbitrarily set at 1,000 aU/ml was used to produce a calibration curve. All ELISA's were performed using this protocol unless stated otherwise. For the detection of AP activity plates were coated with $5 \mu \mathrm{g} / \mathrm{ml}$ LPS from $S$. typhosa (Sigma), washed and blocked using PBS-BSA. Serial dilutions of sera were incubated starting from 1:10 in GVB/MgEGTA (VBS containing $10 \mathrm{mM}$ EGTA, $5 \mathrm{mM} \mathrm{MgCl}_{2}$, $0.05 \%$ Tween-20, and $0.1 \%$ gelatin; $\mathrm{pH} 7.5$ ) for 1 hour at $37^{\circ} \mathrm{C}$. After washing bound $\mathrm{C} 3$ was detected using rabbit anti-mouse C3 conjugated to DIG and anti-DIG HRP.

For LP activity plates were coated with Mannan at $100 \mu \mathrm{g} / \mathrm{ml}$ (Sigma, M7504) washed and blocked using PBS-BSA. After washing serial dilutions of sera were incubated starting from 1:100 diluted in BVB++ buffer for 1 hour at $37^{\circ} \mathrm{C}$. Bound $\mathrm{C} 3$ was detected using rabbit anti-mouse C3 conjugated to DIG and anti-DIG HRP. 


\section{Detection of autoantibodies in serum}

Anti-C1q autoantibodies were detected as described [26]. Briefly, C1q binding peptide 2J (Roos et al. 2001b) was coated at $12.5 \mathrm{mM}$ in coating buffer for 2 hours at $37^{\circ} \mathrm{C}$. Plates were washed and incubated with serum of Rag2-/- mice as a source of C1q at 1:20 dilution in PBS-T-BSA for 1 hour at $37^{\circ} \mathrm{C}$. Next, serial dilutions of serum samples were incubated in PBS-T-BSA containing $0.5 \mathrm{M} \mathrm{NaCl}$ for 1 hour at $37^{\circ} \mathrm{C}$. Bound mouse $\operatorname{IgG}$ was detected using goat anti-mouse IgG-HRP (DAKO, Glostrup, Denmark). Anti-histone autoantibodies were detected as described (Termaat et al. 1993). Data are expressed relative to an anti-C1q and anti-Histone positive standard serum pool from old MRL-lpr mice arbitrarily set at 1,000 aU/ml.

\section{Detection of levels of MBL-A, MBL-C, C1q and C 3 in serum}

Both MBL-A and MBL-C in serum were quantified using a commercial kit (HBT, Uden, The Netherlands) as indicated by the manufacturer. Serum C1q was detected by ELISA as described earlier (Trouw et al. 2003). Data are expressed relative to a standard serum arbitrarily set at 1,000 U/ml. Serum C3 was detected by sandwich ELISA by coating goat anti-mouse C3 (Nordic, Tilburg, The Netherlands), and detection of bound C3 by rabbit anti-mouse C3-Dig (generated in our laboratory) and anti-Dig-HRP (Boehringer Mannheim). Data are expressed relative to a standard serum arbitrarily set at $1,000 \mathrm{aU} / \mathrm{ml}$.

\section{Renal function and pathology}

To estimate renal function, serum samples were tested in a Blood Urea Nitrogen (BUN) assay kit (Sigma). BUN levels were expressed in mg/dL. Albuminuria was measured using an autoanalyser (Hitachi-911, Hitachi, Tokyo, Japan). Data are expressed as $\mu \mathrm{g}$ albumin excretion per 24 hours.

\section{Histological studies}

For light microscopy, renal tissue was fixed in methyl Carnoy's solution, embedded in paraffin and $3 \mu \mathrm{m}$ sections were stained with hematoxylin-eosin (HE) or periodic acidSchiff (PAS). Evaluation of histo-pathologic changes was performed on coded sections by a pathologist (IB) and expressed as an Activity Index (AI) and Chronicity Index (CI) as described by Austin et al.. These indexes score several parameters of active renal inflammation such as glomerular proliferation, leukocyte exudation, karhyorrhexis/fibrinoid necrosis and hyaline deposits as well as chronic alternations such as glomerular sclerosis, fibrous crescents, tubular atrophy and interstitial fibrosis (Austin, et al. 1984).

For immunohistochemistry, acetone fixed, $3 \mu \mathrm{m}$, cryostat sections of snap frozen tissue were stained with Oregon Green-conjugated goat anti-mouse IgG (Molecular probes, Leiden, The Netherlands), or FITC-conjugated goat anti-mouse IgM (Nordic). Mouse $\mathrm{C} 1 \mathrm{q}$ was detected using rabbit anti-mouse $\mathrm{C} 1 \mathrm{q}$ (Trouw et al. 2003) and goat anti-rabbit IgG FITC (Nordic). Mouse C3 was detected using goat anti-mouse C3 FITC (Nordic). Mouse MBL-A and MBL-C were detected using rabbit anti-mouse MBL-A and MBL-C antibodies that were generated and described previously (Wagner et al. 2003), followed by goat anti-rabbit FITC (Nordic). 


\section{Statistics}

Statistical analysis was performed using GraphPad Prism 3.03 software. Differences between groups for various parameters were tested for significance using Mann Whitney tests. Correlations between several parameters were analyzed using Spearman rank correlation tests. $\mathrm{P}$ values were considered statistically significant when $\mathrm{P}<0.05$.

\section{Results}

\section{CP activity decreases with age in MRL-lpr mice but AP and LP activity remain constant}

We have analyzed serum samples of MRL +/+ and MRL-lpr mice of 6 weeks of age and 4 months of age and assessed the activity of the CP, AP and LP in serum by ELISA. CP activity is decreased by $63 \%$ in old MRL-lpr mice compared to young MRL-lpr mice ( $p$ $=0.0221$ ) (Figure 1A). There was no significant difference in CP activity between MRL $+/+$ mice of both ages. For AP activity there was a trend towards lower AP activity in aged mice of both strains. We observed an average reduction in AP activity of $52 \%$ and $63 \%$ for MRL+/+ and MRL-lpr mice respectively, but due to the variance this was not statistically significant. (Figure 1B). There was no difference in LP activity between young versus old MRL-lpr or MRL +/+ mice (Figure 1C). In order to rule out that preformed antibodies against mannan may activate the CP in our LP assay we have performed three experiments. Firstly, we have analyzed the deposition of mouse immunoglobulins from sera of young and old C57BL/6 mice as well as MRL+/+ and MRL-lpr mice and repeatedly found no significant binding. Secondly, we performed the assays for LP and CP activity in the presence of D-Mannose, which resulted in inhibition of LP only, indicating that the assay for LP activity is MBL dependent. Thirdly, we have compared NMS with C1q-/- serum and found no difference in LP activity. Together, these data strongly suggest that the CP does not contribute to LP activity in the current assay (data not shown).

\section{C1q, C3, MBL-A and MBL-C all are decreased in serum of old mice}

Using sandwich ELISA's we quantified the concentration of C1q, C3, MBL-A and MBL-C in serum of young and old mice of both strains. Serum C1q concentrations were decreased by $66 \%$ in old MRL-lpr mice $(p=0.002)$ compared to young MRL-lpr mice as well as to old MRL+/+ mice $(\mathrm{p}=0.05)$. In fact two mice had nearly undetectable levels of serum C1q (Figure 2A). C1q levels did not change in MRL +/+ mice. Interestingly the young MRL-lpr mice had a higher $\mathrm{C} 1 \mathrm{q}$ concentration than either young or old MRL+/+ mice. C3 levels were decreased by 31\% in old MRL-lpr mice ( $\mathrm{p}$ $=0.041$ ). C3 levels did not change significantly in MRL +/+ mice (Figure 2B).

Both MBL-A and MBL-C serum levels were decreased in old MRL-lpr mice compared to young MRL-lpr mice (Figure 2C,D) by 50\% and $41 \%$ respectively $(\mathrm{p}=0.026$ and $\mathrm{p}=$ 0.0022). MBL-C was also decreased upon aging in $\mathrm{MRL}+/+$ mice by $21 \%(\mathrm{p}=0.035)$ 
A

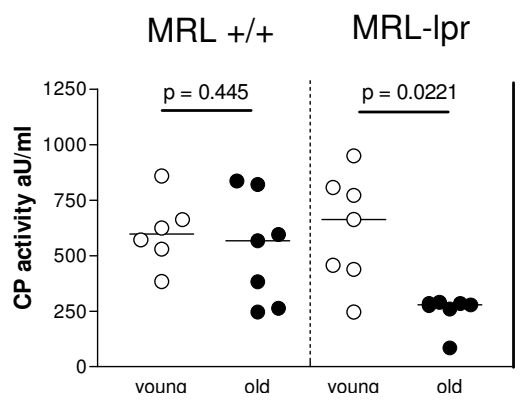

C

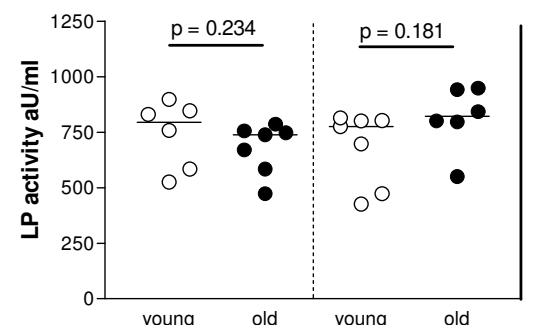

B

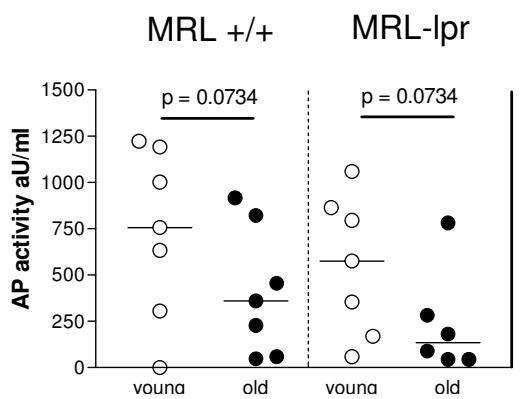

Figure 1 Activity of the $C P, A P$ and LP of complement activation as assessed by ELISA. (A) Classical pathway activity (B) Alternative pathway activity and (C) Lectin pathway activity of young and old MRL-lpr and MRL +/+ mice. Dots represent individual mice, lines represent the median. C3 deposition induced by each pathway was detected and related to a standard serum with an activity of 1,000 aU/ml.

whereas MBL-A was not decreased. Comparison of MBL-A and MBL-C levels in all serum samples revealed a strong correlation between the titers of these two proteins ( $\mathrm{r}$ $=0.67, \mathrm{p}=0.00062$ ) (Figure 2E).

\section{Autoantibodies in relation to complement activity}

We have analyzed both anti-histone and anti-C1q autoantibodies as parameters of autoimmunity. Anti-histone autoantibodies were absent in young MRL +/+ mice and are significantly increased upon aging. In some young MRL-lpr mice anti-histone antibodies could be detected and a pronounced increase in anti-histone titer was observed in old mice ( $p=0.0012$ )(Figure 3A). Anti-C1q autoantibodies were slightly positive in young MRL+/+ mice and did not increase significantly upon aging. Young MRL-lpr mice already had some anti-C1q reactivity which was strongly increased upon aging $(p=0.0012)$ (Figure 3B). We have analyzed the relation between anti-histone and antiC1q titer with activity of the CP, AP or LP. For this analysis we have used the samples of both strains of both ages. Anti-C1q titers and anti-Histone titers were correlated ( $p$ $=0.001)$. Levels of anti-histone autoAb correlated to CP $(p=0.007)$ and AP $(p=0.008)$ activity but not to LP activity $(p=0.749)$. Anti-C1q autoAb levels were correlated with CP activity $(p=0.037)$ but not with AP or LP activity $(p=0.070$ and $p=0.308)$.

\section{Renal deposition of IgG, C1q, MBL-A, MBL-C and C3}

Staining renal sections of MRL +/+ and MRL-lpr mice for mouse IgG as a measure of immune complex deposition revealed background positivity of mouse IgG in glomeruli of young MRL +/+ mice and increased positivity of IgG in glomeruli of old MRL 
A

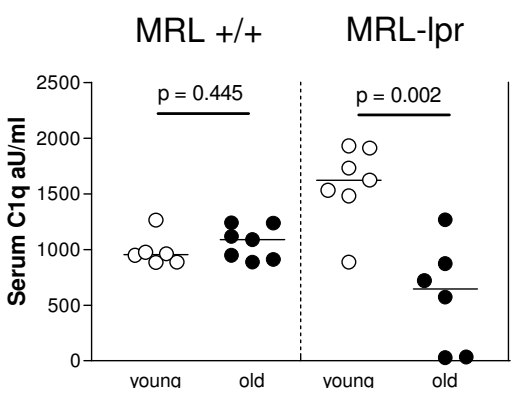

C

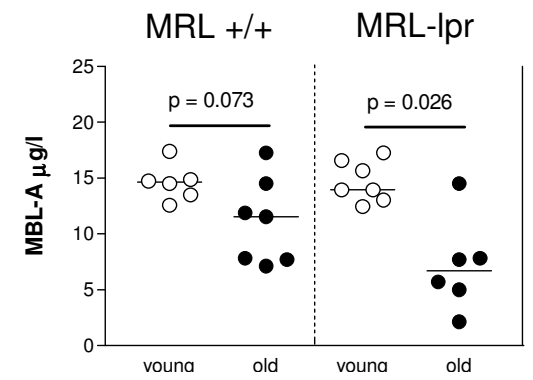

B

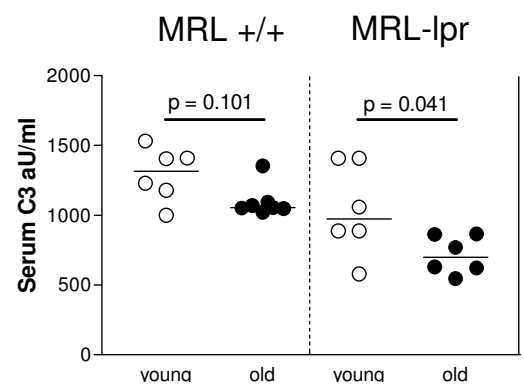

D

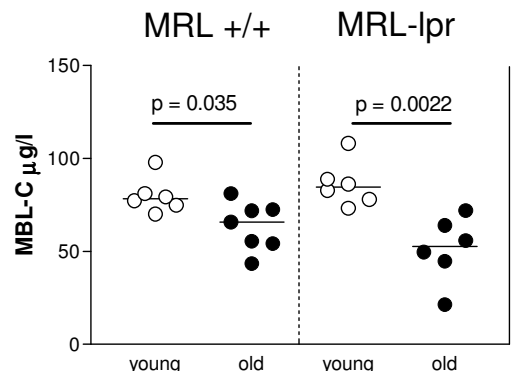

$E$

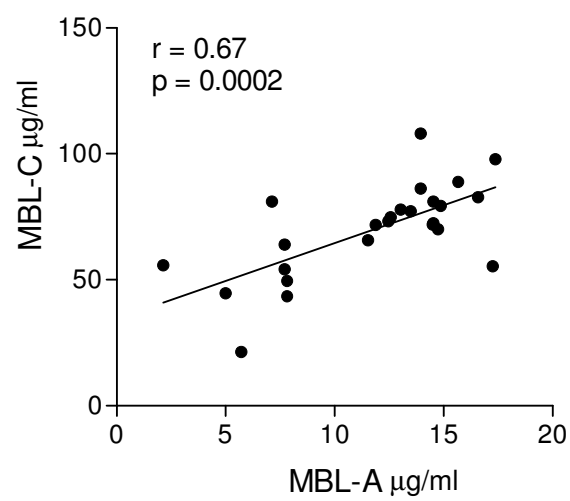

Figure 2 Serum levels of $C 1 q, C 3$ and $M B L-A$ and $M B L-C$ in young and old $M R L+/+$ mice and $M R L-$ lpr mice. Sandwich ELISA for mouse C1q $(A)$, mouse C3 (B), mouse MBL-A $(C)$ and mouse $M B L-C(D)$. Dots represent individual mice, lines represent the median. $C 1 q$ and C3 levels are expressed as aU relative to an standard serum which was arbitrarily set at 1,000 aU/ml. $M B L-A$ and $M B L-C$ are expressed as $\mathrm{mg} / \mathrm{ml}$. (E) relation between serum concentrations of $M B L-A$ and $M B L-C$. 
A
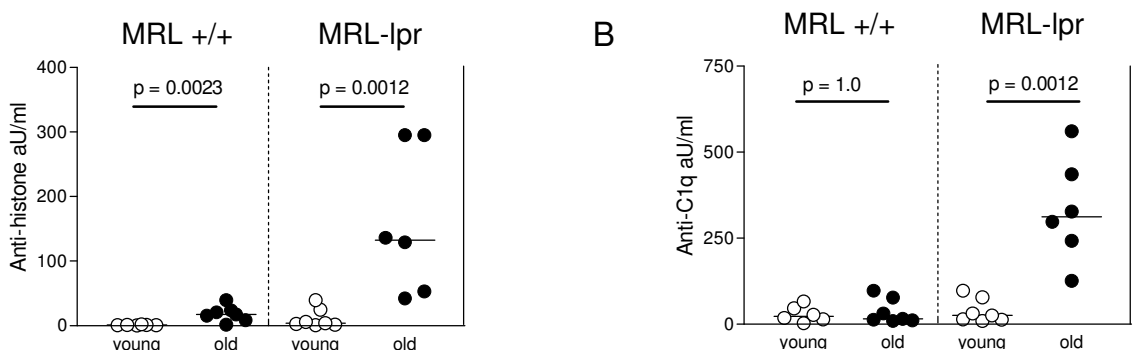

Figure 3 Autoantibody titers in young and old MRL+/+ and MRL-lpr mice. Anti-histone autoantibodies $(A)$ and anti-C1q autoantibodies $(B)$ as detected by ELISA. Dots represent individual mice, lines represent the median. Autoantibody titers are expressed as aU relative to a standard serum, which was arbitrarily set at 1,000 aU/ml.

+/+ mice and young MRL-lpr mice. Massive IgG deposition was observed in old MRLlpr mice.

Staining these sections for the deposition of mouse C1q revealed a similar profile with especially glomeruli of old MRL-lpr mice being brightly positive. Normal mouse kidneys (data not shown) and kidneys of young MRL +/+ and MRL-lpr mice were slightly positive for MBL-A and negative for MBL-C except for slight positivity in young MRLlpr mice. The positivity for MBL was mainly found in large vessels, peri-tubular capillaries and glomerular capillaries (Figure 4). Upon aging both MBL-A and MBL-C deposited in glomeruli, now in a capillary and mesangial pattern (Figure 4). The increased deposition was more pronounced in MRL-lpr mice than in MRL +/+ mice. MBLA seems to be more abundantly present than MBL-C. Staining for C3 as a marker of complement activation revealed a similar pattern as that for IgG, C1q and MBL-A and MBL-C.

\section{Renal function and albuminuria in relation to MBL concentrations}

We have analyzed renal function using BUN, and observed mean BUN values in MRL+/+ mice of $33 \mathrm{mg} / \mathrm{dL}$ which decreased slightly upon aging. Young MRL-lpr mice had BUN values around $25 \mathrm{mg} / \mathrm{dL}$ and this value rose significantly to $37 \mathrm{mg} / \mathrm{dL}$ in old MRL-lpr mice. These data indicate that renal function is affected but not completely lost in our cohorts (Figure 5A). We have also analyzed albuminuria as a measure for renal injury and observed no albuminuria in either young or old MRL+/+ mice (Figure 5B), while two old MRL-lpr mice clearly develop albuminuria (Figure 5B). MBL-A concentrations as analyzed for all mice together did not correlate with either BUN or albumin values, whereas for MBL-C there was a negative correlation with the BUN values $(\mathrm{p}=0.03)$.

Assessment of histological changes in renal sections revealed no chronic changes in our cohorts. For the activity index (AI) mostly glomerular cell proliferation and leukocyte influx were observed, but also occasional cellular crescents and hyaline deposits. Both young and old MRL+/+ mice displayed only marginal signs of renal inflammati- 
on. Young MRL-lpr mice displayed a slightly increased histopathological score when compared to MRL+/+ mice and upon aging this index rises sharply in MRL-lpr mice ( $p$ $=0.002$ ) (Figure 5C). The AI was negatively correlated to both MBL-A and MBL-C $(\mathrm{p}=$ 0.04 and $\mathrm{p}=0.02$ respectively).

\section{Discussion}

The lectin pathway of complement activation has been extensively studied because of the associations between functional deficiencies and several diseases (Baxter et al. 2001; Garred et al. 2002;Garred et al. 2003;Mullighan et al. 2002;Peterslund et al. 2001). However, the contribution of the lectin pathway to organ damage has not been investigated in detail. In SLE and lupus nephritis complement activation is thought to play a potential role in organ damage (Cameron 1999; Walport 2001a;Walport 2001b). Several reports describe a relation between decreased levels of CP and AP components and organ damage (Buyon et al. 1992;Gunnarsson et al. 2002;Siegert et al. 1991;Sturfelt 2002). No such data is available for LP components. Therefore we have analyzed whether the lectin pathway of complement activation is involved in murine lupus nephritis.

To investigate the contribution of the lectin pathway to murine lupus-nephritis we have used MRL-lpr and MRL +/+ mice. These mice develop a spontaneous autoimmune disease, which is accelerated in MRL-lpr mice by the silencing of the Fas gene. Therefore MRL-lpr have a fast and aggressive autoimmune disease and MRL+/+ mice have a milder autoimmune disease when compared at the same age. The role of complement in murine lupus nephritis became questionable since some studies using C1qdeficient (Mitchell et al. 2002) and C3-deficient (Sekine et al. 2001) MRL-lpr and MRL+/+ mice suggested that complement activation is not essential in murine lupus nephritis. However, recent experiments using Crry-Ig, a rodent complement inhibitor at the level of $\mathrm{C} 3$, showed that inhibition of complement activation prevented renal damage in MRL-lpr mice (Bao et al. 2002;Bao et al. 2003a;Bao et al. 2003b). These data and data from factor B-deficient MRL-lpr mice (Watanabe et al. 2000) clearly indicate that complement does play a role in this disease and that these mice provide a good tool to study the contribution of the lectin pathway to murine lupus nephritis.

In the present study we observed a decrease in CP activity in MRL-lpr mice upon aging. The AP and LP activity remained unchanged. The decrease in CP activity may to some extent be explained by the decrease in key molecule for the $\mathrm{CP} C 1 \mathrm{q}$. Interestingly the key-molecules of the AP, C3 and for the LP, MBL-A and MBL-C were both reduced upon aging of MRL-lpr mice whereas AP and LP activity remained unchanged. For the AP activity a trend of reduced AP activity was obvious however due to variance it did not reach statistical significance, whereas the decrease in C3 levels was borderline significant, therefore we feel that this is not in disagreement with each other. For the discrepancy observed for the LP, these data may suggest that other molecules that are able to bind to mannan might support LP activity in these aging mice. It has been reported that human L-ficolin and H-ficolin are able to activate the 


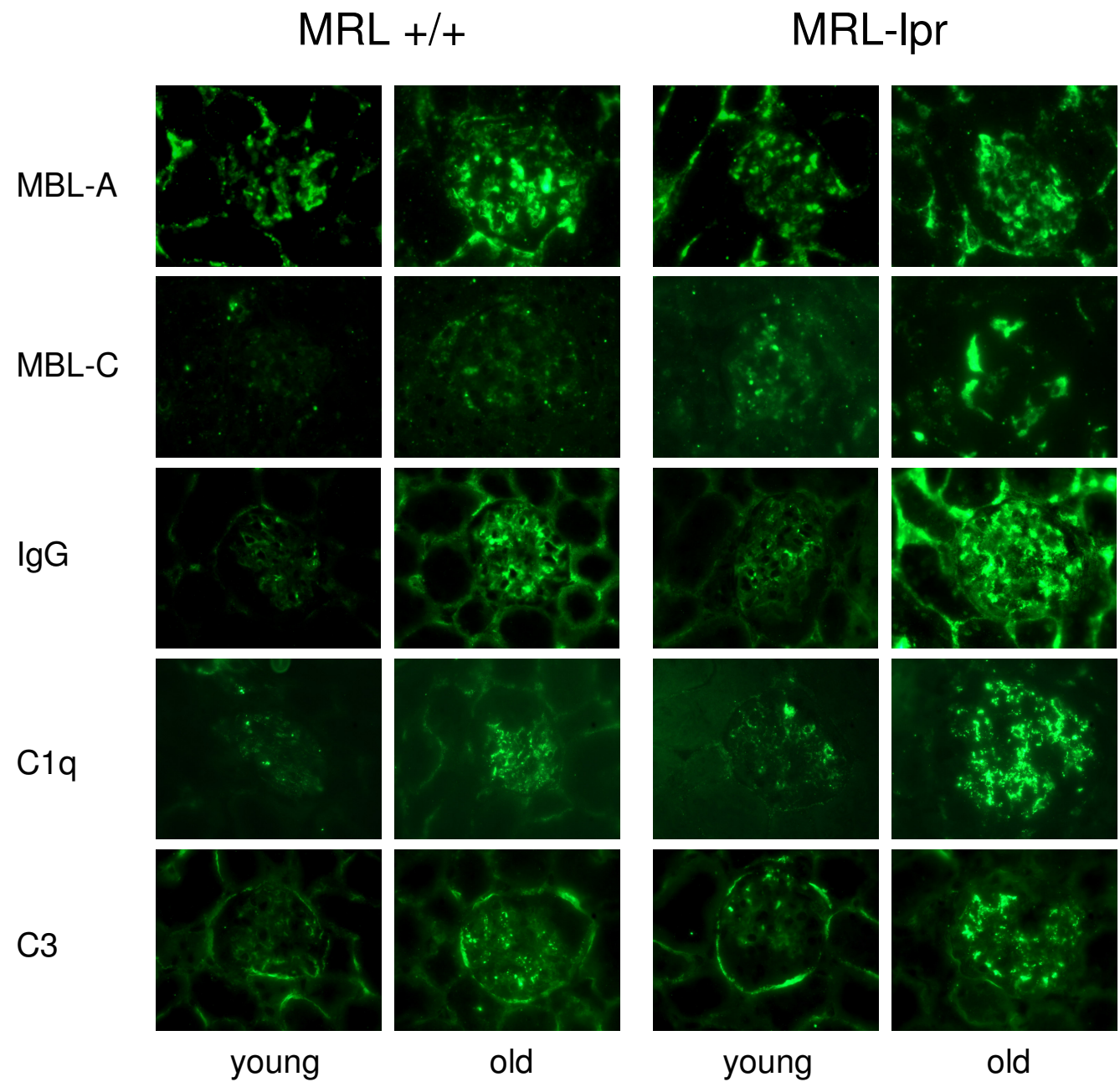

Figure 4 Immunofluorescence analysis of renal deposition of $M B L-A, M B L-C, I g G, C 1 q$ and $C 3$. Renal sections of either young or old $M R L+/+$ or MRL-lpr mice were stained for the presence of mouse MBL-A, MBL-C, IgG, C1q or C3. Representative pictures are shown. Original magnification $400 x$.

LP. However, this has not been reported for mouse molecules. Furthermore, human ficolins do not bind to mannan and therefore their contribution to LP activity in MRLlpr mice is considered unlikely.

In order to rule out that our detection system for LP activity may also allow complement activation via the $\mathrm{CP}$, mediated by the binding of anti-mannan antibodies as has been described previously for human serum (Roos et al. 2003), we have performed several experiments. Firstly, we have analyzed the deposition of mouse immunoglobulins from mouse sera of young and old non-autoimmune C57BL/6 mice as well as auto- 
A

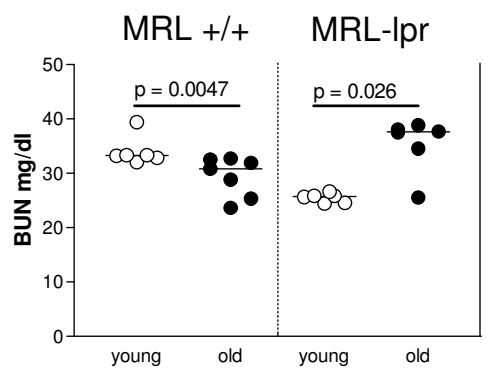

C

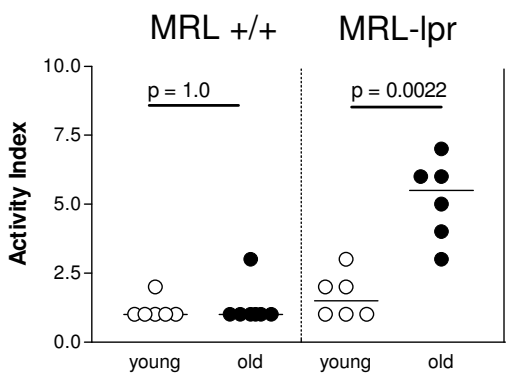

B

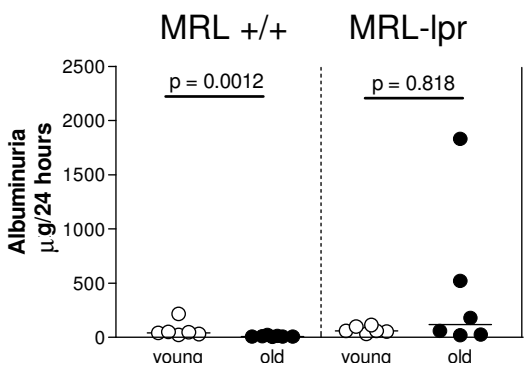

Figure 5 Parameters of renal disease (A) Blood Urea Nitrogen, (B) Albuminuria and (C) Activity Index values for young and old MRL+/+ and MRL-lpr mice. Dots represent individual mice, lines represent the median. $B U N$ values are expressed as $\mu g / d L$, Albuminuria is expressed as $m g / 24$ hours and histological abnormalities are expressed in terms of an Activity Index as described by Austin et al. (Austin, III et al. 1984).

immune prone MRL+/+ and MRL-lpr mice and we repeatedly found no significant binding of mouse immunoglobulins to these mannan coated plates. Secondly, we have performed the assays for LP and CP activity in the presence of D-Mannose (a well known ligand for MBL), resulting in inhibition of only LP assay indicating that complement activation in the LP test is MBL dependent. Thirdly, we have compared NMS with C1q-/- serum and found no difference in LP activity. Together, these data strongly suggest that the $\mathrm{CP}$ does not contribute significantly to LP activity in our assay. Deposition of immune complexes in glomeruli is thought to be an initiating event in the pathogenesis of lupus-nephritis (Cameron 1999;Oates and Gilkeson 2002). We observed IgG positivity paralleled by $\mathrm{C} 1 \mathrm{q}$ positivity, indicating $\mathrm{CP}$ involvement. In addition we observed $\mathrm{C} 3$ deposition which can be activated via all three pathways of complement activation, and deposition of MBL-A and MBL-C, indicating that also the LP is involved. In the present study we can not conclude on the relative contribution of the three pathways of complement activation, but we do show that MBL-A and MBL-C are decreased in serum and do deposit in the kidney during murine lupusnephritis. One report describes the deposition of MBL in several forms of glomerulonephritis including lupus-nephritis (Lhotta et al. 1999). These authors state that MBL is found on the same locations where IgG deposition and $\mathrm{CP}$ activation have taken place and suggest that MBL may bind to agalactosyl oligosacharides of IgG that terminate in $\mathrm{N}$-acetylglucosamine. Also in this mouse model of lupus nephritis we observed MBL deposition on the same locations as IgG and C1q. In line with our observation in mice one report also describes decreased levels of MBL during lupus nephritis in 
humans (Lau et al. 1996). However others have reported the serum concentration of MBL to be in the same range as the MBL concentration of healthy individuals (Lhotta et al. 1999). Both disease activity and treatment may be different between these two reports and may account for these differences.

Deficiencies of early components of the $\mathrm{CP}(\mathrm{C} 1 \mathrm{q}, \mathrm{C} 1 \mathrm{r}, \mathrm{C} 1 \mathrm{~s}, \mathrm{C} 4)$ are strongly related to an increased susceptibility to SLE (Botto et al. 1998;Mitchell et al. 2002;Walport 2001b). MBL deficiency is also associated with an increased risk to develop SLE (Garred et al. 2001), although to a much lesser extent. Furthermore, MBL deficiency was shown to be associated with a higher disease activity and an enhanced risk for infections in SLE patients (Garred et al. 2001). In autoimmune diseases one can distinguish induction of autoimmunity and organ damage as two separate events. Therefore if genetic analysis indicates that a component is protective against autoimmunity, it may still very well contribute to organ damage in WT individuals. Data from the present study as well as previously reported findings in human lupus nephritis, suggest that MBL may also contribute to organ damage in SLE and therefore could have a dual role in this disease. In this respect, it has been reported that MBL deficiency contributes to an earlier and more severe development of rheumatoid arthritis whereas, MBL wildtype alleles were also associated with additional joint inflammation (Garred et al. 2000).

In conclusion, the present study provides evidence that the lectin pathway of complement activation is activated in murine lupus nephritis based on the observation that the serum concentrations of both MBL-A and MBL-C are decreased as lupus nephritis develops and that these components deposit in the kidney in a similar pattern as C3, possibly contributing to renal damage.

\section{Acknowledgements}

This work was supported by grants from the Dutch Kidney Foundation (grant 98.1763) and the European Union (QLGI-CT-200201215). The authors wish to thank Vanessa van Ham for excellent technical support. 


\section{References}

1. Andrews B.S., Eisenberg R.A., Theofilopoulos A.N., Izui S., Wilson C.B., McConahey P.J., Murphy E.D., Roths J.B. and Dixon F.J. (1978) Spontaneous murine lupus-like syndromes. Clinical and immunopathological manifestations in several strains. J.Exp.Med. 148, 1198-1215.

2. $\quad$ Austin H.A., III, Muenz L.R., Joyce K.M., Antonovych T.T. and Balow J.E. (1984) Diffuse proliferative lupus nephritis: identification of specific pathologic features affecting renal outcome. Kidney Int. 25, 689-695.

3. Bao L., Haas M., Boackle S.A., Kraus D.M., Cunningham P.N., Park P., Alexander J.J., Anderson R.K., Culhane K., Holers V.M. and Quigg R.J. (2002) Transgenic expression of a soluble complement inhibitor protects against renal disease and promotes survival in MRL/lpr mice. J.Immunol. 168, 3601-3607.

4. $\quad$ Bao L., Haas M., Kraus D.M., Hack B.K., Rakstang J.K., Holers V.M. and Quigg R.J. (2003a) Administration of a Soluble Recombinant Complement C3 Inhibitor Protects Against Renal Disease in MRL/lpr Mice. J.Am.Soc.Nephrol. 14, 670-679.

5. Bao L., Zhou J., Holers V.M. and Quigg R.J. (2003b) Excessive Matrix Accumulation in the Kidneys of MRL/lpr Lupus Mice Is Dependent on Complement Activation. J.Am.Soc.Nephrol. 14, 2516-2525.

6. Baxter N., Sumiya M., Cheng S., Erlich H., Regan L., Simons A. and Summerfield J.A. (2001) Recurrent miscarriage and variant alleles of mannose binding lectin, tumour necrosis factor and lymphotoxin alpha genes. Clin.Exp.Immunol. 126, 529-534.

7. Botto M., Dell'Agnola C., Bygrave A.E., Thompson E.M., Cook H.T., Petry F., Loos M., Pandolfi P.P. and Walport M.J. (1998) Homozygous C1q deficiency causes glomerulonephritis associated with multiple apoptotic bodies. Nat Genet 19, 56-59.

8. Buyon J.P., Tamerius J., Belmont H.M. and Abramson S.B. (1992) Assessment of disease activity and impending flare in patients with systemic lupus erythematosus. Comparison of the use of complement split products and conventional measurements of complement. Arthritis Rheum. 35, 1028-1037.

9. Cameron J.S. (1999) Lupus nephritis. J.Am.Soc.Nephrol. 10, 413-424.

10. Christiansen O.B., Kilpatrick D.C., Souter V., Varming K., Thiel S. and Jensenius J.C.(1999) Mannanbinding lectin deficiency is associated with unexplained recurrent miscarriage. Scand.J.Immunol. 49, 193-196.

11. Collard C.D., Vakeva A., Morrissey M.A., Agah A., Rollins S.A., Reenstra W.R., Buras J.A., Meri S. and Stahl G.L. (2000) Complement activation after oxidative stress: role of the lectin complement pathway. Am.J.Pathol. 156, 1549-1556.

12. Endo M., Ohi H., Ohsawa I., Fujita T., Matsushita M. and Fujita T. (1998) Glomerular deposition of mannose-binding lectin (MBL) indicates a novel mechanism of complement activation in IgA nephropathy. Nephrol.Dial.Transplant. 13, 1984-1990.

13. Garred P., Larsen F., Madsen H.O. and Koch C. (2003) Mannose-binding lectin deficiency--revisited. Mol.Immunol. 40, 73-84.

14. Garred P., Madsen H.O., Marquart H., Hansen T.M., Sorensen S.F., Petersen J., Volck B., Svejgaard A., Graudal N.A., Rudd P.M., Dwek R.A., Sim R.B. and Andersen V. (2000) Two edged role of mannose binding lectin in rheumatoid arthritis: a cross sectional study. J.Rheumatol. 27, 26-34. 
15. Garred P., Pressler T., Lanng S., Madsen H.O., Moser C., Laursen I., Balstrup F., Koch C. and Koch C. (2002) Mannose-binding lectin (MBL) therapy in an MBL-deficient patient with severe cystic fibrosis lung disease. Pediatr.Pulmonol. 33, 201-207.

16. Garred P., Voss A., Madsen H.O. and Junker P. (2001) Association of mannose-binding lectin gene variation with disease severity and infections in a population-based cohort of systemic lupus ery thematosus patients. Genes Immun. 2, 442-450.

17. Gunnarsson I., Sundelin B., Heimburger M., Forslid J., van Vollenhoven R., Lundberg I. and Jacobson S.H. (2002) Repeated renal biopsy in proliferative lupus nephritis--predictive role of serum C1q and albuminuria. J.Rheumatol. 29, 693-699.

18. Hansen S. and Holmskov U. (1998) Structural aspects of collectins and receptors for collectins. Immunobiology 199, 165-189.

19. Hansen S., Thiel S., Willis A., Holmskov U. and Jensenius J.C. (2000) Purification and characterization of two mannan-binding lectins from mouse serum. J.Immunol. 164, 2610-2618.

20. Kilpatrick D.C., Starrs L., Moore S., Souter V. and Liston W.A. (1999) Mannan binding lectin concentration and risk of miscarriage. Hum.Reprod. 14, 2379-2380.

21. Kuhlman M., Joiner K. and Ezekowitz R.A. (1989) The human mannose-binding protein functions as an opsonin. J.Exp.Med. 169, 1733-1745.

22. Lau Y.L., Lau C.S., Chan S.Y., Karlberg J. and Turner M.W. (1996) Mannose-binding protein in Chinese patients with systemic lupus erythematosus. Arthritis Rheum. 39, 706-708.

23. Lhotta K., Wurzner R. and Konig P. (1999) Glomerular deposition of mannose-binding lectin in human glomerulonephritis. Nephrol.Dial.Transplant. 14, 881-886.

24. Liu H., Jensen L., Hansen S., Petersen S.V., Takahashi K., Ezekowitz A.B., Hansen F.D., Jensenius J.C. and Thiel S. (2001) Characterization and quantification of mouse mannan-binding lectins (MBL-A and MBL-C) and study of acute phase responses. Scand.J.Immunol. 53, 489-497.

25. Mitchell D.A., Pickering M.C., Warren J., Fossati-Jimack L., Cortes-Hernandez J., Cook H.T., Botto M. and Walport M.J. (2002) C1q deficiency and autoimmunity: the effects of genetic background on disease expression. J.Immunol. 168, 2538-2543.

26. Mullighan C.G., Heatley S., Doherty K., Szabo F., Grigg A., Hughes T.P., Schwarer A.P., Szer J., Tait B.D., Bik T.L. and Bardy P.G. (2002) Mannose-binding lectin gene polymorphisms are associated with major infection following allogeneic hemopoietic stem cell transplantation. Blood 99, 3524-3529.

27. Nauta A.J., Raaschou-Jensen N., Roos A., Daha M.R., Madsen H.O., Borrias-Essers M.C., Ryder L.P., Koch C. and Garred P. (2003) Mannose-binding lectin engagement with late apoptotic and necrotic cells. Eur.J.Immunol. 33, 2853-2863.

28. Oates J.C. and Gilkeson G.S. (2002) Mediators of injury in lupus nephritis. Curr.Opin.Rheumatol. 14, 498-503.

29. Ohsawa I., Ohi H., Tamano M., Endo M., Fujita T., Satomura A., Hidaka M., Fuke Y., Matsushita M. and Fujita T. (2001) Cryoprecipitate of patients with cryoglobulinemic glomerulonephritis contains molecules of the lectin complement pathway. Clin.Immunol. 101, 59-66.

30. Oka S., Ikeda K., Kawasaki T. and Yamashina I. (1988) Isolation and characterization of two distinct mannan-binding proteins from rat serum. Arch.Biochem.Biophys. 260, 257-266. 
31. Petersen S.V., Thiel S. and Jensenius J.C. (2001) The mannan-binding lectin pathway of complement activation: biology and disease association. Mol.Immunol. 38, 133-149.

32. Peterslund N.A., Koch C., Jensenius J.C. and Thiel S. (2001) Association between deficiency of mannose-binding lectin and severe infections after chemotherapy. Lancet 358, 637-638.

33. Rector A., Lemey P., Laffut W., Keyaerts E., Struyf F., Wollants E., Vermeire S., Rutgeerts P. and Van Ranst M. (2001) Mannan-binding lectin (MBL) gene polymorphisms in ulcerative colitis and Crohn's disease. Genes Immun. 2, 323-328.

34. Roos A., Bouwman L.H., Gijlswijk-Janssen D.J., Faber-Krol M.C., Stahl G.L. and Daha M.R. (2001a) Human IgA activates the complement system via the mannan-binding lectin pathway. J.Immunol. $167,2861-2868$.

35. Roos A., Bouwman L.H., Munoz J., Zuiverloon T., Faber-Krol M.C., Fallaux-Van Den Houten FC, Klar-Mohamad N., Hack C.E., Tilanus M.G. and Daha M.R. (2003) Functional characterization of the lectin pathway of complement in human serum. Mol.Immunol. 39, 655-668.

36. Roos A., Nauta A.J., Broers D., Faber-Krol M.C., Trouw L.A., Drijfhout J.W. and Daha M.R. (2001b) Specific inhibition of the classical complement pathway by C1q-binding peptides. J.Immunol. 167, 7052-7059.

37. Sekine H., Reilly C.M., Molano I.D., Garnier G., Circolo A., Ruiz P., Holers V.M., Boackle S.A. and Gilkeson G.S. (2001) Complement component C3 is not required for full expression of immune complex glomerulonephritis in MRL/lpr mice. J.Immunol. 166, 6444-6451.

38. Siegert C., Daha M., Westedt M.L., van d., V and Breedveld F. (1991) IgG autoantibodies against C1q are correlated with nephritis, hypocomplementemia, and dsDNA antibodies in systemic lupus ery thematosus. J Rheumatol 18, 230-234.

39. Sturfelt G. (2002) The complement system in systemic lupus erythematosus. Scand.J.Rheumatol. 31, 129-132.

40. Takahashi K., Gordon J., Liu H., Sastry K.N., Epstein J.E., Motwani M., Laursen I., Thiel S., Jensenius J.C., Carroll M. and Ezekowitz R.A. (2002) Lack of mannose-binding lectin-A enhances survival in a mouse model of acute septic peritonitis. Microbes.Infect. 4, 773-784.

41. Termaat R.M., Assmann K.J., van Son J.P., Dijkman H.B., Koene R.A. and Berden J.H. (1993) Antigenspecificity of antibodies bound to glomeruli of mice with systemic lupus erythematosus-like syndromes. Lab Invest 68, 164-173.

42. Trinder P.K., Maeurer M.J., Schorlemmer H.U. and Loos M. (1995) Autoreactivity to mouse C1q in a murine model of SLE. Rheumatol.Int. 15, 117-120.

43. Trouw L.A., Groeneveld T.W.L., Seelen M.A., Duijs J.M.G.J., Bajema I.M., Prins, F. A., Kishore, U., Salant, D. J., Verbeek, J. S., van Kooten C., and Daha M.R. Anti-C1q autoantibodies deposit in glomeruli but are only pathogenic in combination with glomerular C1q-containing immunecomplexes. J Clin Invest . 2004a. In Press

44. Trouw L.A., Seelen M.A., Visseren R., Duijs J.M.G.J., Benediktsson H., de Heer E., Roos A., van Kooten C. and Daha M.R. (2004b) Anti-C1q autoantibodies in murine lupus nephritis. Clin.Exp.Immunol. 135, 41-48.

45. Trouw L.A., Seelen M.A., Duijs J.M., Benediktsson H., Van Kooten C. and Daha M.R. (2003) Glomerular deposition of $\mathrm{C} 1 \mathrm{q}$ and anti-C1q antibodies in mice following injection of antimouse C1q antibodies. Clin.Exp.Immunol. 132, 32-39. 
46. Wagner S., Lynch N.J., Walter W., Schwaeble W.J. and Loos M. (2003) Differential expression of the murine mannose-binding lectins $\mathrm{A}$ and $\mathrm{C}$ in lymphoid and nonlymphoid organs and tissues. J.Immunol. 170, 1462-1465.

47. Walport M.J. (2001a) Complement. First of two parts. N.Engl.J.Med. 344, 1058-1066.

48. Walport M.J. (2001b) Complement. Second of two parts. N.Engl.J.Med. 344, 1140-1144.

49. Watanabe H., Garnier G., Circolo A., Wetsel R.A., Ruiz P., Holers V.M., Boackle S.A., Colten H.R. and Gilkeson G.S. (2000) Modulation of renal disease in MRL/lpr mice genetically deficient in the alternative complement pathway factor B. J.Immunol. 164, 786-794.

50. Watanabe-Fukunaga R., Brannan C.I., Copeland N.G., Jenkins N.A. and Nagata S. (1992)

Lymphoproliferation disorder in mice explained by defects in Fas antigen that mediates apoptosis. Nature 356, 314-317. 


\section{Chapter 3}

\section{Autoantibodies against mannose binding lectin (MBL) in systemic Lupus Erythematosus}

Seelen MA, Trouw LA, van der Hoorn JWA, Fallaux-van den Houten FC,

Huizinga TWJ, Daha MR, Roos A

Department of Nephrology and Rheumatology, Leiden University Medical Center,

Leiden, The Netherlands.

Clin Exp Immunol. 134 (2003) 335-43 


\section{Summary}

In systemic lupus erythematosus (SLE), autoantibodies directed against complement components of the classical pathway, especially against $\mathrm{C} 1 \mathrm{q}$, are associated with severe disease and are of prognostic value for flares of lupus nephritis. Mannose-binding lectin (MBL), the recognition unit of the MBL pathway of complement activation, has structural similarities with C1q. Deficiencies of MBL have been shown to predispose to the development of SLE and to influence the course of the disease. We hypothesised that the presence of autoantibodies to MBL analogous to autoantibodies to $\mathrm{Clq}$ in patients with SLE may contribute to disease development.

The occurrence of anti-MBL autoantibodies was assessed by ELISA in 68 serum samples from 20 patients with SLE and in serum from 70 healthy controls. Levels of antibodies directed against MBL were significantly higher in patients with SLE compared to healthy subjects. No significant difference was found between patients with active disease compared to inactive disease. While the occurrence of anti-C1q autoantibodies was associated with renal involvement, no such relation was found for anti-MBL autoantibodies. A significant correlation was found between anti-MBL and anti-C1q antibody levels. The level of anti-MBL antibodies was negatively correlated with MBLcomplex activity of circulating MBL. Anti-MBL autoantibodies were of IgG isotype and the binding site of IgG anti-MBL was located in the $\mathrm{F}\left(a b^{\prime}\right)_{2}$ portion.

We conclude that anti-MBL antibodies are present in sera from patients with SLE and influence the functional activity of MBL.

\section{Introduction}

The innate immune system plays a crucial role in the pathogenesis of systemic lupus erythematosus $[1,2]$. In the pathogenesis of SLE the complement system has a dual role. On the one hand activation of complement may cause tissue injury, on the other hand, genetic deficiencies of complement components, especially of the early components of the classical pathway, are strongly associated with the occurrence of SLE [3]. Furthermore, the presence of antibodies to $\mathrm{Clq}$ is associated with hypocomplementaemia and nephritis in patients with SLE [4-7]. Recent studies indicate a possible role for the lectin pathway of complement activation in the pathogenesis of SLE $[8,9]$. Mannose-binding lectin (MBL), structurally homologous to C1q, activates the lectin pathway of complement. Like C1q, MBL consists of trimeric subunits with a collagenlike tail. These subunits assemble to higher-order structures consisting of up to six trimers [10]. Binding of the carbohydrate-recognition domain of MBL to different carbohydrates, in a calcium-dependent manner, activates the MBL-associated serine proteases MASP-1, MASP-2 and MASP-3 that are strongly related to the serine proteases of the classical pathway, $\mathrm{C} 1 \mathrm{r}$ and $\mathrm{C} 1 \mathrm{~s}$. Evidence has been provided that activation of MASP-2 is responsible for the activation of the complement cascade [11]. 
MBL deficiency or low serum MBL levels are frequently found in the general population due to point mutations in the structural portion or promoter region of the MBL gene [9-12]. The three known mutations in the structural domain of the MBL gene are located in codon 52 [13], 54 [14] and 57 [15] of exon 1, whereas mutations at position $550(\mathrm{H} / \mathrm{L}$ alleles), -221 (X/Y alleles) and +4 (P/Q alleles) upstream of the MBL gene are located in non-coding regions [16,17]. Circulating concentrations of MBL have been shown to be associated with recurrent bacterial and fungal infections in both children and adults [18-21]. Variant alleles, leading to reduced serum concentrations of MBL, may be associated with the predisposition for SLE [8,22-25]. Association of a promotor polymorphism with the development of SLE has been reported [26-28]. Furthermore, complications caused by bacterial infections in patients with SLE occur more frequently if these individuals carry mutations in the MBL gene [24,29].

Autoantibodies to C1q are found in 30-45\% of patients with SLE [4-7,24]. The presence of anti-C1q autoantibodies is associated with hypocomplementaemia and glomerulonephritis. In the presence of anti-C1q antibodies the $\mathrm{C} 1 \mathrm{q}$ levels are reduced [6]. Stabilisation of deposited C1q in the kidney, by these antibodies, has been suggested to cause ongoing complement activation and thereby damage to the kidney [30]. Increase of anti-C1q levels in serum of patients with SLE is strongly associated with flares of lupus nephritis [5-7,31]

Low MBL concentrations may result from gene polymorphisms, consumption of MBL during disease activity or possibly because of autoantibodies directed against MBL. Because of the structural similarities between $\mathrm{C} 1 \mathrm{q}$ and $\mathrm{MBL}$, and the role of MBL in patients with SLE, we investigated if, analogous to the presence of anti-C1q autoantibodies, autoantibodies to MBL occur.

\section{Patients and Methods}

\section{Patients}

All 20 patients with SLE (5 males and 15 female; mean age 33 years) visited the outpatient clinic of the department of Nephrology. The patients fulfilled the American Rheumatological Association (ARA) criteria for SLE. The clinical data were recorded from the patient files. From each patient at least two serum samples were obtained over time, the maximum number of serum samples/patient was seven. The total number of serum samples from the 20 patients was 68 . Samples were taken (after obtaining informed consent from the patient) during inactive and active phases of disease. The autoantibody titres were measured in different serum samples from each patient during active and inactive disease. Active disease was considered to be present when patients had disease activity ( as defined by clinical criteria) or when laboratory results indicated active nephritis, i.e. proteinuria $>0.5 \mathrm{~g} / 24 \mathrm{~h}$ and erythrocytes ( or red cell casts) on urinalysis. The serum aliquots were stored at $-20^{\circ} \mathrm{C}$ until required for further use. From 70 healthy individuals, working in our hospital, serum samples were obtained and used as controls. 
Purification of MBL and measurement of MBL serum concentrations

Purification of MBL and the assessment of MBL concentrations was performed exactly as described previously [32].

\section{Detection of immunoglobulin G (IgG) binding to MBL}

For detection of IgG antibodies to MBL, Nunc Maxisorb plates (Roshilde, Denmark) were first coated, for $2 \mathrm{~h}$ at $37^{\circ} \mathrm{C}$, with $0.5 \mu \mathrm{g} / \mathrm{ml} \mathrm{MBL}$ in coating buffer $(100 \mathrm{mM}$ $\mathrm{Na}_{2} \mathrm{CO}_{3} / \mathrm{NaHCO}_{3}, \mathrm{pH}$ 9.6). After incubation, the plates were washed three times with phosphate-buffered saline (PBS) containing 0.05\% Tween-20 (PBS/Tw). Unoccupied binding sites were blocked by incubation for $1 \mathrm{~h}$ at $37^{\circ} \mathrm{C}$ with $0.01 \%$ gelatin in PBS. Serum samples diluted in PBS/Tw, containing $1 \%$ bovine serum albumin (PBS/Tw/BSA) and $10 \mathrm{mM}$ EDTA were incubated on the plate for $1 \mathrm{hr}$ at $37^{\circ} \mathrm{C}$. After incubation, bound IgG was detected using digoxigenin (Dig) (Boehringer Mannheim, Mannheim, Germany)-conjugated monoclonal mouse anti-human IgG (HB43, mAb anti-IgG, hybridoma obtained from the American Type Culture Collection (ATCC)), diluted in PBS/Tw/BSA. Subsequently, HRP-conjugated Fab rabbit anti-Dig Abs (Boehringer Mannheim) were added and enzymatic activity of HRP was assessed using 2,2'-azino-bis(3-ethyl benzathioline-6-sulfonic acid) (Sigma, St. Louis, MO). The optical density (OD) at $415 \mathrm{~nm}$ was measured using a microplate biokinetics reader (EL312e; Biotek instruments, Winooski, VT). The concentration of IgG reactive with MBL is expressed in units $/ \mathrm{ml}$ of serum $(\mathrm{U} / \mathrm{ml})$, related to a standard serum. Values below the detection limit of the assay (OD value $<1.5$-fold the OD value of background) were given an arbitrary value of $40 \mathrm{U} / \mathrm{ml}$ Pooled sera from patients with SLE were used as standard serum. The concentration of IgG reactive with MBL in the standard serum was arbitrarily set at $1000 \mathrm{U} / \mathrm{ml}$.

\section{Detection of circulating complexes of MBL and IgG binding to MBL.}

Microtiterplates were coated with monoclonal mouse anti-human MBL (3E7, kindly provided by Dr. T Fujita, Fukushima, Japan) or an isotype-matched control mouse monoclonal antibody (IgG1 anti-rat kappa chain). After a blocking step, serum samples were incubated (diluted 1:10) and IgG binding was detected as described above.

\section{Detection of anti-C1q Ab}

Anti-C1q autoantibodies were assessed as described previously [6,33]. Purified C1q (2 $\mu \mathrm{g} / \mathrm{ml}$ ) was coated on 96-well Nunc Maxisorb plates in coating buffer, in a final volume of $100 \mu \mathrm{L}$, for $2 \mathrm{~h}$ at $37^{\circ} \mathrm{C}$. Plates were washed with PBS/Tw for three times after each incubation period. Serum samples were diluted in PBS/0.05\% Tween/1\% FCS/1M $\mathrm{NaCl}$ for $1 \mathrm{~h}$ at $37^{\circ} \mathrm{C}$. IgG antibodies were detected using digoxigenin (Dig)- conjugated monoclonal mouse anti-human IgG (HB43), as described above. This assay is used as a routine diagnostic assay in our laboratory for detection of anti-C1q. Values $>90$ $\mathrm{U} / \mathrm{ml}$, compared to a standard serum, are considered as high. 


\section{Functional activity of the MBL complex activity}

MBL complex activity was assessed using the method described by Petersen et al. [34] with slight modifications. In brief, mannan-coated plates were incubated with serum, diluted in GVB++ ((VBS (1.8 mM Na-5,5-diethylbarbital, $0.2 \mathrm{mM}$ 5,5-diethylbarbituric acid, $145 \mathrm{mM} \mathrm{NaCl}$ ) containing $0.5 \mathrm{mM} \mathrm{MgCl}_{2}, 2 \mathrm{mM} \mathrm{CaCl}_{2}, 0.05 \%$ Tween-20, and 0.1 $\%$ gelatin; pH 7.5)) containing $1 \mathrm{M} \mathrm{NaCl}$, for $16 \mathrm{~h}$ at $4{ }^{\circ} \mathrm{C}$. Plates were washed with PBS/Tween containing $5 \mathrm{mM} \mathrm{CaCl}$, followed by incubation with purified C4 [32] (1 $\mu \mathrm{g} / \mathrm{ml}$ ), diluted in VBS containing $1 \mathrm{mM} \mathrm{MgCl}, 2 \mathrm{mM} \mathrm{CaCl}_{2}, 0.05 \%$ Tween-20, and 1 $\% \mathrm{BSA}, \mathrm{pH} 7.5$, for $1 \mathrm{~h}$ at $37^{\circ} \mathrm{C}$. Activation of $\mathrm{C} 4$ was assessed using mAb C4-4a (antihuman C4d, from Dr. C.E. Hack) conjugated to Dig. Functional activity was expressed in arbitrary units $/ \mathrm{ml}(\mathrm{aU} / \mathrm{ml})$, based on serial dilutions of a human pool serum that was used as a standard on each plate. Activity of this standard was set at $1000 \mathrm{U} / \mathrm{ml}$.

\section{Isolation and characterisation of MBL-binding immunoglobulin}

To determine the type and size of the immunoglobulin binding to MBL, $3 \mathrm{ml}$ of serum from a patient with SLE was applied to a Superdex HR 200 column (Pharmacia, Uppsala, Sweden) equilibrated with PBS, and fractions of $2.0 \mathrm{ml}$ were collected. Total protein concentration in the fractions was determined in a bicinchonini acid (BCA) protein assay (Pierce, OMNILAB, Breda, The Netherlands). Size marker proteins IgM, IgA and IgG, and IgG anti MBL Ab were assessed by ELISA of the fractions.

\section{Isolation of $F\left(a b^{\prime}\right)_{2}$ fragments.}

IgG was purified from $2 \mathrm{ml}$ serum obtained from a pool of five sera from patients with known reactivity against MBL as well as from serum from a healthy volunteer. Pepsin digestion was performed using pepsin at a 1:10 $(\mathrm{w} / \mathrm{w})$ pepsin/protein ratio for $18 \mathrm{~h}$ at $37^{\circ} \mathrm{C}$ in Whalpole buffer. The reaction was stopped by addition of $1 \mathrm{M}$ Tris base, 250 $\mu 1 / \mathrm{ml}$ digest. The mixture was applied on a G150 Sepharose column (Pharmacia) to separate the $F\left(a b^{\prime}\right)_{2}$ fragments from the undigested IgG. Binding of $F\left(a b^{\prime}\right)_{2}$ fragments to MBL was assessed using a rabbit anti-human light-chain (kappa and lambda) antibody.

\section{Statistics}

The Mann-Whitney $\mathrm{U}$ test, the Kendall tau-b non-parametric correlation coefficient and the Fisher exact test were used. P-values $<0.05$ were considered statistically significant. 


\section{Results}

\section{Detection of anti-MBL autoantibodies in patients with SLE}

First, the presence of anti-MBL antibodies was investigated in sera from patients with SLE. A pool of sera with demonstrable activity was made and further examined. Using this serum pool, a dose-dependent binding of IgG to solid-phase MBL was demonstrated, while a serum from a healthy control did not show significant reactivity (Fig. 1A).

A

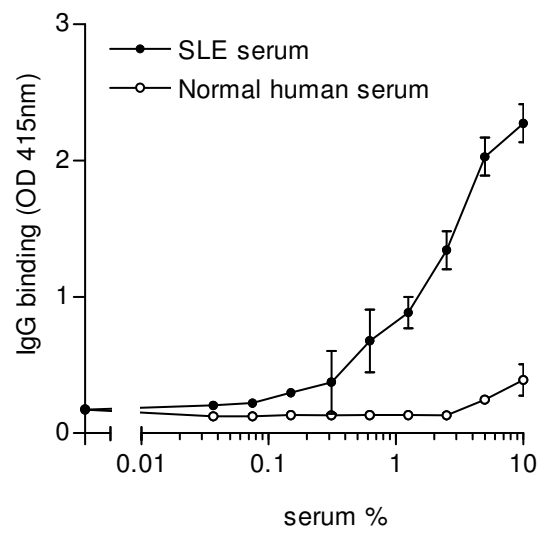

B

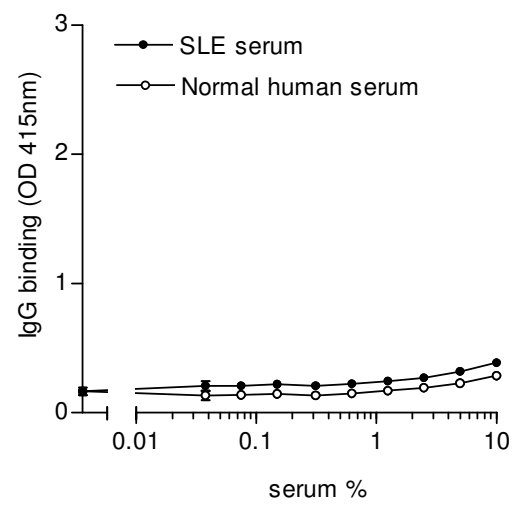

Figure 1. Binding of $\operatorname{IgG}$ to immobilised $M B L$.

Microtiterplates were coated with MBL (A) or gelatin (B). Pooled serum from patients with SLE (standard serum,) or a healthy control serum were added in serial dilutions in the presence of EDTA (10 mM). Binding of IgG was analysed. Results represent the mean value \pm standard deviation (s.d.).

This assay was performed in the presence of EDTA to prevent MBL binding via its Ctype lectin domains. This serum pool was used as a standard serum for further experiments. As a control, ELISA wells were coated with gelatin alone; no detectable IgG binding was observed (Fig. 1B). Binding of IgG to MBL could not be inhibited by addition of an excess of purified MBL in the fluid phase, suggesting that the antibody is primarily binding to solid-phase MBL (results not shown).

Subsequently, IgG anti-MBL autoantibodies were identified in 68 sera from 20 patients with SLE and 70 samples from healthy controls. The frequency of the clinical variables of disease activity that were observed at any period during disease activity are presented in Table 1. 
Table 1. Clinical presentation of disease activity in 20 patients with SLE

Clinical variable of Disease activity
Number of patients of patients
Occurrence of disease

parameters

(\% of patients)

General

10

Fatigue 30

Fever

Raynaud's phenomenon

Skin

11

Erythema

35

Photosensitivity

30

Oral ulcers

Dscoid lesions

Vasculitis

Alopecia

Joints

13

Arthritis

50

Arthralgia

30

Tendinitis

Serosa

Pericarditis

7

Pleuritis 25

Peritonitis

Kidney

Proteinuria ${ }^{1}$

Haematuria $^{2}$

Nervous system

Seizure

30

10

15

Cva

4

Lupus headache

Mononeuritis multiplex

Personality disorder

$$
\begin{array}{r}
0 \\
5 \\
5 \\
5 \\
10
\end{array}
$$

$1>0.5 \mathrm{~g} / 24 \mathrm{~h}$

2> $10 \mathrm{RBC} /$ high power field

The results of anti-MBL measurements were expressed in units relative to the standard serum. Statistical analysis was performed on the mean level of anti-MBL IgG of the different serum samples from one patient. Levels of anti-MBL autoantibodies were significantly higher in patients with SLE than in healthy controls (Fig. 2A). When the anti- 

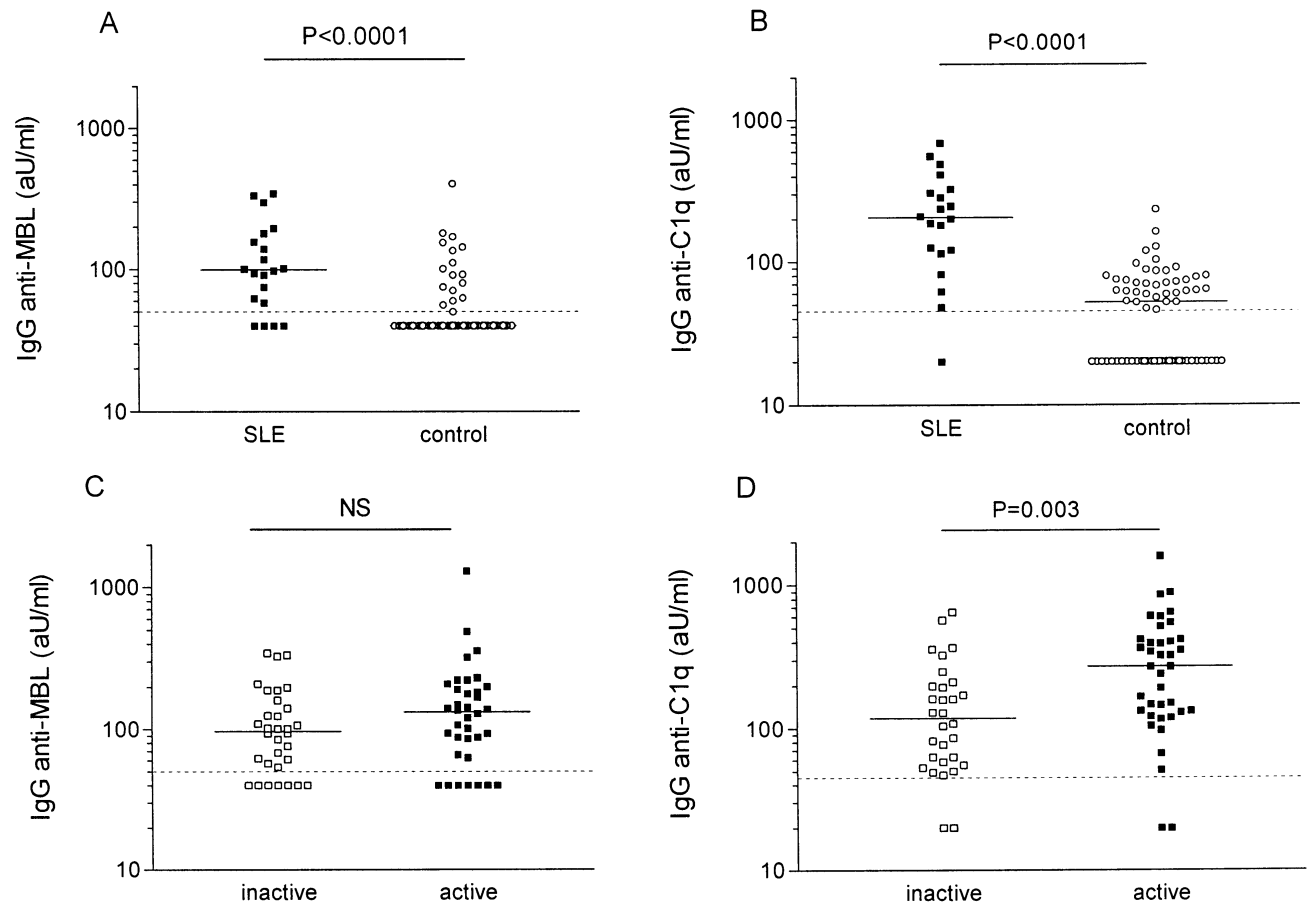

Figure 2 Anti-MBL and anti-C1q autoantibodies in different serum samples

(A) Anti-MBL reactivity was measured in 68 serum samples of 20 patients with SLE and in 70 samples from healthy controls. (C) Anti-MBL autoantibody levels of samples obtained during inactive and active phases of disease. (B) Anti-C1q levels in patients with SLE and healthy controls. (D) Anti-C1q autoantibody levels of samples obtained during inactive and active phases of disease. The median of each group is indicated by the solid line. The dashed line indicates the detection limit. aU, arbitrary units.

MBL titers were compared between sera obtained during inactive and active phases of disease, no significant difference was found (Fig. 2C). In the same samples, anti-C1q levels were also determined (Fig. 2B). A significant difference in anti-C1q titre was found between sera of patients with SLE as compared to controls. As expected significantly higher anti-C1q levels were found in SLE sera during active disease compared with inactive disease (fig 2D).

\section{Association of anti-MBL autoantibodies with disease activity and correlation with the presence of anti-C1q}

Anti-C1q antibody levels are elevated in patients with active SLE and predictive for renal disease [4-7,31]. We investigated whether the presence of high anti-MBL levels was associated with disease activity and predictive for renal involvement.

In the sera studied $(n=68)$, we detected a significant association with active disease for high levels of anti-C1q, but not for anti-MBL antibodies (Table 2A). Furthermore, 
Table 2A. Number of sera from SLE patients with high or low anti-C1q and anti-MBL levels during inactive and active phases of disease

Number of sera with

high or low anti-C1q levels
Number of sera with

high or low anti-MBL levels

\begin{tabular}{lccccc} 
& \multicolumn{2}{c}{ high or low anti-C1q levels } & & \multicolumn{2}{c}{ high or low anti-MBL levels } \\
\cline { 2 - 3 } Disease activity & $>90 \mathrm{aU} / \mathrm{ml}$ & $<90 \mathrm{aU} / \mathrm{ml}$ & & $>100 \mathrm{aU} / \mathrm{ml}$ & $<100 \mathrm{aU} / \mathrm{ml}$ \\
\hline Inactive & 17 & 13 & 15 & 17 \\
Active & 34 & 4 & 22 & 14 \\
& Fisher exact test $P=0.005$ & & Fisher exact test $P=0.3$ & \\
\hline
\end{tabular}

The value for high levels of anti-MBL was set at a level at which te $10 \%$ percent of the healthy control group were considered as having high anti-MBL levels. Thereb, anti-MBL levels $>100 \mathrm{aU} / \mathrm{ml}$ were defined as high.

Table 2B. The mean antibody level of anti-MBL and anti-C1q per patient measured in sera from SLE patients with or without renal involvement

\section{Number of sera with}

high or low anti-C1q levels

\section{Number of sera with}

high or low anti-MBL levels

\begin{tabular}{lcccc} 
Disease activity & $>90 \mathrm{aU} / \mathrm{ml}$ & $<90 \mathrm{aU} / \mathrm{ml}$ & $>100 \mathrm{aU} / \mathrm{ml}$ & $<100 \mathrm{aU} / \mathrm{ml}$ \\
\hline Inactive & 17 & 13 & 15 & 17 \\
Active & 34 & 4 & 22 & 14 \\
& Fisher exact test $P=0.005$ & Fisher exact test $P=0.3$ & \\
\hline
\end{tabular}

The value for high levels of anti-MBL was set at a level at which te $10 \%$ percent of the healthy control group were considered as having high anti-MBL levels. Thereb, anti-MBL levels $>100 \mathrm{aU} / \mathrm{ml}$ were defined as high.

levels of anti-MBL antibodies in patients with SLE with renal involvement were statistically not different from levels in patients without renal involvement. For anti-C1q, as expected, antibody levels were significantly higher in patients with renal involvement (Table 2B).

As anti-C1q antibodies are directed mostly against the collagenous tail of C1q [35], we investigated whether there was any correlation with the occurrence of anti-MBL antibodies. The presence of anti-C1q was significantly associated with the presence of anti-MBL antibodies (Table 3) and a statistically significant correlation was found between the anti-MBL and anti-C1q levels $(\mathrm{R}=0.21, \mathrm{P}=0.004)$. 
A

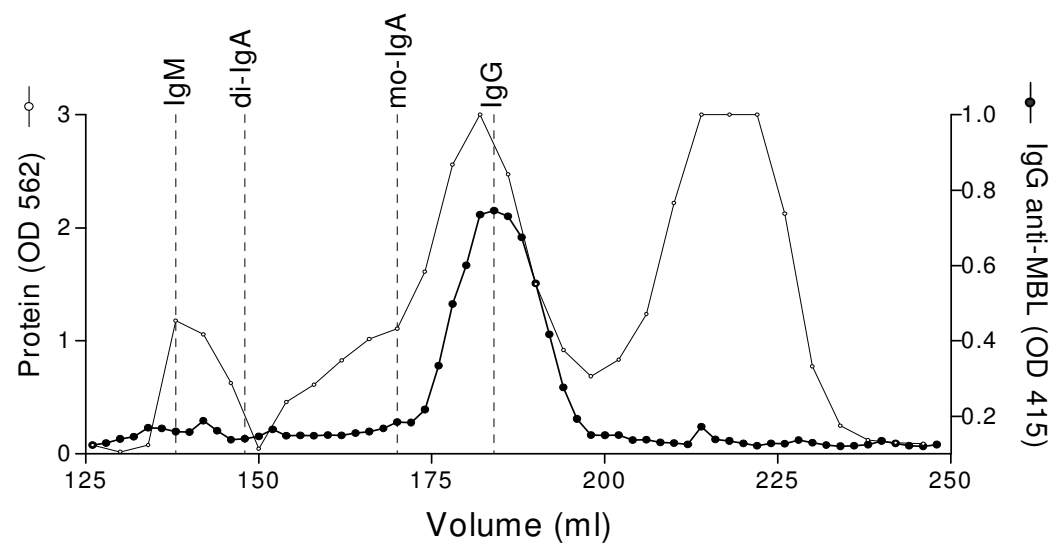

B

C
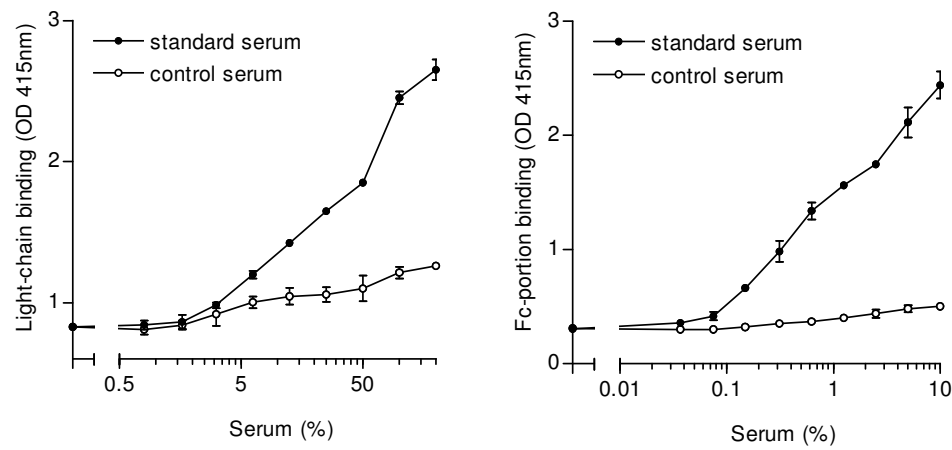

$\mathrm{D}$

E
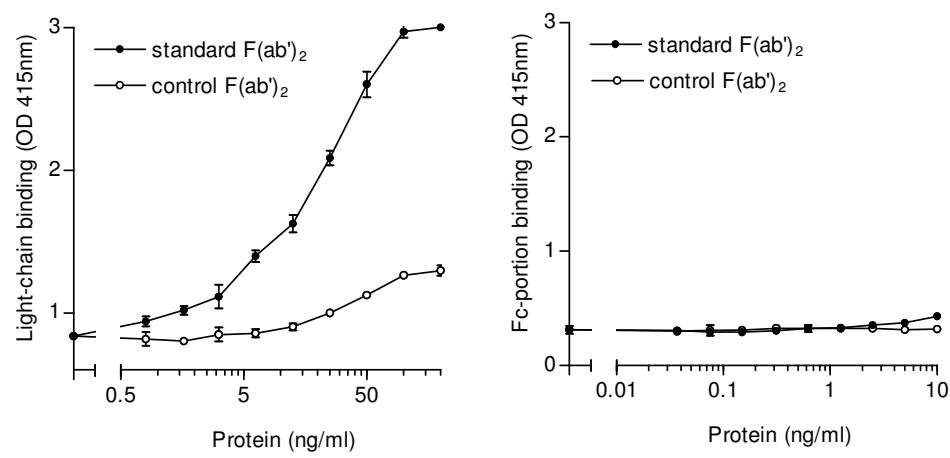

Figure 3. Biochemical characterisation of anti-MBL autoantibodies

After gel filtration, on a Superdex HR 20,0 of serum from a patient with SLE, fractions were analysed for the presence of IgG anti-MBL ( indicated by the closed circles). The protein pattern, as well as the position of filtration of $\operatorname{IgM}$, dimeric $\operatorname{Ig} A$ (di-IgA), monomeric $\operatorname{Ig} A$ (moIgA) and IgG are depicted ( $A$ ). Anti-MBL reactivity was detected in serial dilutions of whole serum $(B, C)$ and purified $F\left(a b^{\prime}\right)_{2}$ fragments $(D)$ and $(E)$, using antibodies against the light chains $(B)$ and $(D)$ and the Fc portion $(m A b H B 43)(C)$ and $(E)$, respectively. 
The data presented above indicate that IgG autoantibodies directed against MBL are present in patients with SLE, but are not clearly associated with disease activity in the patients examined in the present study.

\section{Biochemical characterisation of anti-MBL autoantibodies}

To examine whether binding of anti-MBL antibodies to MBL occurs via the antigen recognition domain of $\operatorname{IgG}$, we studied the antibody in more detail. Serum containing anti-MBL antibodies was fractionated using a gel filtration column. The elution position of IgG, IgA, and IgM was assessed by ELISA (Fig. 3A). Anti-MBL IgG antibodies coeluted from the column with monomeric IgG, thus excluding that IgG which binds to MBL is part of a larger (immune-) complex. No binding of IgM and IgA to MBL was observed (data not shown).
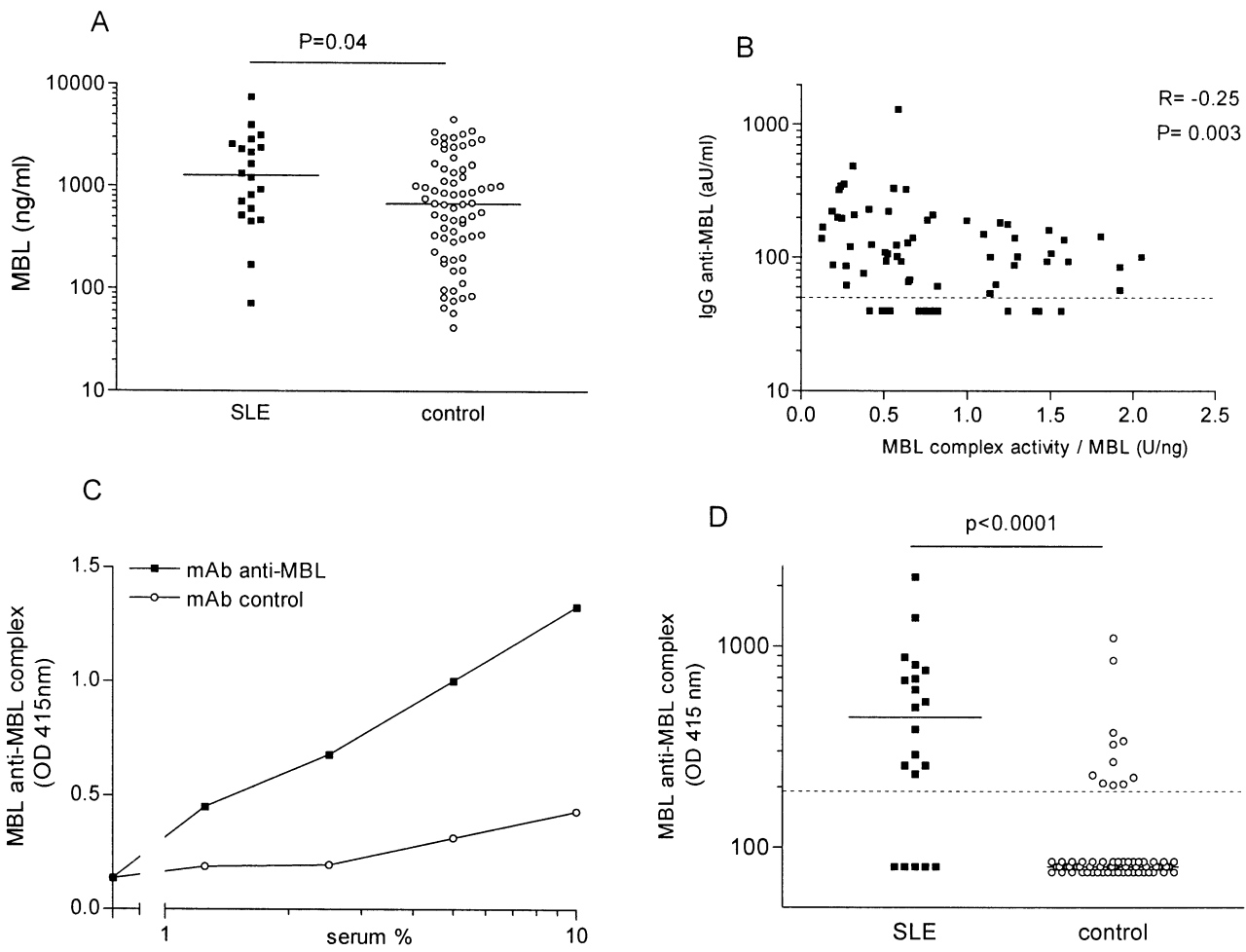

Figure 4 Interaction of anti-MBL with $M B L$ in vivo

The mean MBL concentration per patient is shown in serum samples of 20 patients with SLE and in 70 samples of healthy controls (A) Statistical analysis was performed on the mean MBL level of the different serum samples from one patient. The correlation between anti-MBL levels and ratio between the $M B L$ complex activity and the MBL concentration is shown (B). For detection of complexes between IgG and MBL in serum, plates were coated with $m A b$ anti$M B L$ or control $m A b$, as indicated, and incubated with serial dilutions of an SLE serum containing anti-MBL antibodies, followed by detection of IgG binding (C). The number of circulating complexes between IgG and MBL in serum samples from patients with SLE and controls (D). aU, arbitrary units. 


\begin{tabular}{cccc} 
& & \multicolumn{2}{c}{ Anti-C1q } \\
\cline { 3 - 4 } & & $>90 \mathrm{aU} / \mathrm{ml}$ & $<90 \mathrm{aU} / \mathrm{ml}$ \\
\hline \multirow{2}{*}{ Anti-MBL } & $>100 \mathrm{aU} / \mathrm{ml}$ & 33 & 4 \\
& $<100 \mathrm{aU} / \mathrm{ml}$ & 18 & 13 \\
& & Fisher exact test $P=0.05$ \\
\hline
\end{tabular}

$\mathrm{aU}$, arbitrary units.

Table 3. Number of serum samples from patients with high or low levels of anti-C1q and anti-MBL antibodies

To analyse the binding site of IgG involved in the binding to $\mathrm{MBL}, \mathrm{F}(\mathrm{ab})_{2}$ fragments were generated from IgG isolated from pooled serum of patients with SLE with known reactivity against MBL, as well as from IgG of healthy donors without anti-MBL autoantibodies, using pepsin digestion. Using a polyclonal antibody against kappa and lambda light chains (Fig 3B) or a monoclonal antibody directed against the Fc portion of IgG (HB43) (Fig 3C), it iwasdemonstrated that IgG from the SLE serum, but not IgG from the control serum, binds dose-dependently to coated MBL. A strong dose-dependent binding of $F\left(a b^{\prime}\right)_{2}$ fragments from SLE serum but not of control $F\left(a b^{\prime}\right)_{2}$ fragments was demonstrated to MBL, using the polyclonal anti-light chain antibody (fig 3D). In contrast, binding of the Fc portion of IgG anti-MBL was not detectable after digestion of IgG (fig 3E) indicating the complete digestion of IgG. Binding of $F(a b)_{2}$ fragments to MBL strongly suggests specific recognition of MBL by the antigen recognition domain.

\section{Anti-MBL autoantibodies are found in complex with circulating MBL and are asso- ciated with decreased MBL function}

We investigated the influence of anti-MBL autoantibodies on the function of circulating MBL. It is conceivable that anti-MBL may affect the circulating MBL concentration. Patients with SLE had significantly higher MBL concentrations compared to healthy controls ( $\mathrm{P}=0.04)$ (Fig. 4A). No significant difference was found between samples obtained during an inactive or active phase of disease (median MBL concentration $2175 \mathrm{ng} / \mathrm{ml}$ and $2802 \mathrm{ng} / \mathrm{ml}$ respectively, $(\mathrm{P}=0.20))$. Levels of anti-MBL autoantibodies were higher in patients with high serum levels of $\mathrm{MBL}(\mathrm{R}=0.26, \mathrm{P}=0,002)$. We further assessed whether the anti-MBL antibodies influence the MBL complex activity. As expected [34], a strong correlation between the MBL serum concentration and the MBL complex activity was found $(\mathrm{R}=0.65, \mathrm{P}<0.0001)$. A negative correlation was found between anti-MBL antibody levels and MBL complex activity adjusted for MBL concentration (Fig 4B). These data indicate a reduced functional activity of circulating 
MBL-MASP complexes in the presence of anti-MBL autoantibodies. To examine whether IgG is bound to circulating MBL in vivo, we examined the presence of complexes between MBL and IgG in ELISA. A strong dose-dependent binding of IgG-MBL complexes was observed following the incubation of SLE patient serum to wells coated with $\mathrm{mAb}$ anti-MBL, but not to well coated with a mAb of irrelevant specificity (Fig. $4 \mathrm{C})$. Further analysis of the presence of these complexes revealed strongly enhanced levels of IgG-MBL complexes in patients with SLE as compared to healthy controls (Fig. 4D, P <0.001). The level of these complexes was positively correlated with antiMBL levels $(R=0.27, P<0.001)$ and negatively correlated with the functional activity of MBL ( $\mathrm{R}=-0.17, \mathrm{P}=0.04)$ Together, these data suggest that IgG anti-MBL antibodies interact with MBL in vivo.

\section{Discussion}

In the present study we demonstrate the presence of anti-MBL autoantibodies in patients with SLE. The data suggest an effect of anti-MBL antibodies on the MBL complex activity of circulating MBL. The presence of anti-MBL antibodies did not result in a decrease of the MBL serum concentration. MBL, a member of the collectin family, is a major recognition unit in the most recently described pathway of complement activation. Collectins are proteins with a C-type lectin domain structurally related to C1q, the first component of the classical pathway of complement activation. Binding of MBL to carbohydrates on certain microbial surfaces can activate the complement system and mediate phagocytosis through receptors on phagocytes. However binding of $\mathrm{C} 1 \mathrm{q}$ to carbohydrate structures has not been found.

The importance of the complement system in the pathogenesis of SLE is recognised in different, contrasting, ways. On the one hand activation of complement by immune complexes, deposited in tissue, leads to tissue damage. On the other hand, deficiencies of (particularly) the early complement proteins of the classical pathway are associated with SLE. Furthermore, presence of autoantibodies to neoepitopes on C1q, exposed upon binding to surfaces, is found in one-third of patients with SLE and is associated with renal involvement and hypocomplementaemia [36].

Apoptosis and the role of complement in the clearance of apoptotic material has been implicated in the pathogenesis of SLE [37]. Increased circulating levels of apoptotic material have been demonstrated in patients with SLE [38]. Binding of C1q and MBL to apoptotic products has been postulated to play a role in the clearance of apoptotic debris via phagocytosis [39,40]. Furthermore autoantibodies associated with SLE are reactive with this apoptotic material [41]. An increased production, and decreased and aberrant clearance, of apoptotic material might cause autoantibody production to antigens present on this material. Because of the presence of $\mathrm{Clq}$ on these apoptotic cells, this might also be true for generating anti-C1q antibodies. In recent literature binding of MBL to apoptotic material has clearly been shown [42]. Hence, it is possible that because of a greater quantity of apoptotic material in sera of patients with SLE, and a possible less efficient clearance of this material, autoantibodies are formed against MBL present on apoptotic cells. 
We assessed the presence of anti-MBL autoantibodies in 68 sera of patients with SLE during inactive and active phase of disease. A highly significant difference was found between the anti-MBL levels in patients with SLE and those in healthy subjects. Because anti-C1q levels are strongly correlated to active kidney disease in SLE, we investigated whether the increased anti-MBL levels in patients with SLE were attributed to disease activity. We found no difference between anti-MBL levels in sera of patients with active disease and inactive disease. As expected, the levels of anti-C1q in the different sera obtained during active disease were significantly higher than those obtained during inactive disease. As we examined only a limited number of patients in the present study, a definite conclusion on the importance of anti-MBL autoantibodies for disease in patients with SLE can not be given and requires more extensive investigations.

Because of the similarity of the collagen tails of C1q and MBL, a possible cross-reactivity of the anti-C1q antibodies with MBL was considered. A positive correlation was found between anti-MBL and anti-C1q levels in sera from patients with SLE. Therefore one could speculate about the cross-reactivity of anti-C1q with MBL. On the other hand, the presence of autoantibodies directed to a variety of antigens is typically found in patients with SLE and therefore anti-C1q and anti-MBL could be directed against different autoantigens. In four sera $(6 \%)$ we found anti-MBL antibodies without antiC1q reactivity, suggestive for an anti-MBL specific antibody. This would be in agreement with the findings of Martensson et al. [33] who found no cross-reactivity of antiC1q antibodies with MBL.

To examine the nature of anti-MBL autoantibodies, the interaction with MBL was studied in greater detail. We demonstrated that MBL binding was a property of monomeric IgG. Binding to MBL was calcium-independent, as it was established in the presence of EDTA, thus excluding that carbohydrates present on IgG were binding to the Ctype lectin domain of MBL. Furthermore, using $\mathrm{F}\left(\mathrm{ab}^{\prime}\right)_{2}$ fragments of IgG, we showed that binding was localized in the antigen-recognition domain of IgG. These findings strongly suggest that IgG binding to MBL represent a true antibody-antigen interaction.

During an active phase of renal involvement in SLE, the C1q levels are decreased because of activation of the classical pathway of complement activation, triggered by the interaction of $\mathrm{C} 1 \mathrm{q}$ with immune complexes. A second cause for reduced $\mathrm{C} 1 \mathrm{q}$ levels is the presence of anti-C1q antibodies. Genetic deficiency of $\mathrm{C} 1 \mathrm{q}$ is strongly correlated with the development of SLE. Association of reduced MBL levels (as a consequence of gene polymorphisms) with SLE has been reported previously [23]. Anti-MBL antibodies, similarly to anti-C1q antibodies, could be a cause of low MBL levels in patients with SLE. Higher MBL levels were, however, found in the sera from patients with SLE. A possible explanation could be an increase of MBL levels owing to an acute phase response, although we found no significant difference in MBL levels in sera obtained from patients during active or inactive phases of disease. Anti-MBL autoantibody levels were higher in patients with high MBL concentrations, suggesting that these autoantibodies do not contribute to increased MBL turnover. Possibly the presence of anti-MBL antibodies, and higher concentrations of MBL, are both a result of disease 
activity. Furthermore, it could be that anti-MBL autoantibodies are preferentially generated in patients with higher MBL levels owing to an increased exposure of the immune system to (target-bound) MBL.

We continued to examine the effect of the presence of anti-MBL autoantibodies on MBL concentration and function. A significant, negative correlation was observed between the levels of anti-MBL autoantibodies and the MBL complex activity of circulating MBL. The latter parameter represents the ability of the MBL-MASP complexes to activate $\mathrm{C} 4$, corrected for the MBL serum concentration. Therefore, the association between anti-MBL antibodies and decreased MBL function suggests that these autoantibodies can interfere with the MBL-MASP complex. Such an interference is conceivable in at least three different ways: first, anti-MBL antibodies may inhibit MBL binding to mannan; second, these antibodies may interfere with the binding of MASP-2 to MBL; and, third, anti-MBL antibodies may bind to the (ligand-bound) MBL-MASP complex and prevent MASP-2 activation. A further argument for the interaction of autoantibodies with MBL in vivo is the presence of circulating complexes between MBL and IgG found in the serum samples of patients with SLE in association with the presence of IgG anti-MBL. A negative correlation between MBL complex activity and circulating IgG-MBL complexes was found, supporting the suggestion that anti-MBL antibodies bind to MBL in vivo. It is conceivable that these complexes actually are released into the circulation after previous formation in the solid phase. Further experiments are required to establish whether the interaction of IgG with MBL is indeed involved in the association between the presence of anti-MBL antibodies and impaired MBL function in vivo.

To our knowledge this is the first report on the presence of anti-MBL autoantibodies in serum from patients with SLE. As far as the results show we cannot predict activity of disease by the presence of anti-MBL autoantibodies. Fascinatingly, these anti-MBL autoantibodies are associated with decreased MBL function. A greater number of patients should be tested for reactivity against MBL before a final conclusion can be made on the role of anti-MBL autoantibodies in the pathogenesis of SLE.

\section{Acknowledgements}

The authors thank Ngaisah Klar-Mohamad and Ria C. Faber-Krol for excellent technical assistance, Dr. C.E. Hack (Amsterdam, The Netherlands) and Dr. T. Fujita (Fukushima, Japan) for their kind gift of reagents used in this study and Dr. M.J.K. Mallat for the statistical analysis of the data. Part of this work was supported by the Dutch Kidney Foundation (PC 95). 


\section{References}

1. Walport MJ. Complement. First of two parts. N Engl J Med 2001; 344:1058-66.

2. Walport MJ. Complement. Second of two parts. N Engl J Med 2001; 344:1140-4.

3. Pickering MC, Botto M, Taylor PR, Lachmann PJ, Walport MJ. Systemic lupus erythematosus, complement deficiency, and apoptosis. Adv Immunol 2000; 76:227-324.

4. Gunnarsson I, Ronnelid J, Huang YH et al. Association between ongoing anti-C1q antibody production in peripheral blood and proliferative nephritis in patients with active systemic lupus ery thematosus. Br J Rheumatol 1997; 36:32-7.

5. Moroni G, Trendelenburg M, Del Papa N et al. Anti-C1q antibodies may help in diagnosing a renal flare in lupus nephritis. Am J Kidney Dis 2001; 37:490-8.

6. Siegert C, Daha M, Westedt ML, van d, V, Breedveld F. IgG autoantibodies against C1q are correlated with nephritis, hypocomplementemia, and dsDNA antibodies in systemic lupus erythematosus. J Rheumatol 1991; 18:230-4.

7. Trendelenburg M, Marfurt J, Gerber I, Tyndall A, Schifferli JA. Lack of occurrence of severe lupus nephritis among anti-C1q autoantibody-negative patients. Arthritis Rheum 1999; 42:187-8.

8. Davies EJ, Snowden N, Hillarby MC et al. Mannose-binding protein gene polymorphism in systemic lupus erythematosus. Arthritis Rheum 1995; 38:110-4.

9. Turner MW. Mannose-binding lectin (MBL) in health and disease. Immunobiology 1998; 199:327-39.

10. Hansen S, Holmskov U. Structural aspects of collectins and receptors for collectins. Immunobiology 1998; 199:165-89.

11. Matsushita M, Thiel S, Jensenius JC, Terai I, Fujita T. Proteolytic activities of two types of mannosebinding lectin-associated serine protease. J Immunol 2000; 165:2637-42.

12. Garred P, Thiel S, Madsen HO, Ryder LP, Jensenius JC, Svejgaard A. Gene frequency and partial protein characterization of an allelic variant of mannan binding protein associated with low serum concentrations. Clin Exp Immunol 1992; 90:517-21.

13. Madsen HO, Garred P, Kurtzhals JA et al. A new frequent allele is the missing link in the structural polymorphism of the human mannan-binding protein. Immunogenetics 1994; 40:37-44.

14. Sumiya M, Super M, Tabona P et al . Molecular basis of opsonic defect in immunodeficient children. Lancet 1991; 337:1569-70.

15. Lipscombe RJ, Sumiya M, Hill AV et al. High frequencies in African and non-African populations of independent mutations in the mannose binding protein gene. Hum Mol Genet 1992; 1:709-15.

16. Madsen HO, Garred P, Thiel S et al. Interplay between promoter and structural gene variants control basal serum level of mannan-binding protein. J Immunol 1995; 155:3013-20.

17. Madsen HO, Satz ML, Hogh B, Svejgaard A, Garred P. Different molecular events result in low pro tein levels of mannan-binding lectin in populations from southeast Africa and South America. J Immunol 1998; 161:3169-75.

18. Richardson VF, Larcher VF, Price JF. A common congenital immunodeficiency predisposing to infection and atopy in infancy. Arch Dis Child 1983; 58:799-802. 
19. Summerfield JA, Sumiya M, Levin M, Turner MW. Association of mutations in mannose binding protein gene with childhood infection in consecutive hospital series. BMJ 1997; 314:1229-32.

20. Koch A, Melbye M, Sorensen $\mathrm{P}$ et al. Acute respiratory tract infections and mannose-binding lectin insufficiency during early childhood. JAMA 2001; 285:1316-21.

21. Peterslund NA, Koch C, Jensenius JC, Thiel S. Association between deficiency of mannose-binding lectin and severe infections after chemotherapy. Lancet 2001;358:637-8.

22. Davies EJ, Teh LS, Ordi-Ros J et al. A dysfunctional allele of the mannose binding protein gene associates with systemic lupus erythematosus in a Spanish population. J Rheumatol 1997; 24:485-8.

23. Garred P, Voss A, Madsen $\mathrm{HO}$ et al . Association of mannose-binding lectin gene variation with disease severity and infections in a population-based cohort of systemic lupus erythematosus patients. Genes Immun 2001; 2:442-50.

24. Ip WK, Chan SY, Lau CS, Lau YL. Association of systemic lupus erythematosus with promoter poly morphisms of the mannose-binding lectin gene. Arthritis Rheum 1998; 41:1663-8.

25. Sullivan KE, Wooten C, Goldman D, Petri M. Mannose-binding protein genetic polymorphisms in black patients with systemic lupus erythematosus. Arthritis Rheum 1996; 39:2046-51.

26. Villarreal J, Crosdale D, Ollier W et al. Mannose binding lectin and FcgammaRIIa (CD32) polymorphism in Spanish systemic lupus erythematosus patients. Rheumatology (Oxford) 2001; 40:1009-12.

27. Tsutsumi A, Sasaki K, Wakamiya N et al. Mannose-binding lectin gene: polymorphisms in Japanese patients with systemic lupus erythematosus, rheumatoid arthritis and Sjogren's syndrome. Genes Immun 2001; 2:99-104.

28. Huang YF, Wang W, Han JY et al. Increased frequency of the mannose-binding lectin LX haplotype in Chinese systemic lupus erythematosus patients. Eur J Immunogenet 2003; 30:121-4.

29. Garred P, Madsen HO, Halberg P et al. Mannose-binding lectin polymorphisms and susceptibility to infection in systemic lupus erythematosus. Arthritis Rheum 1999; 42:2145-52.

30. Trouw LA, Seelen MA, Duijs JM, Benediktsson H, Van Kooten C, Daha MR. Glomerular deposition of $\mathrm{C} 1 \mathrm{q}$ and anti-C1q antibodies in mice following injection of antimouse C1q antibodies. Clin Exp Immunol 2003; 132:32-9.

31. Siegert CE, Daha MR, Tseng CM, Coremans IE, van Es LA, Breedveld FC. Predictive value of IgG autoantibodies against C1q for nephritis in systemic lupus erythematosus. Ann Rheum Dis 1993; 52:851-6.

32. Roos A, Bouwman LH, Gijlswijk-Janssen DJ, Faber-Krol MC, Stahl GL, Daha MR. Human IgA activates the complement system via the mannan-binding lectin pathway. J Immunol 2001; 167:2861-8.

33. Martensson U, Thiel S, Jensenius JC, Sjoholm AG. Human autoantibodies against Clq: lack of cross reactivity with the collectins mannan-binding protein, lung surfactant protein A and bovine conglutinin. Scand J Immunol 1996; 43:314-20.

34. Petersen SV, Thiel S, Jensen L, Steffensen R, Jensenius JC. An assay for the mannan-binding lectin pathway of complement activation. J Immunol Methods 2001; 257:107-16.

35. Antes U, Heinz HP, Loos M. Evidence for the presence of autoantibodies to the collagen-like portion of C1q in systemic lupus erythematosus. Arthritis Rheum 1988; 31:457-64. 
36. Coremans IE, Spronk PE, Bootsma H et al. Changes in antibodies to C1q predict renal relapses in systemic lupus erythematosus. Am J Kidney Dis 1995; 26:595-601.

37. Taylor PR, Carugati A, Fadok VA et al. A hierarchical role for classical pathway complement proteins in the clearance of apoptotic cells in vivo. J Exp Med 2000; 192:359-66.

38. Emlen W, Niebur J, Kadera R. Accelerated in vitro apoptosis of lymphocytes from patients with systemic lupus erythematosus. J Immunol 1994; 152:3685-92.

39. Nauta AJ, Trouw LA, Daha MR et al . Direct binding of C1q to apoptotic cells and cell blebs induces complement activation. Eur J Immunol 2002; 32:1726-36.

40. Nauta AJ, Daha MR, Kooten C, Roos A. Recognition and clearance of apoptotic cells: a role for complement and pentraxins. Trends Immunol 2003; 24:148-54.

41. Mevorach D, Mascarenhas JO, Gershov D, Elkon KB. Complement-dependent clearance of apoptotic cells by human macrophages. J Exp Med 1998; 188:2313-20.

42. Ogden CA, deCathelineau A, Hoffmann PR et al. C1q and mannose binding lectin engagement of cell surface calreticulin and CD91 initiates macropinocytosis and uptake of apoptotic cells. J Exp Med 2001; 194:781-9 


\section{Chapter 4}

\section{A role for mannose-binding lectin dysfunction in generation of autoantibodies in systemic lupus erythematosus}

Marc A Seelen, Egon A van der Bijl, Leendert A Trouw, Tahlita CM Zuiverloon, Jeric R Munoz, Francien C Fallaux-van den Houten, Nicole Schlagwein, Mohamed R Daha, Tom WJ Huizinga, Anja Roos

Department of Nephrology and Rheumatology, Leiden University Medical Center, Leiden, The Netherlands. 
Objective. To investigate the possible association of the mannose binding lectin (MBL)pathway of complement activation with different disease parameters and disease activity in patients with systemic lupus erythematosus (SLE).

Methods. MBL genotype, MBL serum concentration, MBL complex activity and MBLpathway activity were assessed in 53 patients. The activity of the MBL-MASP complex was assessed on basis of its ability to activate exogenous C4. For MBL-pathway activity the formation of the terminal complex of complement activation (C5b-9) was measured. Results were analysed in relation to clinical variables and autoantibody profiles in these patients.

Results. MBL complex activity and MBL-pathway activity were both reduced in patients carrying MBL variant alleles. Anti-cardiolipin and anti-C1q autoantibodies were observed significantly more frequently in patients with MBL variant alleles. Furthermore, the presence of these autoantibodies was associated with a decreased MBL concentration and function. In contrast, anti-MBL autoantibodies were not found in patients with MBL variant alleles, possibly related to impaired binding of variant MBL to apoptotic material.

Conclusion. In patients with SLE, a reduced functional activity of the MBL-pathway of complement, in relation to expression of MBL variant alleles, is associated with increased levels of autoantibodies against cardiolipin and C1q, but not against MBL. We hypothesize that an enhanced production of autoantibodies may be related to disturbed clearance of apoptotic material due to impaired MBL function.

\section{Introduction}

Susceptibility to systemic lupus erythematosus (SLE) is related to genetic as well as environmental factors. It is thought that a combination of genes, rather than a single gene, predisposes to the development of SLE. Many genes have been reported to be linked with the development of spontaneous SLE, including several loci encoding different complement components and complement receptors [1]. Genetic deficiencies of complement components, especially of the early components of the classical pathway, are strongly associated with the occurrence of SLE [2]. In this respect, the genetic association between deficiency of $\mathrm{C} 1 \mathrm{q}$, the recognition factor of the classical complement activation pathway, with SLE is nearly $100 \%$. This association between C1q deficiency and systemic autoimmunity has been linked to a role for $\mathrm{C} 1 \mathrm{q}$ in recognition and clearance of apoptotic material [3,4]. Defective clearance and increased generation of apoptotic material has been demonstrated in patients with SLE [5]. Furthermore, autoantibodies found in patients with SLE are mostly directed against antigens present on apoptotic material [6].

Recent studies indicate also a possible role for the lectin pathway of complement activation in the pathogenesis of SLE [7]. Variant alleles leading to reduced serum concentrations of mannose-binding lectin (MBL) are associated with a predisposition for SLE [8-11]. MBL is a major recognition factor of the lectin pathway of complement. The 
molecule is composed of trimeric subunits assembled to higher order structures consisting of up to six trimers. This structure resembles the bouquet-like structure of C1q [12]. Also the MBL-associated serine proteases MASP-1, MASP-2 and MASP-3 are functionally related to the serine proteases of the classical pathway, C1r and C1s. After binding of the calcium-dependent carbohydrate recognition domain of MBL to different carbohydrates, activation of the complement cascade can take place [13]. MBL is able to bind to apoptotic cell debris via its lectin domain, which is involved in the phagocytosis of apoptotic cells by macrophages [14,15]. Since MBL has been postulated to play a role in the clearance of apoptotic material [3], this mechanism could provide a possible explanation for the association between MBL deficiency and the occurrence of SLE.

MBL deficiency or low serum MBL levels are frequently found in the general population due to single nucleotide polymorphisms (SNPs) in the structural portion or promoter region of the $\mathrm{mbl} 2$ gene $[7,12,16]$. Three SNPs have been identified in the structural domain of the MBL gene, located in codon 52 [17], 54 [18] and 57 [19] of exon 1, whereas additional SNPs exist upstream of the MBL gene at position -550 (H/L alleles), $-221(\mathrm{X} / \mathrm{Y}$ alleles) and +4 (P/Q alleles) $[20,21]$. The occurrence of these SNPs in the MBL gene are associated with predisposition for the development of SLE and with complications caused by bacterial infections in patients with SLE [8,10,22]. Furthermore, a tendency towards more renal disorders in SLE patients with MBL variant alleles has been reported [8].

Studies on the association of MBL and SLE until now have focused on MBL genotype and MBL concentration. In the present study, we examined whether functional impairment of the MBL-pathway is associated with parameters of disease activity. The results indicate that MBL gene polymorphisms, low MBL concentration and impaired functional activity of the MBL pathway are associated with the presence of anti-cardiolipin and anti-C1q antibodies in patients diagnosed with SLE.

\section{Patients and Methods}

\section{Patients}

Fifty three patients with a mean age of 39 years made up of $92 \%$ females all fulfilling at least 4 American College of Rheumatology criteria for SLE were included in this study. The patients visited the out-patient clinic of the Rheumatology department at the Leiden University Medical Center from 1997 to 1998. The median disease activity in these patients was $4.3(0-18)$ as measured with the SLE Disease Activity Index (SLEDAI), and organ damage measured with the Systemic Lupus International Collaborating Clinics/ACR Damage Index found in the patient group was 2 (1-4.5). Informed consent was obtained from all patients. The clinical and laboratory variables tested were the following: the ACR criteria for SLE (skin rash, photosensitivity, oral ulcers, renal involvement, joint involvement, serositis, neurological disorders, haematologic disorders and autoantibody profile), age at disease onset, SLE Disease Activity 
Index (SLEDAI), and SLE damage index adjusted for years of disease. Paired serum and DNA samples were available.

PCR amplification of exon 1 of the MBL gene and oligonucleotide ligation assay (OLA) for MBL genotyping

MBL genotyping was performed using genomic DNA from SLE patients $(\mathrm{N}=53)$ and from a population of healthy Caucasian controls $(\mathrm{N}=59)$. Exon 1 of the MBL gene was amplified from genomic DNA by PCR. Detection of MBL-mutant alleles at codon 52, 54 and 57 were carried out with three different oligonucleotide ligation assays (OLA). The PCR amplification and OLA were performed exactly following the procedure as described before [23].

\section{Measurement of MBL serum concentrations}

MBL concentrations in serum were assessed precisely as described previously [24].

\section{Functional activity of the MBL complex}

The assessment of activity of MBL and its associated serine proteases (MBL complex activity) was performed using a slightly modified method as described by Petersen et al. [25]. In brief, mannan-coated plates were incubated for 16 hours at $4{ }^{\circ} \mathrm{C}$ with serum, diluted in $\mathrm{GVB}++$ containing $1 \mathrm{M} \mathrm{NaCl}$. Plates were washed with PBS/Tween containing $5 \mathrm{mM} \mathrm{CaCl}_{2}$, followed by incubation with purified $\mathrm{C} 4(1 \mu \mathrm{g} / \mathrm{ml})$, diluted in VBS containing $1 \mathrm{mM} \mathrm{MgCl} 2,2 \mathrm{mM} \mathrm{CaCl}_{2}, 0.05 \%$ Tween-20, and $1 \% \mathrm{BSA}, \mathrm{pH} 7.5$, for 1 hour at $37{ }^{\circ} \mathrm{C}$. Binding of activated $\mathrm{C} 4$ was assessed using mAb C4-4a (anti-human C4d, from Dr. C.E. Hack, Amsterdam, The Netherlands) conjugated to dig, followed by HRP-conjugated sheep anti-dig antibodies as described above. MBL-complex activity was expressed in arbitrary units per $\mathrm{ml}$, based on serial dilutions of a human poolserum that was used as a standard on each plate. Activity of this standard was set at $1,000 \mathrm{U} / \mathrm{ml}$.

\section{Functional activity of the whole MBL-pathway}

The functional activity of the MBL-pathway in whole serum, from MBL binding to mannan up to the deposition of C5-9, was assessed by ELISA [23].

Plates (Nunc Maxisorb, Nunc, Roskilde, Denmark) were coated with mannan $(100 \mu \mathrm{g} / \mathrm{ml}$, from Saccharomyces cerevisiae; Sigma, St. Louis, MO) in coating buffer $\left(100 \mathrm{mM} \mathrm{Na} \mathrm{CO}_{3} / \mathrm{NaHCO}_{3}, \mathrm{pH} 9.6\right)$, for $2 \mathrm{~h}$ at $37^{\circ} \mathrm{C}$. After each step, plates were washed three times with PBS containing 0.05\% Tween-20. Residual binding sites were blocked by incubation with PBS containing $1 \%$ BSA for $1 \mathrm{~h}$ at $37^{\circ} \mathrm{C}$. Next, serum samples were diluted in GVB++ (VBS (1.8 mM Na-5,5-diethylbarbital, $0.2 \mathrm{mM}$ 5,5-diethylbarbituric acid, $145 \mathrm{mM} \mathrm{NaCl}$ ) containing $0.5 \mathrm{mM} \mathrm{MgCl}, 2 \mathrm{mM} \mathrm{CaCl}$, $0.05 \%$ Tween20 , and $0.1 \%$ gelatin; $\mathrm{pH} 7.5)$ in the presence of $\mathrm{mAb} 2204(20 \mu \mathrm{g} / \mathrm{ml})$ as an inhibitor of $\mathrm{C} 1 \mathrm{q}$, to exclude contribution of the classical pathway via antibodies reactive with mannan. This mixture was pre-incubated for $15 \mathrm{~min}$ on ice, before addition to the plates. The plates were then sequentially incubated for $1 \mathrm{~h}$ at $4{ }^{\circ} \mathrm{C}$ and for $1 \mathrm{~h}$ at $37^{\circ} \mathrm{C}$. The amount of C5b-9 generated, as a measure of MBL pathway activation, was detected 
with mouse mAb AE11 (anti-human C5b-9, kindly provided by Dr. T.E. Mollnes, Oslo, Norway) conjugated to digoxygenin-3-O-methylcarbonyl-rounded e-aminocaproic acid-N-hydroxysuccinimide ester (dig) (from Boehringer Mannheim, Mannheim, Germany). The degree of binding of $\mathrm{mAb}$ was subsequently detected using dig-conjugated sheep anti-mouse antibodies (Fab fragments) followed by HRP-conjugated sheep anti-dig antibodies (Fab fragments, both from Boehringer Mannheim Germany). Enzyme activity of HRP was detected following incubation with 2,2'-azino-bis(3-ethylbenzthiazoline-6-sulfonic acid) (from Sigma; $2.5 \mathrm{mg} / \mathrm{ml}$ in $0.1 \mathrm{M}$ Citrate $/ \mathrm{Na}_{2} \mathrm{HPO}_{4}$ buffer, $\mathrm{pH}$ 4.2) in the presence of $0.01 \% \mathrm{H}_{2} \mathrm{O}_{2}$, for 30-60 min at room temperature. The OD at $415 \mathrm{~nm}$ was measured using a microplate biokinetics reader (EL312e, from Biotek Instruments, Winooski, VT, USA). Functional activity of the MBL-pathway was expressed in units per $\mathrm{ml}$, relative to a positive standard consisting of pooled human serum arbitrarily set at $1,000 \mathrm{U} / \mathrm{ml}$.

\section{Functional activity of the classical pathway}

Classical pathway activity was assessed by determining $\mathrm{C} 4$ activation on immobilised IgM using an ELISA-based procedure as described by Roos et al. [23].

\section{Detection of antibodies against C1q, MBL, DNA and anti-cardiolipin.}

Anti-C1q autoantibodies were assessed as described [26]. A recently described method to detect anti-MBL antibodies was used to determine MBL-Abs [27].

Antibodies against DNA were measured using an immunofluorescent method as described by Aarden et al (28). Antibodies against cardiolipin were measured using a commercially available Varelisa Cardiolipin IgG antibodies kit (Pharmacia diagnostics, Germany).

\section{Statistics}

The Mann-Whitney test and the Chi-square test were used for statistical analysis. Correlation was evaluated using the Spearman Rank correlation coefficient. P values less than 0.05 were considered statistically significant. 


\section{Results}

MBL genotype from patients in relation to disease expression

All 53 patients were genotyped for MBL variant alleles at codon 52 (named D), at codon 54 (named B) and at codon 57 (named $\mathrm{C}$ ) of exon 1 of the mbl2 gene. The wildtype genotype (A/A) was observed in 37 out of the 53 patients $(70 \%)$, the A/B genotype was found in 4 patients, 5 patients carried the $\mathrm{A} / \mathrm{C}$ genotype and 5 patients the A/D genoype, whereas the $\mathrm{B} / \mathrm{B}$ and $\mathrm{D} / \mathrm{C}$ genotype were both found in 1 patient. This genotype distribution was compared to a population of healthy Caucasian controls. Both in the Caucasian SLE patients $(\mathrm{N}=44)$ and in the healthy controls $(\mathrm{N}=59), 66 \%$ expressed the wildtype genotype (A/A).

Table 1. Clinical variables and MBL genotype distribution in patients with SLE.

\begin{tabular}{|c|c|c|c|c|c|c|c|}
\hline \multirow[t]{2}{*}{ Clinical variables } & \multirow{2}{*}{$\begin{array}{c}\text { Number of } \\
\text { Patients }^{\mathrm{a}} \\
(\text { total=53) }\end{array}$} & \multirow[t]{2}{*}{$(\%)$} & \multicolumn{2}{|c|}{$\begin{array}{c}\text { Genotype } A / A \\
(\mathbf{N}=37)\end{array}$} & \multicolumn{2}{|c|}{$\begin{array}{c}\text { Genotype } A / 0 \text { or } 0 / 0 \\
(\mathrm{~N}=16)\end{array}$} & \multirow[t]{2}{*}{$\begin{array}{c}\text { P } \\
\text { Value }^{b}\end{array}$} \\
\hline & & & present & absent & present & absent & \\
\hline Malar rash & 11 & 21 & 9 & 26 & 2 & 14 & ns \\
\hline Ulcers & 22 & 42 & 15 & 20 & 7 & 9 & ns \\
\hline Arthritis & 26 & 49 & 17 & 19 & 9 & 7 & ns \\
\hline Serositis & 41 & 77 & 27 & 7 & 14 & 2 & ns \\
\hline Renal involvement & 25 & 47 & 17 & 20 & 8 & 8 & ns \\
\hline Neurologic involvement & 18 & 34 & 12 & 25 & 6 & 10 & ns \\
\hline Haematologic involvement & 23 & 43 & 15 & 22 & 8 & 8 & ns \\
\hline Thrombosis & 4 & 8 & 2 & 35 & 2 & 14 & ns \\
\hline
\end{tabular}

a. Indicated are the number (percentage) of patients with clinical or laboratory findings of disease activity at the

moment the serum samples were taken.

b. The association between MBL genotype and clinical variables was tested by a Chi-square test.

We divided the patients with SLE in two groups: one group with the wildtype genotype $(\mathrm{A} / \mathrm{A})$ and one group of carriers of variant alleles (A/0 or $0 / 0$ genotype). Because of the limited number of patients with the $0 / 0$ allele it was not possible to study these patients as an independent group. The frequencies of the different clinical variables and MBL genotype distribution in the two patient groups are shown in table 1 . No difference was observed between carriers of wildtype alleles (A/A) and variant alleles (non-A/A) in clinical presentation of the disease variables. In contrast, significant differences were noted between carriers of MBL wildtype alleles and MBL variant alleles 
with respect to the autoantibody profile. A significant difference was observed concerning the presence of anti-cardiolipin antibodies and anti-C1q antibodies: autoantibodies against cardiolipin and against $\mathrm{C} 1 \mathrm{q}$ were significantly associated with the occurrence of MBL gene polymorphisms (Table 2). In contrast, there was a trend towards a lower presence of anti-MBL autoantibodies in SLE patients with variant alleles.

Table 2. The presence or absence of different autoantibodies in SLE patients with wild type MBL genotype and variant MBL genotype.

\begin{tabular}{lccccc} 
& \multicolumn{2}{c}{$\begin{array}{c}\text { Genotype } \boldsymbol{A} / \boldsymbol{A} \\
(\mathbf{N = 3 7})\end{array}$} & $\begin{array}{c}\text { Genotype } \boldsymbol{A} / \mathbf{0} \text { or } \mathbf{0 / 0} \\
(\mathbf{N = 1 6})\end{array}$ & $\begin{array}{c}\text { P } \\
\text { Value }\end{array}$ \\
\hline Autoantibody specificity & present & absent & present & absent & \\
\hline Anti-dsDNA & 23 & 14 & 9 & 7 & 0.69 \\
Lupus anti-coagulant & 4 & 31 & 4 & 12 & 0.2 \\
Anti-cardiolipin & 10 & 25 & 10 & 6 & 0.03 \\
Anti-C1q & 3 & 34 & 5 & 9 & 0.03 \\
Anti-MBL & 7 & 29 & 0 & 15 & 0.066 \\
\hline
\end{tabular}

\section{Functional characterisation of the MBL pathway in SLE}

The impact of MBL gene polymorphisms on MBL protein expression and function in SLE patients was examined using three different parameters, namely MBL serum concentration, MBL complex activity and MBL pathway activity.

The MBL concentrations in all sera were assessed by ELISA (Fig 1A). The MBL concentration in the sera from SLE patients with the A/A genotype varied from $0.3 \mathrm{ng} / \mathrm{ml}$ to $3.8 \mu \mathrm{g} / \mathrm{ml}(\mathrm{N}=34$, median $0.829 \mu \mathrm{g} / \mathrm{ml})$. The MBL concentrations in sera from patients with variant alleles were significantly decreased as expected (median $0.279 \mu \mathrm{g} / \mathrm{ml}, \mathrm{N}=$ $14, \mathrm{P}=0.0002$ ). To demonstrate the functional activity of the complex of MBL with the associated MASPs, activation of exogenous $\mathrm{C} 4$ by MBL complexes bound to mannan was assessed in an MBL complex activity assay (Fig 1B). The activity of the MBL complex varied from $425 \mathrm{aU} / \mathrm{ml}$ to 3,930 aU/ml (median 1,497 aU/ml) in the patients with a wildtype MBL genotype and a significantly decreased activity was found in sera from patients with a variant allele (median $371 \mathrm{aU} / \mathrm{ml}, \mathrm{P}=0.0003$ ). For the activity of the MBL pathway in full serum an ELISA was used measuring the formation of the terminal complex (C5b-9) via autologous complement components on solid phase mannan. The activity of the complete MBL-pathway in SLE patients with a wildtype MBL 

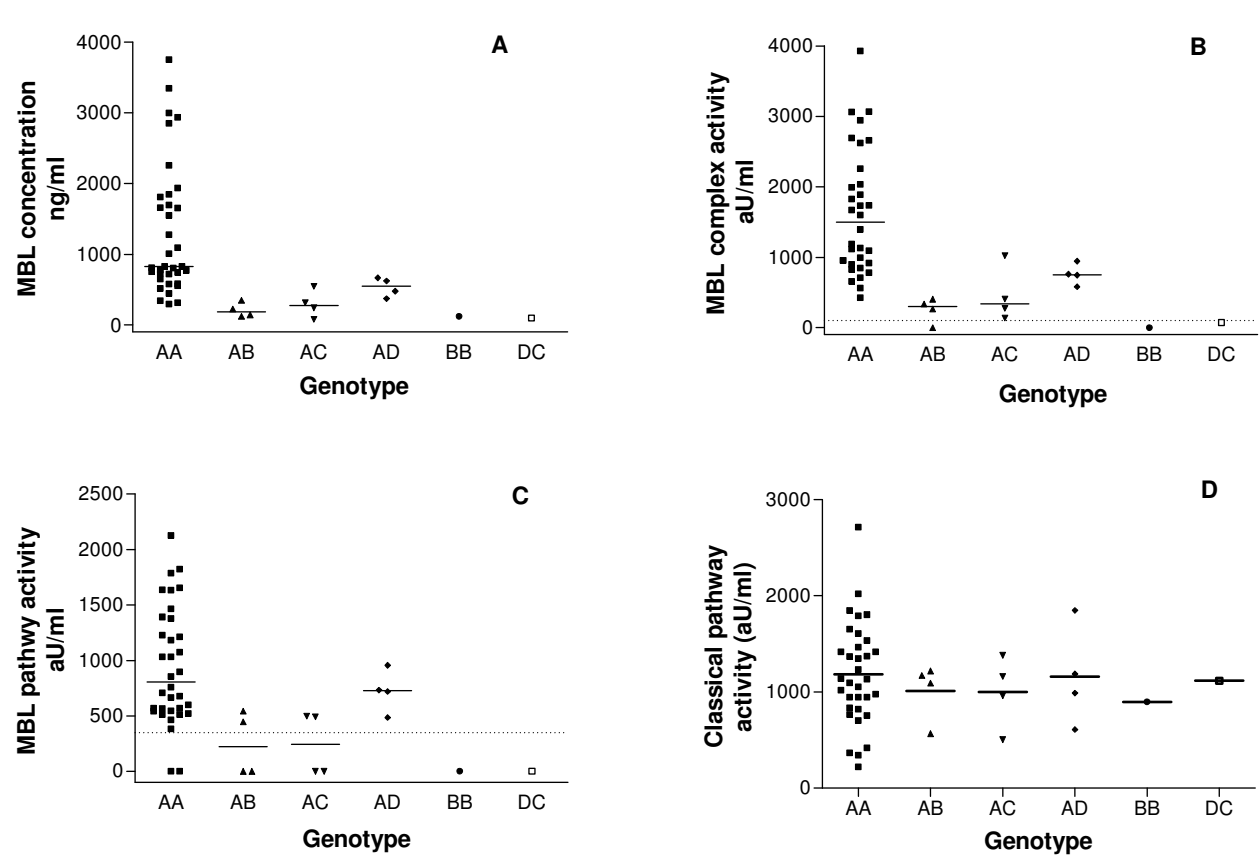

Figure 1. MBL function and classical pathway activity in relation to $M B L$ genotype. The MBL genotype from 53 patients with SLE was determined. MBL concentration (A), MBL complex activi ty $(B), M B L$ pathway activity $(C)$ and classical pathway activity $(D)$ was assessed in sera from patients with the different $M B L$ genotypes. A significant difference was found when $M B L$ con centration $(P=0.0002), M B L$ complex activity $(P=0.0003)$ and $M B L$ pathway activity $(P=0.0036)$ in patients with wildtype $M B L$ were compared with patients carrying variant alleles (Mann Whitney test). The dotted lines indicate the detection limit of the assay.

genotype varied from undetectable (below 350) until 2,126 aU/ml (median $808 \mathrm{aU} / \mathrm{ml}$ ), which is significantly different from the decreased activity found in carriers of variant alleles (median $467 \mathrm{aU} / \mathrm{ml}, \mathrm{P}=0.0036$ ) (Fig 1C). Also the classical pathway activity was assessed in the same sera. No difference was found in classical pathway activity between patients with wildtype MBL genotype and patients with a variant allele (Fig 1D). Both the MBL complex activity and the MBL-pathway activity showed a significant correlation with the MBL concentration $(\mathrm{R}=0.82 ; \mathrm{P}<0.001$, and $\mathrm{R}=0.65 ; \mathrm{P}<0.001$, respectively (Fig. 2)). However, several serum samples showed a low or undetectable MBL-pathway activity whereas the MBL concentration and the MBL complex activity were in the normal range (Fig. 2B). MBL-pathway activity showed a significant correlation with the classical pathway activity $(\mathrm{R}=0.41 ; \mathrm{P}=0.004)(\mathrm{Fig} 2 \mathrm{C})$, whereas MBL concentration was not correlated to classical pathway activity $(R=0.02, P=0.91)$.

\section{Functional activity of the MBL pathway in relation to disease}

We analysed the MBL concentration, MBL complex activity and MBL-pathway activity for possible association with the different clinical variables. No significant association between the different clinical variables and MBL concentration or functional acti- 

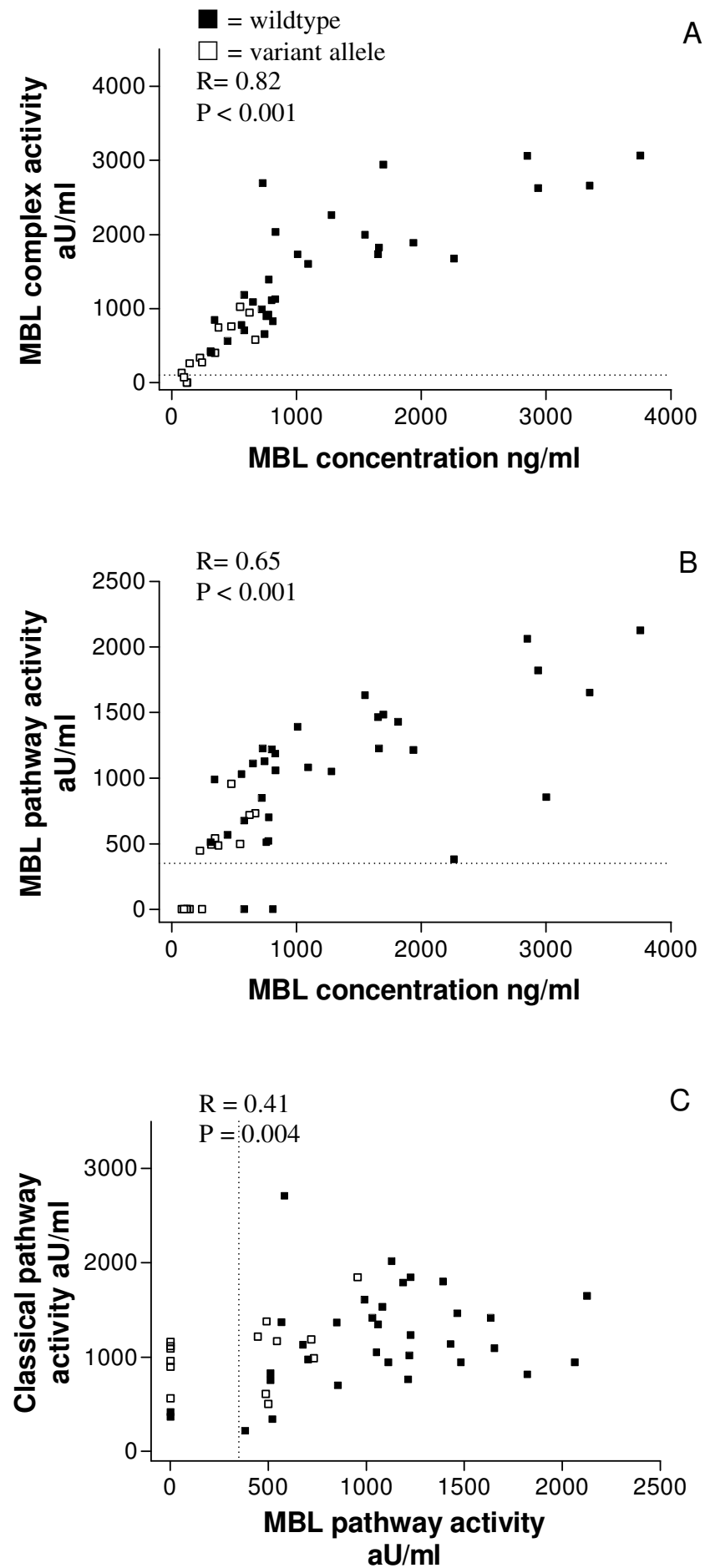

\section{Figure 2.}

$M B L$ function in relation to $M B L$ concentration and classical pathway activity.

The correlation of MBL concentration and $M B L$ complex activity (A) as well as the correlation between MBL concentration and $M B L$ pathway activity (B) is shown for different sera from SLE patients carrying wildtype or variant alleles as indicated. The correlation between MBL pathway activity and classical pathway activity is shown for the same sera (C). The dotted lines indicate the detection limit of the assay. 

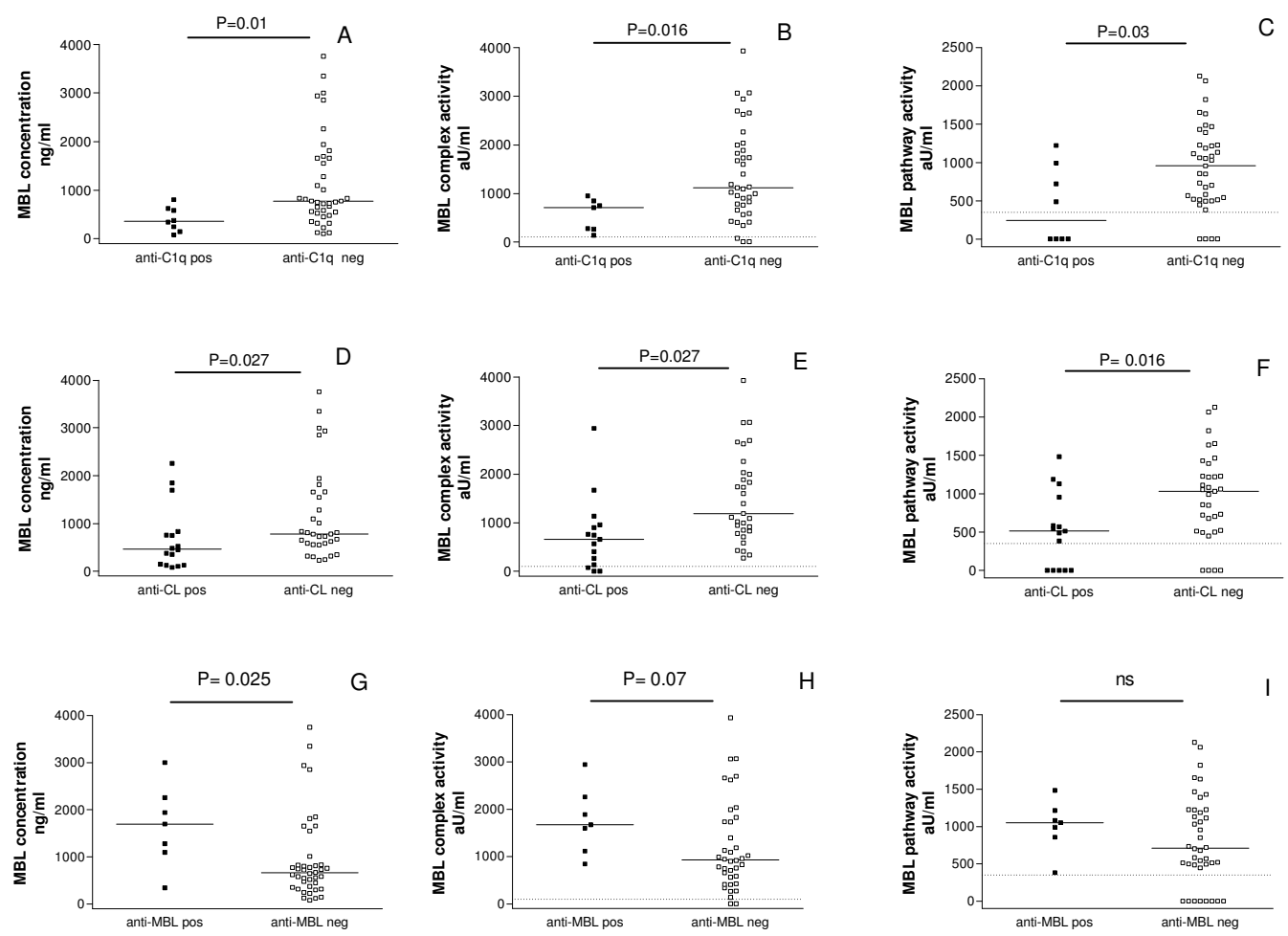

Figure 3. The presence of autoantibodies is associated with MBL concentration and function.

Sera from SLE patients were dived into two groups on basis of the absence or presence of auto antibodies against $C 1 q(A-C)$, cardiolipin $(D-F)$ and $M B L(G-I)$. MBL concentration, $M B L$ complex activity and $M B L$ pathway activity in the different sera is shown for each group. Differences between the two groups were evaluated by the Mann Whitney test.

vity was found. However, significantly lower MBL concentrations (Fig $3 \mathrm{~A}, \mathrm{P}=0.03$ ), MBL complex activity (Fig 3B, $\mathrm{P}=0.03$ ) and MBL pathway activity (Fig. $3 \mathrm{C}, \mathrm{P}=0.02$ ) was found in patients with anti-C1q antibodies as compared to patients without these autoantibodies. Similarly, the presence of anti-cardiolipin autoantibodies was associated with low serum levels of MBL (Fig. 3D, $\mathrm{P}=0.01$ ), low MBL complex activity (Fig. $3 \mathrm{E}, \mathrm{P}=0.02$ ) and low MBL pathway activity (Fig. $3 \mathrm{~F}, \mathrm{P}=0.03$ ). In sharp contrast to these findings, patients with autoantibodies against MBL in their serum had significantly higher MBL concentrations ( $p=0.025$ ) (Fig 3G). A similar but non-significant trend was found for MBL complex activity $(\mathrm{P}=0.07)$ whereas MBL pathway activity was not significantly different between patients with or without anti-MBL autoantibodies (Fig 3 $\mathrm{H}$ and I). No significant association was found between the presences of autoantibodies and classical pathway activity ( $\mathrm{P}>0.28$; data not shown). Together, these data demonstrate an association of autoantibodies against cardiolipin and C1q with MBL dysfunction. 


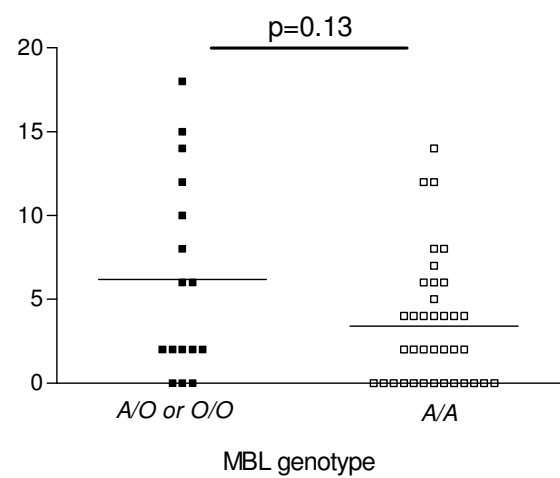

C

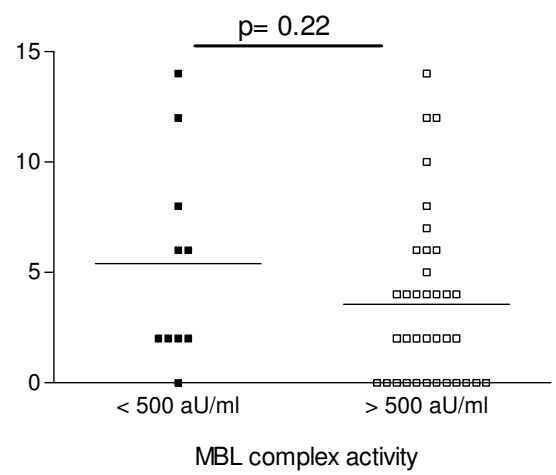

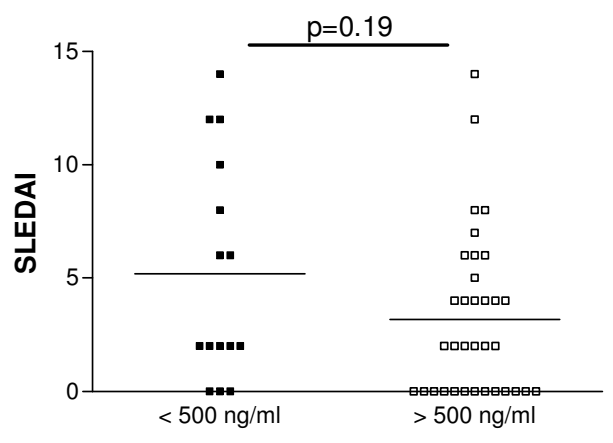

$\mathrm{MBL}$ concentration

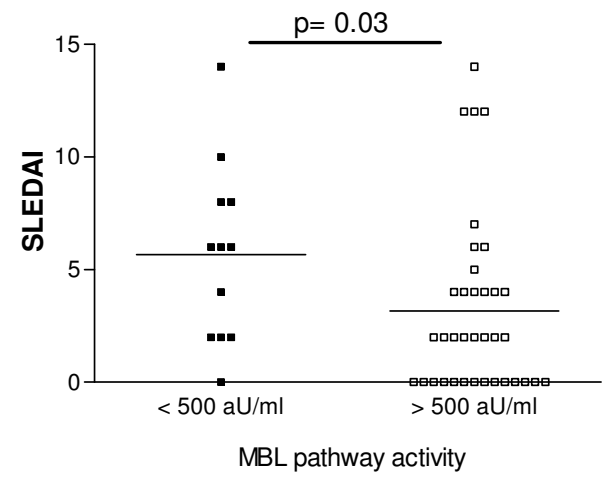

Figure 4. SLE disease activity in relation to MBL genotype and function. SLE disease activity indexes (SLEDAI) are shown for SLE patients carrying wildtype MBL genotype or variant alleles (A), and low or high levels of $M B L$ concentration, $M B L$ complex activity and $M B L$ pathway activity $(B-D)$, respectively, as indicated.

\section{MBL genotype and function in relation to SLE disease activity}

In order to examine whether MBL pathway dysfunction is also related to disease activity we analysed the SLE Disease Activity Index (SLEDAI) in SLE patients divided in two groups on basis of the MBL genotype, the MBL concentration, the MBL complex activity, and the MBL- pathway activity, respectively.

Disease activity was not significantly different between patients with MBL wildtype or variant alleles, between patients with high or low MBL concentration and between patients with high or low MBL complex activity (Fig. 4 A-C). However, patients with low MBL-pathway activity $(<500 \mathrm{aU} / \mathrm{ml})$ had significantly more disease activity, measured with the SLE Disease Activity Index (SLEDAI), compared to patients with high (> $500 \mathrm{aU} / \mathrm{ml}$ ) MBL-pathway activity (Fig 4D). No significant difference was found between SLEDAI of patients with high or low classical pathway activity $(P=0.25$; data not shown). The MBL genotype, MBL concentration, MBL complex activity or MBL- 
pathway activity were not significantly associated with organ damage measured with the Systemic Lupus International Collaborating Clinics/ACR Damage Index.

\section{Discussion}

The present study demonstrates in patients with SLE a significant association of the presence of anti-cardiolipin and anti-C1q autoantibodies with the presence of MBL variant alleles, with low serum MBL concentrations, and with impaired MBL function. The results further indicate that expression of MBL variant alleles in SLE patients is not only associated with reduced MBL concentrations but also with impaired MBL complex activity and impaired MBL pathway activity.

The presence of a wide variety of autoantibodies is a characteristic finding in SLE. Most of the autoantibodies are directed against membranous, intracellular or nuclear target antigens. Some antibodies are directed against fluid phase proteins such as C1q [29] and MBL [27]. Autoantibodies against nuclear proteins, such as anti-nuclear (ANA) and anti-dsDNA antibodies, are used as diagnostic markers in SLE [30], whereas anti-C1q and anti-dsDNA antibodies are also used to monitor lupus activity. A rise in the titer of anti-C1q antibodies is reported to be predictive for renal flares [31]. In patients with SLE, impaired normal mechanisms of waste-disposal due to complement deficiency have been hypothesised, and therefore this material can be a source of autoantigens.

Recently it has been shown that MBL binds to apoptotic material and mediates its clearance by macrophages [3,14,15]. Therefore, patients with low MBL serum concentrations and impaired MBL function could have a decreased rate of clearance of apoptotic material, which may result into higher autoantibody levels directed against target antigens, such as phosopholipids and $\mathrm{C} 1 \mathrm{q}$, present on apoptotic material. In contrast to previously published results by Garcia-Laorden et al. [32], in our study anti-cardiolipin antibodies were more frequently found in patients with MBL variant alleles compared to patients with MBL wildtype genotype. In addition, we demonstrated that C1q autoantibodies are more frequently present in patients with MBL variant alleles, and decreased MBL concentrations and impaired MBL activity were found in patients with autoantibodies against $\mathrm{C} 1 \mathrm{q}$ and cardiolipin. These findings support our hypothesis of increased generation of autoantibodies to antigens present on apoptotic material in SLE patients with MBL dysfunction. Furthermore, increased MBL concentrations were found in SLE patients with anti-MBL autoantibodies and anti-MBL autoantibodies were not found in patients with variant alleles. These results could indicate that only intact wildtype MBL can bind efficiently to apoptotic material and therefore be presented by antigen presenting cells. However, the clinical relevance of anti-MBL antibodies in patients with SLE has to be demonstrated.

A genetic deficiency for $\mathrm{C} 1 \mathrm{q}$ is almost always associated with SLE in humans. However, C1q deficiency is very rare and therefore it is not a major cause for SLE in the human population. In a recent meta-analysis by Garred et al.[33], it was observed that the presence of MBL variant alleles $(\mathrm{A} / 0$ and $0 / 0)$ were associated with a signifi- 
cantly increased risk to develop SLE when the diagnosis of SLE was based on the fulfilling of at least four ACR criteria. In our study we did not find such an association although our patients were similarly defined. However, this is probably due to the size of the patient cohort examined in the present study. It was proposed by Garred and colleagues that the $M B L_{2}$ gene is a disease modifier locus rather than a true disease susceptibility locus, being involved in accelerated progression of the disease. In this respect, our study supports this idea by showing that $M B L_{2}$ variant alleles are associated with increased production of autoantibodies that are known to be associated with disease manifestations in SLE. Furthermore, our study indicates for the first time an association between the presence of autoantibodies in SLE patients and functional impairment of the MBL pathway of complement, which supports the genetic studies indicating a role for MBL in SLE.

MBL serum concentrations are known to be dependent on MBL genotype. Individuals with variant alleles have decreased MBL serum concentrations compared to serum concentrations of individuals with wildtype MBL genotype. We show that SLE patients with MBL variant alleles have less functionally active MBL as compared to patients with wildtype MBL. This was demonstrated by an impaired ability to activate exogenous C4 by MBL-MASP complexes bound to mannan, as well as by an impaired capacity to activate the whole complement cascade upon binding of MBL to mannan. Within the population carrying the wildtype $M B L_{2}$ gene the concentration of MBL also varies from very low to normal levels, which could be at least partially explained by differences in promoter genotypes. Also differences in serum concentrations for MASPs could play a role in the variable functional activity of MBL in carriers of the MBL wildtype genotype [34]. Differences in functional activity of the whole MBL-pathway within the population carrying the wildtype MBL genotype could be due to differences in MBL and MASP concentrations as well as differences in concentrations of the other complement components.

Therefore, we assessed MBL complex activity as well as whole MBL-pathway activity and classical pathway activity to examine the role of the MBL pathway in more detail in patients with SLE. The MBL complex activity and the MBL pathway activity were both dependent on MBL genotype. Furthermore, a highly significant correlation was found between MBL concentration and MBL complex activity without evidence for MASP-2 deficiency [35]. Also a statistically significant correlation was found between MBL concentrations and MBL-pathway activity. However, this relation was less profound compared to the relation between MBL concentrations and MBL complex activity, and a few discordant samples were noticed. A possible explanation for this finding is complement consumption in patients with SLE. For a fully active MBLpathway appropriate serum complement concentrations are required. To further investigate this possibility classical pathway activity was assessed in the same samples. Classical pathway activity was significantly correlated with MBL pathway activity but not associated with MBL genotype. Since this correlation was shown to be independent of MBL, this is most likely due to differences in the levels of complement consumption shared by the MBL pathway and classical pathway. Furthermore, in serum samples from patients with wildtype MBL genotype with a remarkable discrepancy between MBL complex activity and MBL pathway activity, low classical pathway acti- 
vity was found. Therefore one could speculate that some of the patients with lower levels of MBL-pathway activity are those patients with more active disease. Indeed, for the SLE patients examined in the present study an association was found between disease activity and MBL-pathway activity, as a functional parameter of the whole complement cascade starting from MBL binding to mannan. However, MBL complex activity and MBL serum concentrations were not significantly associated with the disease activity index, indicating that the association between MBL pathway activity and SLEDAI cannot be solely explained by MBL deficiency. Therefore, these results suggest that a combination of factors, such as possible defects at the level of MBL as well as acquired defects at other levels of the cascade, could be critical in this respect. These acquired defects may include decreased levels of C4 and/or C3, which are well know to be associated with severe disease in patients with SLE [36].

The results of our study could implicate that patients with less functional MBL may present with more severe disease because of impaired clearance of apoptotic material and therefore enhanced antibody production. The combined presence of anti-cardiolipin and anti-C1q autoantibodies was strongly associated with increased disease activity in the present study $(\mathrm{P}=0.006$, not shown). In addition, it has been shown that SLE patients with MBL variant alleles show higher incidence of infections [33]. Therefore, the increased production of antibodies in SLE patients with MBL dysfunction could possibly also be related to impaired MBL-dependent clearance of non-self antigens. Active disease and therefore more complement consumption in patients with lower MBL concentrations could further deteriorate MBL-pathway activity as well as classical pathway activity, thus enhancing the susceptibility to infections, and possibly also the disturbed clearance of apoptotic material. In a recent study on the binding of MBL to apoptotic cells, it was observed that complement activation by apoptotic cells is predominantly due to activation of the classical pathway and not the MBL pathway of complement [5].

The present study supports a role for MBL as a disease modifier in patients with SLE. Functional impairment of the MBL pathway of complement, which is common in the human population, appears to be associated with enhanced production of autoantibodies against $\mathrm{C} 1 \mathrm{q}$ and cardiolipin. In view of the role of $\mathrm{MBL}$ and $\mathrm{C} 1 \mathrm{q}$ in the recognition of self debris, MBL deficiency may lead to disturbed in vivo clearance of apoptotic material, resulting into enhanced production of autoantibodies against antigens associated with apoptotic material, including C1q. Binding of autoantibodies to apoptotic cells could subsequently further modulate the response of phagocytic cells towards phagocytosis of apoptotic cells [3], thus leading to an amplification of systemic autoimmunity.

\section{Acknowledgements}

Part of this work was supported by the Dutch Kidney Foundation (PC 95, C98-1763) and by a grant of the European Union (QLGT-CT2001-01039). 


\section{References}

1. Tsao BP. The genetics of human systemic lupus erythematosus. Trends Immunol 2003; 24: 595-602.

2. Pickering MC, Botto M, Taylor PR, Lachmann PJ, Walport MJ. Systemic lupus erythematosus, complement deficiency, and apoptosis. Adv Immunol 2000; 76: 227-324.

3. Nauta AJ, Daha MR, Kooten C, Roos A. Recognition and clearance of apoptotic cells: a role for complement and pentraxins. Trends Immunol 2003; 24:148-154.

4. Botto M, Dell'Agnola C, Bygrave AE, Thompson EM, Cook HT, Petry F et al. Homozygous C1q deficiency causes glomerulonephritis associated with multiple apoptotic bodies. Nat Genet 1998; 19: $56-9$

5. Emlen W, Niebur J, Kadera R. Accelerated in vitro apoptosis of lymphocytes from patients with systemic lupus erythematosus. J Immunol 1994; 152: 3685-3692.

6. Casciola-Rosen LA, Anhalt G, Rosen A. Autoantigens targeted in systemic lupus erythematosus are clustered in two populations of surface structures on apoptotic keratinocytes. J Exp Med 1994; 179: 1317-1330.

7. Turner MW. Mannose-binding lectin (MBL) in health and disease. Immunobiology 1998; 199: 327339.

8. Garred P, Voss A, Madsen HO, Junker P. Association of mannose-binding lectin gene variation with disease severity and infections in a population-based cohort of systemic lupus erythematosus patients. Genes Immun 2001; 2: 442-450.

9. Davies EJ, Teh LS, Ordi-Ros J, Snowden N, Hillarby MC, Hajeer A et al. A dysfunctional allele of the mannose binding protein gene associates with systemic lupus erythematosus in a Spanish population. J Rheumatol 1997; 24: 485-488.

10. Ip WK, Chan SY, Lau CS, Lau YL. Association of systemic lupus erythematosus with promoter polymorphisms of the mannose-binding lectin gene. Arthritis Rheum 1998; 41: 1663-1668.

11. Sullivan KE, Wooten C, Goldman D, Petri M. Mannose-binding protein genetic polymorphisms in black patients with systemic lupus erythematosus. Arthritis Rheum 1996; 39: 2046-2051.

12.. Hansen S, Holmskov U. Structural aspects of collectins and receptors for collectins. Immunobiology 1998; 199: 165-189.

13. Matsushita M, Thiel S, Jensenius JC, Terai I, Fujita T. Proteolytic activities of two types of mannosebinding lectin-associated serine protease. J Immunol 2000; 165: 2637-2642.

14. Ogden CA, deCathelineau A, Hoffmann PR, Bratton D, Ghebrehiwet B, Fadok VA et al. C1q and mannose binding lectin engagement of cell surface calreticulin and CD91 initiates macropinocytosis and uptake of apoptotic cells. J Exp Med 2001; 194: 781-795.

15. Nauta AJ, Raaschou-Jensen N, Roos A, Daha MR, Madsen HO, Borrias-Essers MC, et al. Mannosebinding lectin engagement with late apoptotic and necrotic cells. Eur J Immunol 2003; 33: 2853-63.

16. Garred P, Thiel S, Madsen HO, Ryder LP, Jensenius JC, Svejgaard A. Gene frequency and partial protein characterization of an allelic variant of mannan binding protein associated with low serum concentrations. Clin Exp Immunol 1992; 9: 517-521. 
17. Madsen HO, Garred P, Kurtzhals JA, Lamm LU, Ryder LP, Thiel S et al. A new frequent allele is the missing link in the structural polymorphism of the human mannan-binding protein.

Immunogenetics 1994; 40: 37-44.

18. Sumiya M, Super M, Tabona P, Levinsky RJ, Arai T, Turner MW et al. Molecular basis of opsonic defect in immunodeficient children. Lancet 1991; 337: 1569-1570.

19. Lipscombe RJ, Sumiya M, Hill AV, Lau YL, Levinsky RJ, Summerfield JA et al. High frequencies in African and non-African populations of independent mutations in the mannose binding protein gene. Hum Mol Genet 1992; 1: 709-715.

20. Madsen HO, Satz ML, Hogh B, Svejgaard A, Garred P. Different molecular events result in low protein levels of mannan-binding lectin in populations from southeast Africa and South America. J Immunol 1998; 16: 3169-3175.

21. Madsen HO, Garred P, Thiel S, Kurtzhals JA, Lamm LU, Ryder LP et al. Interplay between promoter and structural gene variants control basal serum level of mannan-binding protein. J Immunol 1995; 155: 3013-3020.

22. Garred P, Madsen HO, Halberg P, Petersen J, Kronborg G, Svejgaard A et al. Mannose-binding lectin polymorphisms and susceptibility to infection in systemic lupus erythematosus. Arthritis Rheum 1999; 42: 2145-2152.

23. Roos A, Bouwman LH, Munoz J, Zuiverloon T, Faber-Krol MC, Fallaux-van den Houten FC et al. Functional characterization of the lectin pathway of complement in human serum. Mol Immunol 2003; 39: 655-668.

24. Roos A, Bouwman LH, Gijlswijk-Janssen DJ, Faber-Krol MC, Stahl GL, Daha MR. Human IgA acti vates the complement system via the mannan-binding lectin pathway. J Immunol 2001; 167: 28612868 .

25. Petersen SV, Thiel S, Jensen L, Steffensen R, Jensenius JC. An assay for the mannan-binding lectin pathway of complement activation. J Immunol Methods 2001; 257: 107-116.

26. Siegert C, Daha M, Westedt ML, van d, V, Breedveld F. IgG autoantibodies against C1q are correlated with nephritis, hypocomplementemia, and dsDNA antibodies in systemic lupus erythematosus. J Rheumatol 1991; 18: 230-234.

27. Seelen MA, Trouw LA, van der Hoorn JW, Fallaux-van den Houten FC, Huizinga TW, Daha MR et al. Autoantibodies against mannose-binding lectin in systemic lupus erythematosus. Clin Exp Immunol 2003; 134: 335-343.

28. Aarden LA, Lakmaker F, de Groot ER, Swaak AJ, Feltkamp TE. Detection of antibodies to DNA by radioimmunoassay and immunofluorescence. Scand J Rheumatol Suppl. 1975; 11: 12-9.

29. Siegert CE, Breedveld FC, Daha MR. Autoantibodies against C1q in systemic lupus erythematosus. Behring Inst Mitt 1993; 279-286.

30. Tan EM, Cohen AS, Fries JF, Masi AT, McShane DJ, Rothfield NF et al. The 1982 revised criteria for the classification of systemic lupus erythematosus. Arthritis Rheum 1982; 25: 1271-1277.

31. Coremans IE, Spronk PE, Bootsma H, Daha MR, van der Voort EA, Kater L et al. Changes in antibo dies to C1q predict renal relapses in systemic lupus erythematosus. Am J Kidney Dis 1995; 26: 595601. 
32. Garcia-Laorden MI, Rua-Figueroa I, Perez-Aciego P, Rodriguez-Perez JC, Citores MJ, Alamo F et al. Mannose binding lectin polymorphisms as a disease-modulating factor in women with systemic lupus erythematosus from Canary Islands, Spain. J Rheumatol 2003; 30: 740-746.

33. Garred P, Voss A, Madsen HO, Junker P. Association of mannose-binding lectin gene variation with disease severity and infections in a population-based cohort of systemic lupus erythematosus patients. Genes Immun 2001; 2: 442-50.

34. Moller-Kristensen M, Jensenius JC, Jensen L, Thielens N, Rossi V, Arlaud G et al. Levels of mannanbinding lectin-associated serine protease-2 in healthy individuals. J Immunol Methods 2003; 282: 159-167.

35. Stengaard-Pedersen K, Thiel S, Gadjeva M, Moller-Kristensen M, Sorensen R, Jensen LT, et al. Inherited deficiency of mannan-binding lectin-associated serine protease 2. N Engl J Med 2003; 349: 554-60

36. Spronk PE, Limburg PC, Kallenberg CG. Serological markers of disease activity in systemic lupus erythematosus. Lupus 1995; 4: 86-94. 


\section{Chapter 5}

\section{Functional analysis of the classical, alternative, and MBL pathways of the complement system: standardization and validation of a simple ELISA}

Seelen $M A^{1}$, Roos $A^{1}$, Wieslander $J^{2}$, Mollnes $T E^{3}$, Sjöholm $A G^{4}$, Wurzner $R^{5}$, Loos $M^{6}$, Tedesco $F^{7}$, Sim $R B^{8}$, Garred $P^{9}$, Alexopoulos $E^{10}$, Turner $M W^{11}$, Daha $M R^{1}$

1. Department of Nephrology, Leiden University Medical Center, Leiden, The Netherlands.

2. Wieslab IDEON Lund, Sweden.

3. Institute of Immunology, Rikshospitalet, University Hospital, Oslo, Norway.

4. Institute of Laboratory Medicine, Section of Microbiology,

Immunology and Glycobiology,Lund University, Lund, Sweden.

5. Department of Hygiene, microbiology and Social Medicine, Innsbruck Medical University, Innsbruck, Austria

6. Institute of Medical Microbiology and Hygiene,

Johannes Gutenberg, University Mainz, Germany.

7. Department of Physiology and Pathology, University of Trieste, Trieste, Italy

8. Medical Research Council Immunochemistry Unit, Department of Biochemistry, University of Oxford, Oxford, UK

9. Tissue Typing Laboratory-7631 of the Department of Clinical Immunology,

Rigshospitalet, Copenhagen University Hospital, Denmark

10. Department of Nephrology, Hippokration General Hospital, Thessaloniki, Greece

11. Immunobiology Unit, Institute of Child Health, London, UK

J of Immunol Methods 296 (2005) 187-198 


\section{Abstract}

Primary defence against invading microorganisms depends on a functional innate immune system and the complement system plays a major role in such immunity. Deficiencies in one of the components of the complement system can cause severe and recurrent infections, systemic diseases such as systemic lupus erythematosus (SLE) and renal disease. Screening for complement deficiencies in the classical or alternative complement pathways has mainly been performed by haemolytic assays. Here we describe a simple ELISA-based format for the evaluation of three pathways of complement activation. The assays are based on specific coatings for each pathway in combination with specific buffer systems. We have standardized these assays and defined cut off values to detect complement deficiencies at the different levels of the complement system. The results demonstrate the value of these ELISA-based procedures for the functional assessment of complement deficiencies in clinical practice. The assay is now available commercially in kit form.

\section{Introduction}

The complement system has an essential role in innate immune defence and can be activated by three different pathways (Walport 2001). The classical pathway is activated by binding of $\mathrm{C} 1 \mathrm{q}$ to e.g. immunoglobulins present on microorganisms or by direct binding to apoptotic cells; the alternative pathway can be directly activated by invading microorganisms and the lectin pathway is activated by carbohydrate moieties present on the surface of invading microbes. Activation of the complement system generates opsonic components of complement facilitating phagocytosis of microorganisms and other targets (Aderem and Underhill 1999). Initiation of any of the three pathways of complement is associated with the activation of the terminal complement pathway and formation and deposition of C3 and the terminal C5b-9 complement complex (TCC), also termed the membrane attack complex (MAC).

Deficiencies of complement components of all three pathways are associated with distinct clinical pathology. Deficiencies of the classical pathway $(\mathrm{C} 1, \mathrm{C} 4, \mathrm{C} 2)$ are associated with systemic lupus erythematosus (SLE) (Pickering et al., 2000). Deficiency of the central component of all three pathways of complement activation, C3, is associated with SLE, pyogenic infections and glomerulonephritis. Patients with deficiencies of factor D and properdin, components of the alternative pathway, show increased susceptibility to infections with Neisserial species (Sjoholm 2002). Deficiency of MBL, a major initiator of the lectin pathway of complement, is frequently found in the general population due to point mutations in the coding sequence of the MBL2 gene (Sumiya et al., 1991); Lipscombe et al., 1992; Madsen et al., 1994). MBL deficiency has been shown to be associated with bacterial, fungal and viral infections in both children and adults (Eisen and Minchinton 2003). Apart from infectious diseases, MBL polymorphisms have been reported to be associated with systemic diseases such as SLE, 
Table 1. Intra-assay variation for the three pathways of complement activation evaluated with the complement kit.

Mean activity $\quad$ SD $\quad$ CV (\%)

(\%)

\begin{tabular}{lccc}
\hline Classical pathway & 85 & 2.9 & 3 \\
Alternative pathway & 83 & 5.7 & 7 \\
MBL pathway & 74 & 3.9 & 5 \\
\hline One serum sample was tested for classical, alternative and MBL \\
pathway activity in 40 wells on one occasion.
\end{tabular}

rheumatoid arthritis and sepsis (Garred et al., 2003; Garred et al., 2000; Davies et al., 1995). The lectin pathway of complement can also be activated via L-ficolin (Matsushita et al., 2000) and H-ficolin (Matsushita, et al., 2002), but deficiencies for these molecules have not been described in the human population. MBL and ficolins use MASP-2 as the C4-activating enzyme of the lectin pathway. Interestingly, a patient with MASP-2 deficiency was recently described (Stengaard-Pedersen et al., 2003). Deficiency of complement components of the common terminal pathway may lead to defective lysis of microorganisms by the C5b-9 complex, in particular of Neisserial species (Jack, et al., 2001). Deficiency of regulatory proteins of complement activation is associated with angioedema in the case of C-1 inhibitor, and with haemolytic uraemic syndrome, SLE, glomerulonephritis and bacterial infections for factor I and $\mathrm{H}$ deficiency (Sjoholm 2002)

For assessment of the functional activity of the classical and alternative pathways, haemolysis of erythrocytes by complement activation either via the classical (CH50) or alternative pathway (AP50) is used in most laboratories. Functional ELISA based procedures for the classical and alternative pathways have been developed based on previously reported methodology (Fredrikson et al., 1993; Roos et al., 2003). In view of the clinical relevance of MBL deficiencies, several assays have also been developed to assess MBL functional activity in human serum. These assays are based on the use of mannan as a ligand. Of the two known initiators of the lectin pathway, MBL and ficolins, only MBL binds to mannan. Therefore, these assays specifically detect MBLdependent activation of the lectin pathway, and we will therefore use the term MBLpathway to indicate this specificity.

To evaluate the activity of the MBL/MASP complex, Petersen et al. ( 2001) introduced an ELISA-based procedure with mannan-coated plates. Because of interference from classical pathway activation by anti-mannan antibodies, sera are incubated in high ionic strength buffers. At this tonicity, however, activation of $\mathrm{C} 4$ is also inhibited and 
therefore the activity of the MBL complex is assessed in a second step with exogenously added purified C4. Therefore, with this assay only the activity of the MBL/MASP complex can be directly assessed.

The functional activity of the whole MBL pathway of complement has also been evaluated by other procedures. Direct haemolysis of erythrocytes coated with mannan and indirect haemolysis of chicken erythrocytes, as innocent bystander cells, have been used (Kuipers et al., 2002; Ikeda et al., 1987). In both assays exogenous MASP and /or additional complement factors have to be added to the assay system to permit erythrocyte lysis. Furthermore, both types of assay are difficult to perform on a routine basis for clinical use and do not exclude participation of the classical pathway in the assay. In clinical practice, it would be helpful to assess the functional activity of the whole MBL-pathway, from MBL through to C9, without the use of additional complement sources. Such ELISA-based procedures have been developed using mannancoated plates (Roos et al., 2003; Minchinton et al., 2002) and it has been recently demonstrated that the contribution of the classical complement pathway in such an assay can be prevented by addition of an inhibitory antibody directed against $\mathrm{C} 1 \mathrm{q}$ (Roos et al., 2003).

A compromised innate immune system resulting from defective activation of complement can be caused by genetically determined deficiencies of any of the complement components. Furthermore, decreased or absent pathway activity may also be caused by acquired complement deficiencies due to consumption. Here we describe the development of a simple ELISA-based format for the evaluation of all three pathways of complement activation. The assay is now available commercially in kit form. Screening the sera of patients for complement deficiencies or any other functional defect in the complement system can now be performed with one simple assay format for the three pathways analysed in parallel. In the present study we have standardized and validated these assays for the detection of inherited and acquired complement deficiencies associated with all three activation pathways.

\section{Materials and methods}

\section{Serum samples}

Serum samples were obtained from 120 healthy individuals (registered blood donors), 60 females with a mean age of 44.7 years (20-69 years) and 60 males with a mean age of 45.1 years (20-65 years). For each gender 12 donors were selected from each decade from age 20 to 70 . Serum samples obtained were directly aliquoted and stored at $-80^{\circ} \mathrm{C}$. The serum samples were tested in three different laboratories in the novel ELISAbased kit for functional activity of the classical, alternative and MBL pathways, subsequently referred to as the complement kit. From six donors plasma samples were also collected into heparin, EDTA or citrate. These samples were tested in the complement kit and the results were expressed as a percentage of pathway activity compared to the pathway activity assessed in serum samples from the same donors.

Sixty-four serum samples from patients with different well-defined genetically deter 
Table 2. Inter-assay variation for the three pathways of complement activation evaluated with the complement kit.

$$
\text { Mean activity } \quad \text { SD } \quad \mathrm{CV}(\%)
$$

\begin{tabular}{|c|c|c|c|c|}
\hline \multirow[t]{3}{*}{ Classical pathway } & S1 & 98 & 4.3 & 4 \\
\hline & S2 & 92 & 3.9 & 4.2 \\
\hline & S3 & 21 & 1.7 & 8 \\
\hline \multirow[t]{3}{*}{ Alternative pathway } & S1 & 48 & 5.1 & 11 \\
\hline & S2 & 89 & 8.0 & 9 \\
\hline & S3 & 16 & 3.1 & 20 \\
\hline \multirow[t]{3}{*}{ MBL pathway } & S1 & 91 & 3.3 & 4 \\
\hline & S2 & 37 & 4.0 & 11 \\
\hline & S3 & 16 & 2.3 & 15 \\
\hline \multicolumn{5}{|c|}{ Three different serum samples (S1, S2, S3) were tested in triplicate on 6} \\
\hline \multicolumn{5}{|c|}{ occasions for complement activity in the classical, alternative and MBL } \\
\hline \multicolumn{5}{|l|}{ pathways. } \\
\hline \multicolumn{5}{|c|}{$\begin{array}{l}\text { mined complement deficiencies (Turner and Hamvas 2000;Pickering et al., } \\
\text { 2000;Sjoholm 2002) were collected and tested in six different laboratories within } \\
\text { Europe. Thirty-eight samples were taken from patients with low complement levels } \\
\text { caused by complement consumption. From these patients five were diagnosed with } \\
\text { hypocomplementaemic urticarial vasculitis syndrome (HUVS), seven with hereditary } \\
\text { angio-oedema (HAE), thirteen patients with acquired angioedema (AAE), seven } \\
\text { patients with acute post-streptococcal glomerulonephritis and six sera were from } \\
\text { patients positively tested for the presence of C3 nephritic factor (C3NeF). All samples } \\
\text { taken were directly aliquoted and stored at }-80^{\circ} \mathrm{C} \text {. Forty serum samples were selected } \\
\text { from sera sent to one of the laboratories for diagnostic evaluation of complement acti- } \\
\text { vity. These serum samples were from patients with SLE, HUVS or recurrent infections. } \\
\text { These samples were tested for total complement activity in the complement kit. }\end{array}$} \\
\hline
\end{tabular}



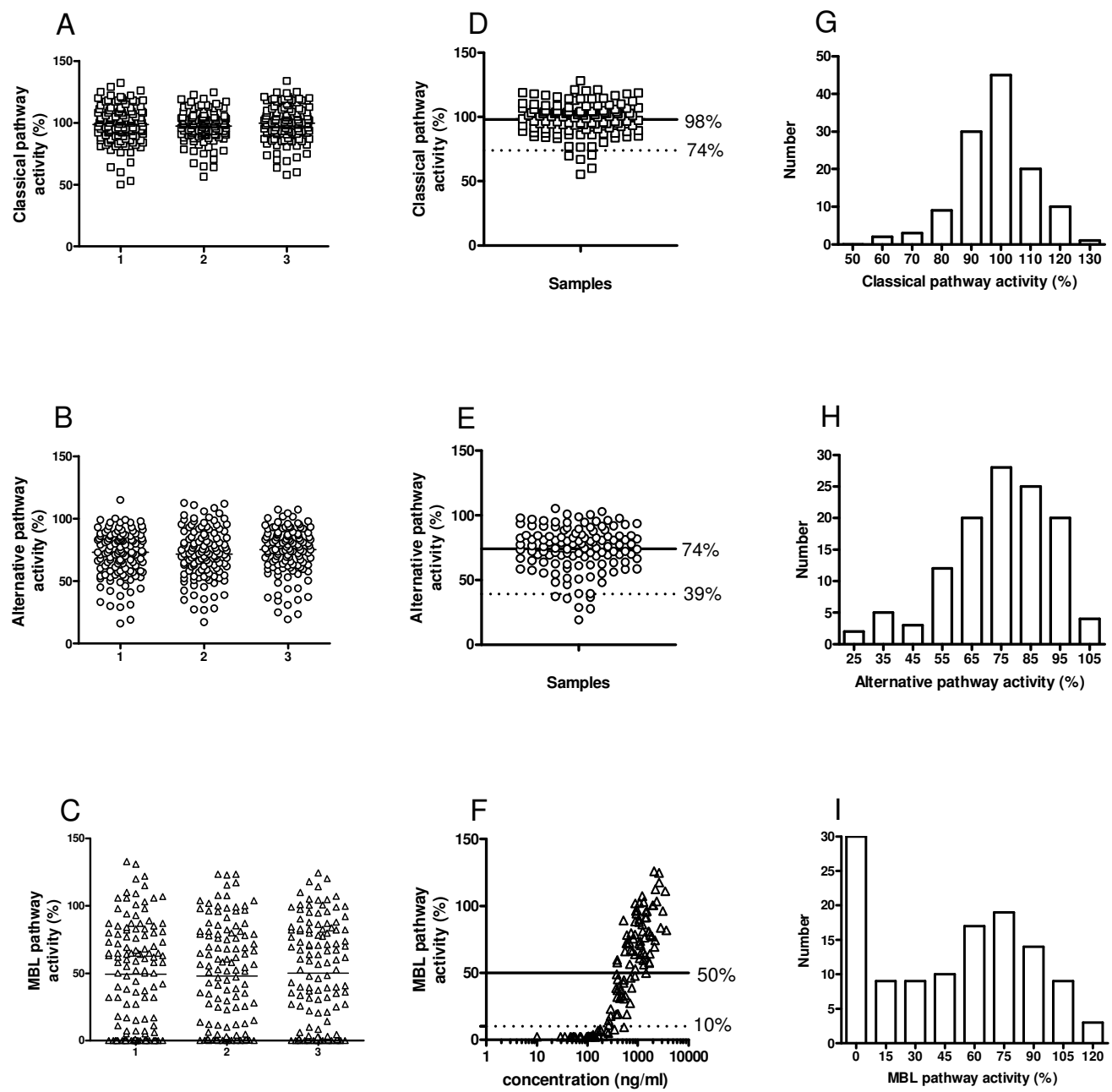

Figure 1 One hundred and twenty sera from healthy volunteers were tested using the complement kit in three different laboratories for classical pathway activity $(A)$, alternative pathway activity (B) and MBL pathway activity (C). The solid lines indicate the mean values of the samples tested. The mean absorbance values of the serum samples tested in the three laboratories for clas sical pathway activity $(D)$, alternative pathway $(E)$ and $M B L$ pathway $(F)$ were, 2.079, 1.558 and 1.009, respectively. The MBL pathway activity is plotted against the MBL concentrations assessed in the same serum samples (F). The solid lines indicate the mean values of the sam ples tested and the dotted lines indicate the cut off values for normal pathway activity. The distribution of pathway activity for $C P, A P$ and $M B L-P$ activity is shown in panels $G, H$ and $I$, respectively. 
Serum $\square$ Heparin plasma $\square$ EDTA plasma $\square$ Citrate plasma

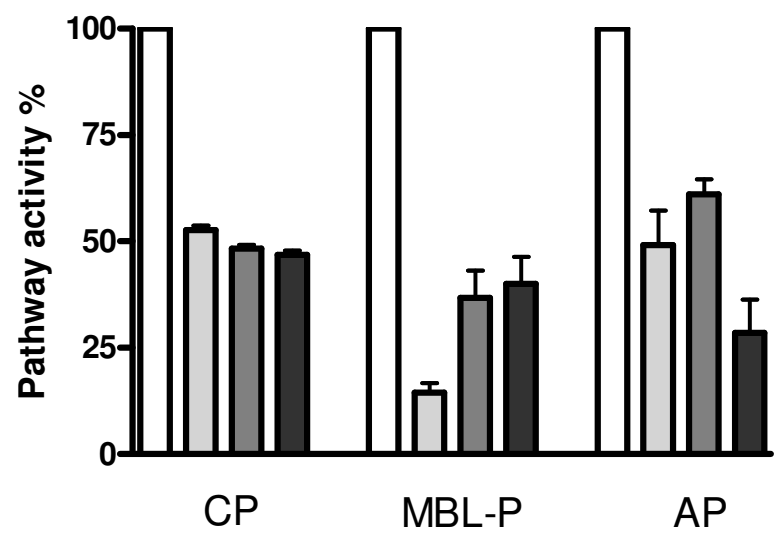

Figure 2. Serum samples, heparin plasma, EDTA plasma and citrate plasma samples were obtained from six donors for assessment of classical, alternative and $M B L$ pathway activity. The pathway activity detected in serum samples was set at $100 \%$ for all three pathways. The mean pathway activity and standard deviations for each condition are shown.

\section{Assessment of pathway activity in normal human serum samples using the complement kit}

The complement kit for assessment of classical, alternative and MBL pathway activity was developed by the EU consortium and prepared centrally at Wieslab (Sweden). It is now commercially available (Wielisa COMPL300 Total Complement Functional Screen kit from Wieslab AB, Lund, Sweden).For the present studies the instructions provided in the manual were followed. In brief, strips of wells for classical pathway (CP) evaluation were pre-coated with IgM, strips for alternative pathway (AP) determination were coated with LPS and MBL pathway (MBL-P) strips were coated with mannan. Sera were diluted 1/101 for the CP and MBL-P assay and 1/18 for the AP assay in specific buffers, which ensured that activation of only one of the pathways occurred (Roos et al., 2003), and were incubated for $1 \mathrm{~h}$ at $37^{\circ} \mathrm{C}$. After washing the strips, alkaline phosphatase-conjugated anti-human C5b-9 was added before incubation at room temperature for $30 \mathrm{~min}$. Additional washing was performed, substrate was added and the wells were incubated for $30 \mathrm{~min}$. Finally, absorbance values were read at $405 \mathrm{~nm}$. In each assay standard positive and negative control sera provided in the kit as lyophilised material were reconstituted with distilled water. The positive serum was a pool of 5 sera from healthy individuals and the negative control consisted of sera heat-inactivated at $56^{\circ} \mathrm{C}$ for $20 \mathrm{~min}$. Complement activity was calculated using the following formula: Activity $=100 \%$ x (mean A405 (sample) - mean A405 (negative control) / (mean A405 (standard serum) - mean A405 (negative control). Samples as well as standard serum and negative control serum were tested in duplicate at a fixed dilution.

\section{Analysis of intra-assay and inter-assay variation}

For the assessment of intra-assay variation of the complement kit, one sample was tested in 40 wells on one occasion for all three pathways. For calculation of the inter-assay variation three samples were selected and tested on 6 different occasions. The mean 

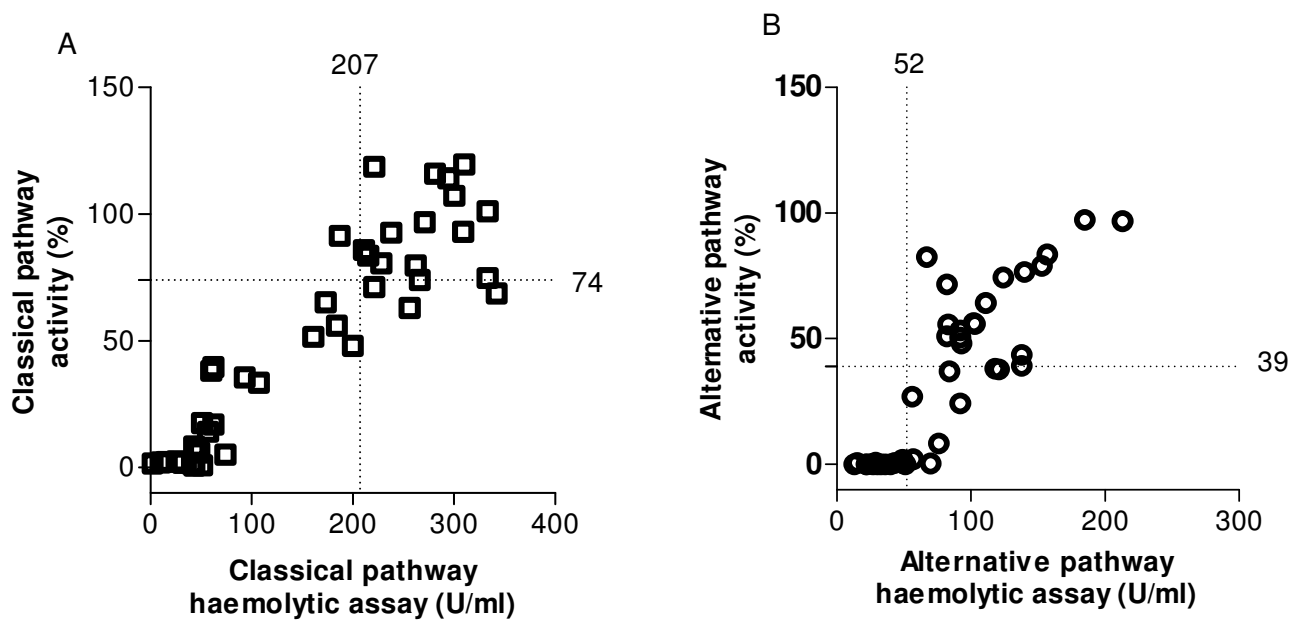

Figure 3 Functional activity of the classical pathway of 40 serum samples from patients tested in a quantitative haemolytic assay plotted against the functional activity assessed with the comple ment kit (A). For the activity of the alternative pathway the results of a quantitative haemo lytic assay are plotted against results obtained in the complement kit (B). The dotted lines indicate the cut off values for healthy controls.

values, standard deviation (SD) and the coefficient of variation (CV $=\mathrm{SD} /$ mean $\times 100 \%)$ were calculated for the classical, alternative and MBL pathways.

\section{Haemolytic assays}

For the haemolytic assessment of classical pathway complement activation, sheep red blood cells (SRBC) were sensitised using rabbit anti-SRBC Abs (Ab-coated erythrocytes (EA)). For a classical pathway test, a total number of $7 \times 10^{9}$ EA diluted in dextrose gelatin Veronal buffer ${ }^{2+}\left(0.5 x\right.$ VBS, $0.05 \%$ gelatin, $167 \mathrm{mM}$ glucose, $0.15 \mathrm{mM} \mathrm{CaCl}_{2}, 0.5$ $\mathrm{mM} \mathrm{MgCl} 2$ (DGVB++); volume 50 $\mu \mathrm{l}$ ) was mixed with serum (final dilution 1/10 in DGVB++, final volume of $100 \mu \mathrm{l})$, for $30 \mathrm{~min}$ at $37^{\circ} \mathrm{C}$. For the analysis of alternative pathway activity, a haemolytic assay for the alternative pathway was performed. Rabbit erythrocytes $\left(7 \times 10^{9}\right)$ suspended in DGVB++ containing $10 \mathrm{mM} \mathrm{MgEGTA}$ were incubated in a 1:1 ratio with human serum, final volume of $100 \mu \mathrm{l}$, for $30 \mathrm{~min}$ at $37^{\circ} \mathrm{C}$. For both assays, after the addition of $1.5 \mathrm{ml}$ of PBS and centrifugation, haemolysis was assessed by measuring absorbance at $414 \mathrm{~nm}$. The lytic activity of a sample was expressed in arbitrary units per $\mathrm{ml}$ using the following formula: Lytic activity = activity of the standard serum (U/ml) x (mean A414 (sample) - mean A414 (0 \%)) / (mean A414 (standard serum) - mean A414 (negative control)). In this formula, the A414 (0\%) represents incubation of EA with buffer only and the A414 (100\%) was assessed after the addition of $\mathrm{H}_{2} \mathrm{O}$. Normal haemolytic activity was defined as higher than $207 \mathrm{U} / \mathrm{ml}$ and higher than $52 \mathrm{U} / \mathrm{ml}$, for the classical pathway test and the alternative pathway test, respectively. 

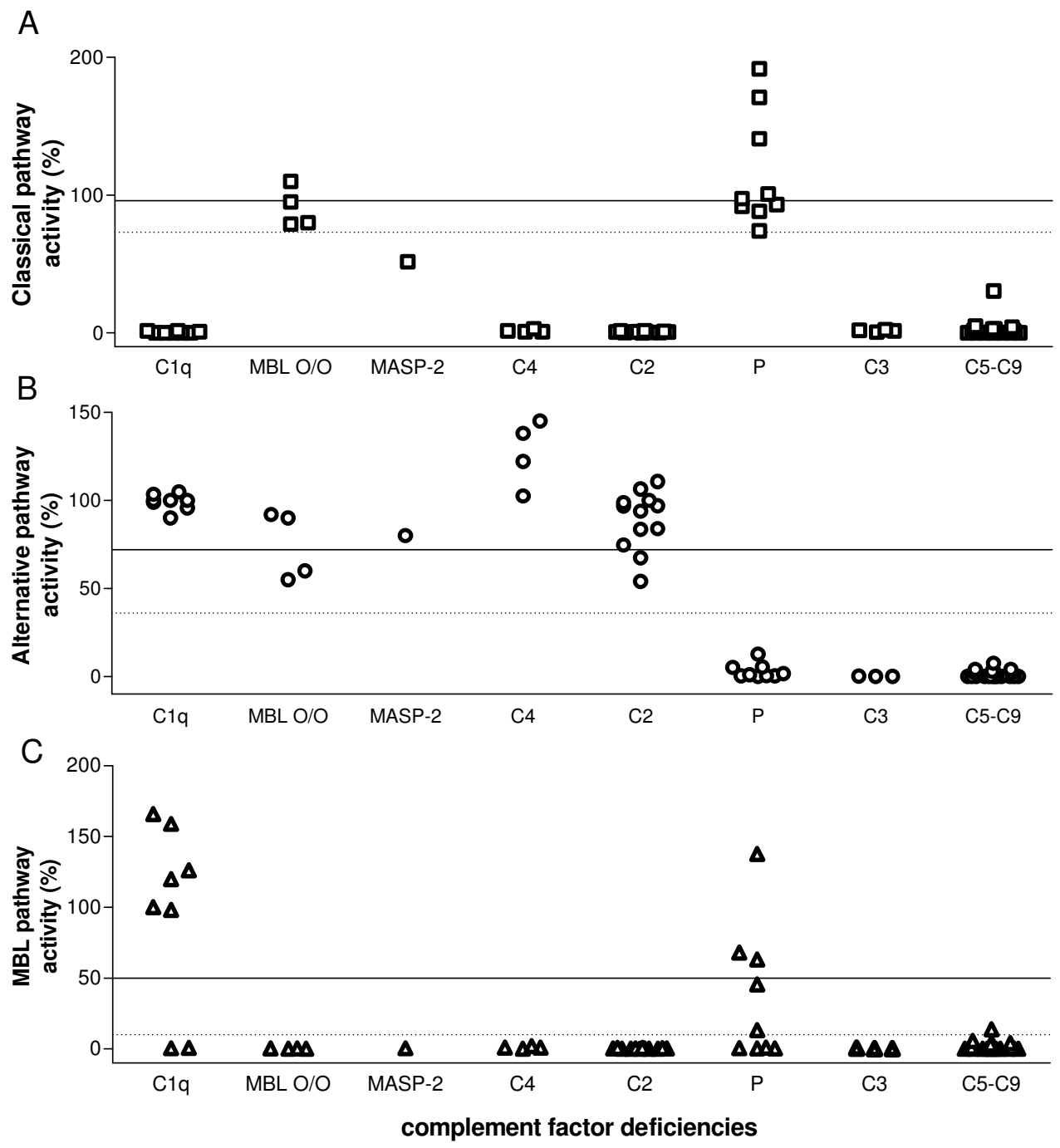

Figure 4 Serum samples with well-defined complement deficiencies were tested in the complement kit for complement pathway activity in the classical pathway (A), the alternative pathway $(B)$ and the MBL pathway (C). The group indicated as C5-C9 includes sera deficient in C5 $(n=3), C 6$ $(N=4), C 7(N=5), C 8(N=4)$ and $C 9(N=2)$. The group indicated as MBL 0/0 includes sera from donors known to be homozygous $(C / C, D / D)$ or compound homozygous $(B / D)$ for $M B L$ variant alleles. The group indicated as properdin $(P)$ deficiency included complete properdin deficiency $(N=5)$, incomplete properdin deficiency $(N=2)$, and properdin dysfunction $(N=2)$. The solid lines indicate the mean value of activity in the different assays for healthy control samples. The dotted lines indicate the lower cut off values for normal activity for the different pathways. 
A

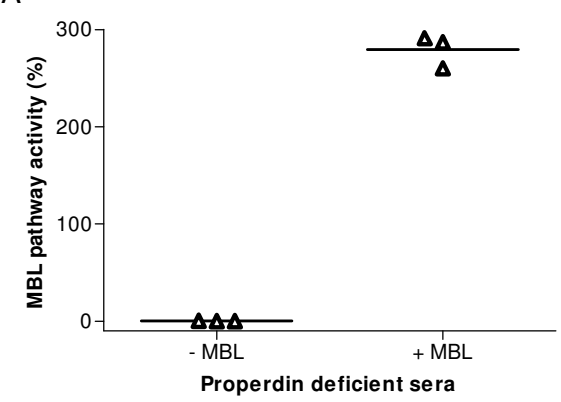

B

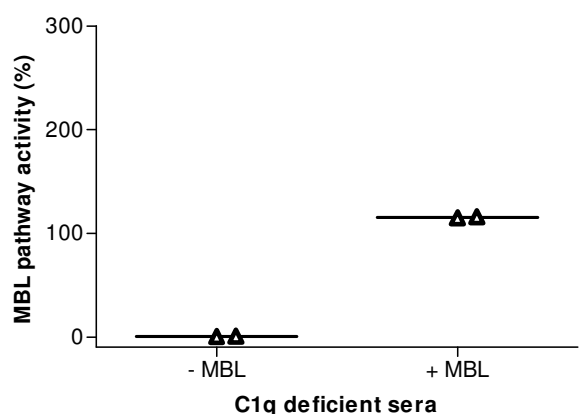

Figure 5 Three serum samples with known properdin deficiency $(A)$ and two samples with C1q deficiency $(B)$ had decreased $M B L$ pathway activity. After reconstitution with purified $M B L$, $M B L$ pathway activity was restored. The solid lines indicate the mean activity for $M B L$ pathway activity as assessed in healthy controls.

\section{Measurement of MBL serum concentrations}

Assessment of MBL concentrations was performed as described previously (Roos et al., 2001)

\section{Statistics}

The Spearman non-parametric correlation coefficient was used for statistical analysis. P-values below 0.05 were considered to be statistically significant.

\section{Results}

\section{Assessment of complement activity via three pathways in healthy donors}

Serum samples from 120 healthy controls were tested for classical pathway activity, alternative pathway activity and MBL pathway activity in three laboratories as described in the Materials and Methods section. The complement activity for each pathway was expressed as a percentage of the activity of a positive standard serum. For both the classical pathway (Fig. 1A) and the alternative pathway (Fig. 1B), complement activity was detectable in all healthy donors. The inter-individual variation for the alternative pathway was somewhat higher than that for the classical pathway. In contrast, a large inter-individual variation was observed for the activity of the MBL pathway of complement (Fig. 1C), with undetectable activity in a number of donors. Results for all three pathways of complement showed a highly significant correlation between the different laboratories. The correlation coefficients for the classical pathway activity, the alternative pathway activity and the MBL pathway activity were above 0.71 , above 0.67 and above $0.93(\mathrm{P}<0.001)$, respectively, for all three pairs of laboratories.

To determine the normal level of activity for the classical and the alternative pathways of complement activation, the mean percentage of activity of the results assessed in the three laboratories was calculated (Fig. 1D, E). The lower cutoff value of normal 
pathway activity for these pathways was defined as the mean percentage of activity minus two times the standard deviation. For the classical pathway activity the mean level of activity was $98 \%$ and the lower cutoff value of normal pathway activity was $74 \%$ (Fig 1D). For the alternative pathway the mean level of activity was $74 \%$ and the lower cutoff value was 39\% (Fig 1E). In contrast to the classical and alternative pathways of complement activation, the MBL pathway activity of the 120 samples showed a large variation. This variation was strongly dependent on the serum concentration of MBL (Fig. 1F). The threshold level of normal MBL pathway activity was arbitrarily set at $10 \%$, resulting in $28 \%$ of the healthy donor sera falling below this threshold (Fig. 1F). More than $90 \%$ of these sera had serum MBL concentrations below 300 $\mathrm{ng} / \mathrm{ml}$. The distributions of pathway activity, for the 120 sera tested, are shown in Figures 1G, 1H and 1I for, CP activity, AP activity and MBL-P activity, respectively.

As shown in Table 1, the intra-assay variation for the three pathways was below $7 \%$, whereas the inter-assay variation was below or equal to $20 \%$.

The results obtained by assessment of plasma samples either collected in heparin, EDTA or citrate showed reduced pathway activity when compared to the activity assessed in serum samples from the same patients (Fig 2).

\section{Correlation with hemolytic assessment of complement activity}

Currently in most diagnostic laboratories the functional activity of the classical and the alternative pathways of complement is assessed by a haemolytic assay, such as the $\mathrm{CH} 50$ for the classical pathway and the AP 50 for the alternative pathway. We selected 40 serum samples showing differing levels of classical pathway and alternative pathway haemolytic activity, and measured these samples in parallel for classical and alternative pathway activity using both hemolytic assays and the complement kit. As indicated in Figure 3, the results obtained in the complement kit showed a good correlation with the results obtained in the quantitative haemolytic assays, both for the classical pathway $(\mathrm{R}=0.89, \mathrm{P}<0.001)$ and for the alternative pathway $(\mathrm{R}=0.84, \mathrm{P}<$ 0.001). For the alternative pathway, the complement kit showed undetectable functional activity for all serum samples with an alternative pathway haemolytic activity below the normal value.

\section{Detection of complement deficiencies with the complement kit}

A total of 64 sera with different defined complement deficiencies were assessed for classical pathway, alternative pathway and MBL pathway activity in the complement kit (Fig 4 A-C).

C1q deficient serum samples showed undetectable classical pathway activity, whereas alternative pathway activity was within the normal range and MBL pathway activity showed a distribution similar to that seen in healthy donors. Serum samples from well characterized MBL variant genotypes showed no detectable MBL pathway activity whereas classical and alternative pathway activities were normal. The MBL pathway was also deficient in a MASP-2-deficient serum sample. Serum samples deficient in C4 or $\mathrm{C} 2$ showed normal alternative pathway activity and undetectable classical and MBL pathway activity. Alternative pathway activity was decreased in all properdin-defi- 

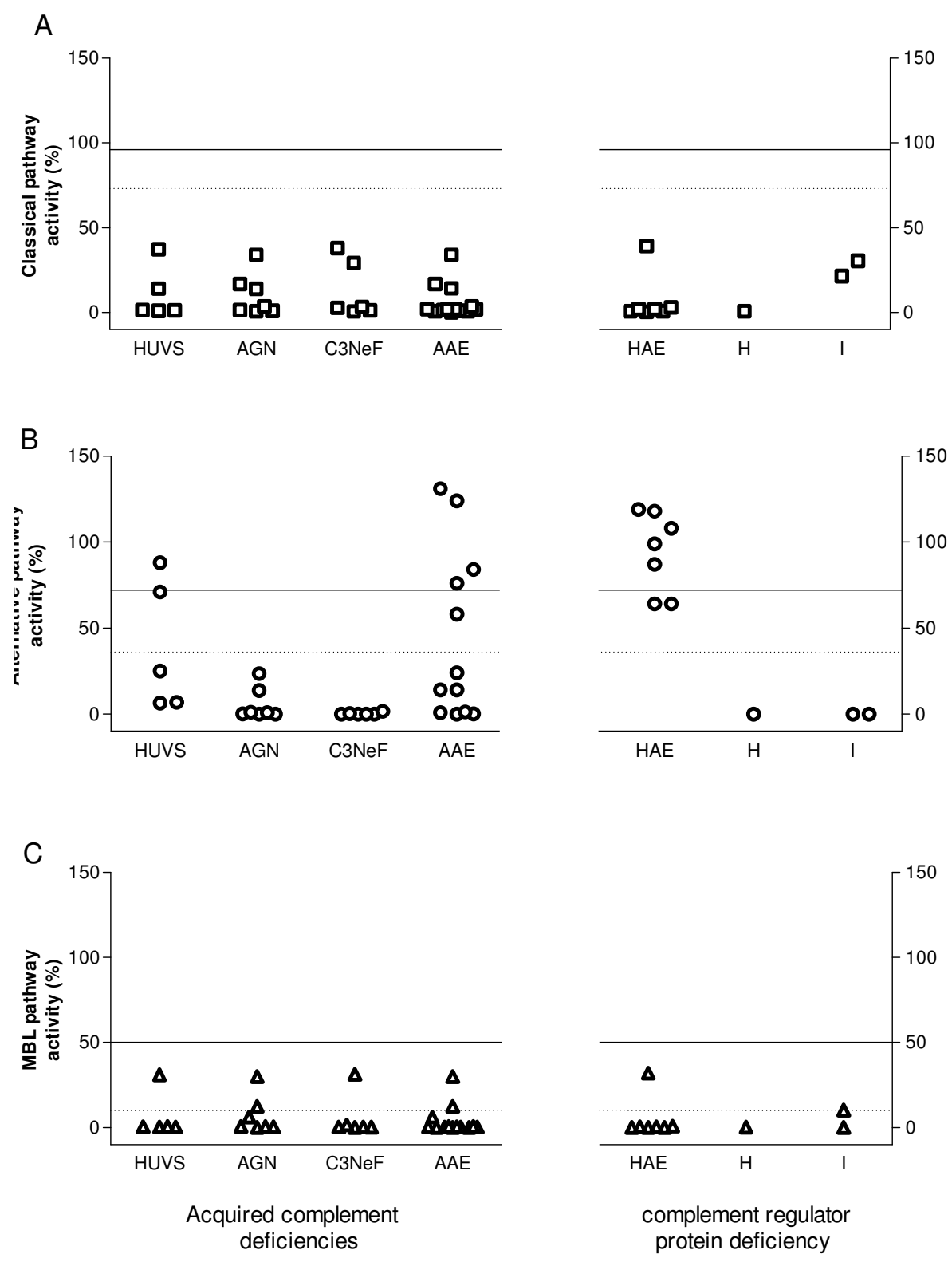

Figure 6 Serum samples with acquired complement deficiencies and deficiencies of complement regulatory proteins were tested for complement activity via the classical pathway $(A)$, the alternative pathway $(B)$ and the MBL pathway $(C)$ in the complement kit. The solid lines indicate the mean activity for the different pathways as assessed in healthy controls. The dotted lines are the cut off values for normal activity in the different pathways. 
cient sera whereas classical pathway activity was normal and MBL pathway activity was low in some, but not all of the sera. As expected, because of the central position of C3 in all three pathways of complement activation, no detectable activity was found in any of the pathways when C3-deficient sera were analyzed. Similarly, sera deficient in complement components of the final common pathway (C5b-9) showed, as anticipated, no activity in any of the three pathways. Taken together, in well-defined complement-deficient sera, the activity of the involved pathway(s), when assessed in the complement kit were below 10\% compared to a standard serum. Among the samples tested one C9-deficient serum showed slightly more than 10\% classical pathway activity while one serum with incomplete properdin deficiency (properdin deficiency type 2) showed slightly more than $10 \%$ alternative pathway activity. With this possible exception the three known phenotypic variants of properdin deficiency (Sjoholm 2002) were all correctly identified with the present ELISA.

MBL deficiency is frequently found in apparently healthy individuals. Therefore, a combined deficiency of properdin and MBL or C1q and MBL was suspected in sera showing a decreased activity in more than one of the pathways. By adding purified MBL to these sera the MBL pathway activity was restored, demonstrating a combined properdin and MBL deficiency, and combined C1q and MBL deficiency, respectively, in these sera (Fig 5A and B).

Impaired complement activation can be found in sera from patients with a genetically determined complement deficiency, as shown above, but complement consumption can also be an explanation for diminished pathway activity. Therefore, sera were collected from patients with disease or having deficiencies of regulatory proteins that might cause complement consumption. For this purpose, sera from patients with HUVS, HAE, AAE, acute post- AGN and sera from patients with C3NeF, were tested in the complement kit. In addition, serum samples with a genetic factor I or factor $\mathrm{H}$ deficiency were tested.

Sustained in vivo complement activation as found in the diseases mentioned above leads to complement deficiencies with decreased activity of one or more of the pathways of complement activation and this was confirmed using the present kit (Figure 6). Also deficiencies of regulatory proteins of the alternative pathway of complement causes consumption of complement components including $\mathrm{C} 3$ and therefore decreased pathway activity in all three pathways of activation.

\section{Discussion}

Haemolytic assays to assess the functional activity of the classical and the alternative pathways of complement activation have been available for some years. However, for the MBL pathway no comparable assay exists. In order to assess the functional activity of the MBL pathway an ELISA has been developed in which the activity of the pathway from MBL through to C9 is assessed in whole serum (Roos et al., 2003). The degree of activity is assessed as the amount of C5b-9 that is generated and bound in 
ELISA wells coated with mannan. At the same time it is possible to measure classical and alternative pathway activation using specific reagents and coatings. These three assays have now been combined in one kit, called the complement kit, and make it possible to identify defects in any of the three initiating pathways and the terminal sequence of complement activation in any given serum sample. The standardisation and validation of this assay revealed it to be a sensitive, specific and simple assay for the detection of complement deficiencies.

The results obtained in three different laboratories using 120 serum samples from healthy donors tested for the three pathways correlated well. Because of the limited variation of complement activity between different sera, particularly in the classical pathway but also in the alternative pathway, a cut off value for normal pathway activity could be defined as the mean value of activity minus two times the standard deviation. This approach resulted in $2.5 \%$ of the healthy population falling below the cutoff value for normal complement activity. The mean value of activity in the alternative pathway for the 120 sera was $74 \%$ of the standard serum alternative pathway activity. Because of the variation in alternative pathway activity observed in sera from healthy individuals we conclude that the pool of sera used in the standard had relatively high alternative pathway activity compared to the donor samples tested.

For MBL pathway activity a different method was required to define a cut off value. Because of the variation in MBL concentration in the normal healthy population, which is mainly genetically determined (Garred et al., 2003), there is also a large variation in MBL pathway activity, with a distribution skewed to the left, as confirmed in the present study. Here an arbitrary minimum level for normal MBL pathway activity was set at $10 \%$ of the standard, which corresponded to MBL concentrations below 300 $\mathrm{ng} / \mathrm{ml}$. Using this threshold level, $98 \%$ of the serum samples with reduced MBL pathway activity had serum MBL concentrations below $300 \mathrm{ng} / \mathrm{ml}$. Studies on the association of low MBL serum concentrations and susceptibility to disease such as infections have shown that patients with serum MBL levels below approximately 300 $\mathrm{ng} / \mathrm{ml}$ are at risk (Sumiya et al., 1991; Peterslund et al., 2001). Therefore, a cut off value of $10 \%$ for MBL-P activity is expected to be useful for the detection of MBL deficiency in the complement kit.

An important practical observation was that plasma samples showed decreased pathway activity compared to serum samples from the same patients. This was especially true for heparinised plasma used for MBL pathway estimations. Reduced pathway activity in plasma samples could be explained by dissociation of C1 complexes and MBL-MASP complexes in a calcium-free environment. It takes time to reassociate these complexes, which makes the complement activation less efficient. Furthermore, anticoagulants may bind to complement factors, thereby influencing their activity. This binding is not reversed when diluting the sample. Therefore, only serum samples should be used to quantify pathway activity in the complement kit. Complement activity in sera deficient in individual complement components was below $10 \%$ in either one or more pathways. Combined complement deficiencies in the MBL pathway and the alternative pathway were demonstrated as well as combined complement deficiencies in the MBL pathway and classical pathway of complement 
activation. MBL pathway activity was reconstituted when purified MBL was added to these sera. The results obtained demonstrate the value of the complement kit in the detection of combined deficiencies in one assay.

Sera from patients diagnosed with diseases known to cause complement consumption were also tested with the complement kit. Decreased activity in all three pathways was demonstrated in most of these sera. Consumption of components of the classical pathway in patients with hereditary and acquired angioedema is caused by deficient or non-functional C1-INH (Carugati et al., 2001). C4 and C2 are consumed depending on the degree of disease activity and, in some patients with AAE, C3 levels are also low. The present findings were consistent with this. In patients with HUVS, C1q in serum is depleted in the presence of anti-C1q autoantibodies and the classical pathway is activated (Wisnieski 2000). In patients with acute post-streptococcal glomerulonephritis the alternative pathway is predominantly activated and the classical pathway of complement can also be activated via immune complexes (Sjoholm 1979). The autoantibody $\mathrm{C} 3 \mathrm{NeF}$ stabilises the $\mathrm{C} 3$ convertase causing enhanced $\mathrm{C} 3$ activation (Daha and van Es 1979). Accordingly, all these conditions are associated with strongly enhanced complement consumption, which was reflected in our data showing decreased complement activity in all three pathways. Complement deficiency is also found in patients with a deficiency in regulatory complement components of the alternative pathway. Patients with factor $\mathrm{H}$ and I deficiency showed decreased activity in all pathways because of secondary C3 deficiency (Sjoholm 2002). Collectively, the results demonstrate the value of the complement kit in the detection of acquired complement deficiencies as well as genetic defects.

Assays measuring haemolysis of erythrocytes by complement activation either via the classical or alternative pathway are used on a routine basis to assess the functional activity of these pathways. To compare the results of complement activation by the classical and alternative pathways assessed by haemolytic assays or the complement kit, serum samples were tested in parallel using both methods. A strong correlation was found between the results obtained by the haemolytic assay compared with those in the complement kit. Compared to the original definition of AP50 and CH50 different type of calculation is used to obtain the results in the present complement assays. Results from the latter assays were originally defined by titration. Therefore, the results of the complement kit, expressed as percent of activity of a standard serum, cannot be used as a direct quantitative description of the complement defect. However, in view of the reproducibility and simplicity of the complement kit, this method should be regarded as preferable to haemolytic assays for screening of classical and alternative pathway activity in clinical practice. In patients suspected of having a deficiency of the humoral immune system the complement system should be screened for deficiencies and immunoglobulin quantity should be assessed. Complement deficiencies in any of the three pathways of complement activation can easily be detected in the new combined assays. We have shown the results of assaying sixty-four sera deficient in one or more of eleven different components of the classical, alternative and MBL pathways. When, after confirmation in a second independent sample, the screening assays suggest a complement deficiency, samples should be further analysed in 
specialist laboratories for precise identification of the deficient component.

In conclusion, a simple assay with a uniform design has been developed by which it is possible to evaluate functional activity of the three pathways of complement activation in parallel. The assay results are reproducible between different laboratories and standardization of the assay will permit its use for patient diagnostics. In this respect we have shown that the assay is able to detect genetic complement deficiencies at all levels of the complement cascade, as well as acquired complement deficiencies associated with in vivo complement consumption.

\section{Acknowledgements}

This work was supported by grants from the European Union (QLGT-CT2001-01039) and the Dutch Kidney Foundation (PC 95, C98-1763). Research at the Institute of Child Health and the Great Dimond Street Hospital for Children National Health Service Trust benefits from research and development funding received from the National Health Service Executive.

\section{References}

1. Aderem A. and Underhill D.M. (1999) Mechanisms of phagocytosis in macrophages. Annu.Rev.Immunol. 17, 593-623.

2. Carugati A., Pappalardo E., Zingale L.C. and Cicardi M. (2001) C1-inhibitor deficiency and angioedema. Mol.Immunol. 38, 161-173.

3. Daha M.R. and van Es L.A. (1979) Activation of the classical pathway of complement by the C3NeFstabilized cell-bound amplification convertase. J.Immunol. 122, 801-805.

4. Davies E.J., Snowden N., Hillarby M.C., Carthy D., Grennan D.M., Thomson W. and Ollier W.E. (1995) Mannose-binding protein gene polymorphism in systemic lupus erythematosus. Arthritis Rheum. 38, 110-114.

5. Eisen D.P. and Minchinton R.M. (2003) Impact of mannose-binding lectin on susceptibility to infectious diseases. Clin.Infect.Dis. 37, 1496-1505.

6. Fredrikson G.N., Truedsson L. and Sjoholm A.G. (1993) New procedure for the detection of complement deficiency by ELISA. Analysis of activation pathways and circumvention of rheumatoid factor influence. J.Immunol.Methods 166, 263-270.

7. Garred P., Larsen F., Madsen H.O. and Koch C. (2003) Mannose-binding lectin deficiency--revisited Mol.Immunol. 40, 73-84.

8. Garred P., Madsen H.O., Marquart H., Hansen T.M., Sorensen S.F., Petersen J., Volck B., Svejgaard A., Graudal N.A., Rudd P.M., Dwek R.A., Sim R.B. and Andersen V. (2000) Two edged role of mannose binding lectin in rheumatoid arthritis: a cross sectional study. J.Rheumatol. 27, 26-34.

9. Garred P., Strom J., Quist L., Taaning E. and Madsen H.O. (2003) Association of mannose-binding lectin polymorphisms with sepsis and fatal outcome, in patients with systemic inflammatory response syndrome. J.Infect.Dis. 188, 1394-1403.

10. Ikeda K., Sannoh T., Kawasaki N., Kawasaki T. and Yamashina I. (1987) Serum lectin with known structure activates complement through the classical pathway. J.Biol.Chem. 262, 7451-7454. 
11. Jack D.L., Klein N.J. and Turner M.W. (2001) Mannose-binding lectin: targeting the microbial world for complement attack and opsonophagocytosis. Immunol.Rev. 180, 86-99.

12. Kuipers S., Aerts P.C., Sjoholm A.G., Harmsen T. and van Dijk H. (2002) A hemolytic assay for the estimation of functional mannose-binding lectin levels in human serum. J.Immunol.Methods 268, 149-157.

13. Lipscombe, R.J., Sumiya, M., Hill, A.V., Lau, Y.L., Levinsky, R.J., Summerfield, J.A., Turner, M.W., 1992. High freguencies in African and non-African populations of independant mutations in the mannose binding protein gene. Hum. Mol. Genet. 1, 709-715.

14. Madsen H.O., Garred P., Thiel S., Kurtzhals J.A., Lamm L.U., Ryder L.P. and Svejgaard A. (1995) Interplay between promoter and structural gene variants control basal serum level of mannan-binding protein. J.Immunol. 155, 3013-3020.

15. Matsushita M., Endo Y. and Fujita T. (2000) Cutting edge: complement-activating complex of ficolin and mannose-binding lectin-associated serine protease. J.Immunol. 164, 2281-2284.

16. Matsushita M., Kuraya M., Hamasaki N., Tsujimura M., Shiraki H. and Fujita T. (2002) Activation of the lectin complement pathway by H-ficolin (Hakata antigen). J.Immunol. 168, 3502-3506.

17. Minchinton R.M., Dean M.M., Clark T.R., Heatley S. and Mullighan C.G. (2002) Analysis of the relationship between mannose-binding lectin (MBL) genotype, MBL levels and function in an Australian blood donor population. Scand.J.Immunol. 56, 630-641.

18. Petersen S.V., Thiel S., Jensen L., Steffensen R. and Jensenius J.C. (2001) An assay for the mannanbinding lectin pathway of complement activation. J.Immunol.Methods 257, 107-116.

19. Peterslund N.A., Koch C., Jensenius J.C. and Thiel S. (2001) Association between deficiency of mannose-binding lectin and severe infections after chemotherapy. Lancet 358, 637-638.

20. Pickering M.C., Botto M., Taylor P.R., Lachmann P.J. and Walport M.J. (2000) Systemic lupus erythematosus, complement deficiency, and apoptosis. Adv.Immunol. 76, 227-324.

21. Roos A., Bouwman L.H., Gijlswijk-Janssen D.J., Faber-Krol M.C., Stahl G.L. and Daha M.R. (2001) Human IgA activates the complement system via the mannan-binding lectin pathway. J.Immunol. $167,2861-2868$.

22. Roos A., Bouwman L.H., Munoz J., Zuiverloon T., Faber-Krol M.C., Fallaux-van den Houten FC, Klar-Mohamad N., Hack C.E., Tilanus M.G. and Daha M.R. (2003) Functional characterization of the lectin pathway of complement in human serum. Mol.Immunol. 39, 655-668.

23. Sjoholm A.G. (1979) Complement components and complement activation in acute poststreptococcal glomerulonephritis. Int.Arch.Allergy Appl.Immunol. 58, 274-284.

24. Sjoholm A.G. (2002) Deficiencies of mannose-binding lectin, the alternative pathway, and the late complement components. In Manual of Clinical Laboratory Immunology (Edited by Rose NR, Hamilton RG, and Detrick B), pp. 847-854. ASM Press, Washington.

25. Stengaard-Pedersen K., Thiel S., Gadjeva M., Moller-Kristensen M., Sorensen R., Jensen L.T., Sjoholm A.G., Fugger L. and Jensenius J.C. (2003) Inherited deficiency of mannan-binding lectin-associated serine protease 2. N.Engl.J.Med. 349, 554-560.

26. Sumiya M., Super M., Tabona P., Levinsky R.J., Arai T., Turner M.W. and Summerfield J.A. (1991) Molecular basis of opsonic defect in immunodeficient children. Lancet 337, 1569-1570. 
27. Turner M.W. and Hamvas R.M. (2000) Mannose-binding lectin: structure, function, genetics and disease associations. Rev.Immunogenet. 2, 305-322.

28. Walport M.J. (2001) Complement. First of two parts. N.Engl.J.Med. 344, 1058-1066.

Wisnieski J.J. (2000) Urticarial vasculitis. Curr.Opin.Rheumatol. 12, 24-31. 


\title{
Chapter 6
}

\section{Age and gender-associated changes of complement activity in a healthy Caucasian population}

\author{
Seelen $M A^{1}$, Mollnes $T E^{2}$, Sjöholm $A G^{3}$, Turner $M W^{4}$, Wieslander $J^{5}$, \\ Daha $M R^{1}$, Roos $A^{1}$
}

1. Department of Nephrology, Leiden University Medical Center, Leiden, The Netherlands.

2. Institute of Immunology, Rikshospitalet University Hospital,

$$
\text { Oslo, Norway. }
$$

3. Institute of Laboratory Medicine, Section of Microbiology, Immunology and Glycobiology,Lund University, Lund, Sweden. 4. Immunobiology Unit, Institute of Child Health, London, UK 5. Wieslab IDEON Lund, Sweden. 


\section{Abstract}

A functionally active complement system is an essential element of an adequate innate immune response. Complement activity depends on the level and function of a large number of complement molecules. Much attention has been given to the development of the complement system in the time period after birth and before development of a fully functional adaptive immune system. Ageing is associated with a progressive decline in immunity. Not much is known on the effect of ageing on functional activity of the complement system.

Functional activity of the classical pathway $(\mathrm{CP})$, alternative pathway $(\mathrm{AP})$ and lectin pathway initiated via MBL (MBL-P) was determined in sera from 120 healthy adults using a novel ELISA-based method. Age- and gender-dependent differences in activity of the three complement pathways were studied. In addition, levels of C1q, C2, C4, factor B and C3 were determined.

Significantly lower AP activity and lower serum concentrations of MBL and C3, but higher factor B levels, were found in females compared to males. The CP and AP activity increased during ageing, whereas an age-dependent decrease in MBL-P activity and MBL serum concentration was found. C2 and factor B levels increased with age in contrast to a decrease of the $\mathrm{C} 1 \mathrm{q}$ and $\mathrm{C} 3$ level. CP activity showed a strong correlation with $\mathrm{C} 2$ levels. Furthermore, the results suggest a co-regulation of complement genes present in the MHC class III region (factor B, C2 and C4), presumably resulting in a correlation between AP and CP activity, as well as between levels of these molecules and activity of the $\mathrm{CP}$ and $\mathrm{AP}$, respectively. MBL-P activity was only significantly correlated with MBL serum concentration. The results from this study do not support an important role of a functional MBL pathway for longevity. Enhanced CP activity and AP activity might partially compensate for a decline in immune defence with age.

\section{Introduction}

The complement system, a major component of innate immunity, plays a crucial role in immune defence against invasive microorganisms in particular during early childhood ${ }^{1 ; 2}$. Deficiencies of complement components can cause severe and recurrent infections. Furthermore, complement deficiencies are associated with systemic diseases such as systemic lupus erythematosus (SLE) ${ }^{3}$, haemolytic uremic syndrome (HUS) ${ }^{4}$ and kidney diseases ${ }^{5}$.

Ageing is associated with a progressive decline in immunity. The impact of ageing on adaptive immunity is well accepted ${ }^{6 ; 7}$. However, less certainty exists on the effect of ageing on innate immunity. Impaired function of neutrophils and macrophages as well as reduced interaction between dendritic cells and $\mathrm{T}$ cells, suggest also a decline in innate immune function ${ }^{8 ; 9}$. As a result of impaired immune function, the ability of elderly to respond to microorganisms is diminished and the number of infectious diseases is increased. Also the increased incidence of autoimmune diseases might be related to altered immunity in elderly ${ }^{10}$. 
The complement system is activated via an enzymatic cascade reaction involving three different activation pathways, namely the classical pathway, the lectin pathway, and the alternative pathway. Complement activity for each of these pathways depends on the expression and function of a large number of complement proteins, and genetic complement deficiencies are described in the great majority of these molecules. These complement deficiencies are associated with various diseases, in many cases via enhanced susceptibility to infections. Furthermore, quantitative and qualitative variation in complement proteins may occur, both due to genetic and environmental factors.

Deficiency of MBL, one of the three major initiators of the lectin pathway of complement, is the most common complement deficiency in man ${ }^{11}$. A decreased MBL function is found in about $30 \%$ of the population and approximately $10 \%$ is deficient for MBL. The importance of the MBL-pathway of complement activation has been demonstrated by the enhanced frequencies of severe infections in childhood. In early childhood the immune defence against microorganism is mainly dependent on innate immunity, i.e. the complement system, because adaptive immunity still has to be developed. Adults, after being treated with bone marrow-ablative therapy, and therefore without functional adaptive immunity, with low MBL levels are also more prone to infections ${ }^{12}$. These findings indicate that the MBL pathway is important when adaptive immunity is insufficient. Because of a decline in adaptive immunity in elderly, an impaired functional activity of the lectin pathway with age could be of influence on the defence against invasive microorganisms.

On the other hand a recent report showed the backside of MBL in patients with insulin-dependent diabetes mellitus, showing that MBL may be involved in the pathogenesis of micro- and macro-vascular complications ${ }^{13}$. Therefore, a decline in functional activity of the MBL pathway could also be an advantage for longevity.

With the use of a recently developed combined assay to assess the functional activity of the classical pathway, the alternative pathway and the MBL-induced lectin pathway (MBL-P) of complement, the effect of ageing on the complement system and differences in pathway activity between genders were analysed. Furthermore, quantitative analysis of key components of the different complement activation pathways was performed in order to explain the variation of complement activity in the human population.

\section{Materials and methods}

\section{Serum samples}

From a population of 120 healthy individuals, registered as blood donors, serum samples were obtained. Sixty females with a mean age of 44.7 years (20-69 years) and 60 males with a mean age of 45.1 years (20-65 years) were included. Serum samples obtained were directly aliquoted and stored at $-80^{\circ} \mathrm{C}$. 
Table1. Correlation coefficients $(*)$ between the functional activity of three complement pathways and serum complement levels in healthy adults.

\begin{tabular}{|c|c|c|c|c|c|c|c|c|c|}
\hline & $\mathrm{CP}$ & $\mathrm{AP}$ & MBL-P & C1-q & MBL & C4 & $\mathrm{C} 2$ & $f B$ & Age \\
\hline $\mathrm{CP}$ & - & - & 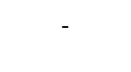 & - & - & - & - & - & $\begin{array}{c}0.41 \\
P<0.0001\end{array}$ \\
\hline$A P$ & $\begin{array}{c}0.44 \\
P<0.0001\end{array}$ & - & - & - & - & - & - & - & $\begin{array}{c}0.29 \\
P=0.0012\end{array}$ \\
\hline MBL-P & $\begin{array}{c}-0.04 \\
\text { NS }\end{array}$ & $\begin{array}{c}0.009 \\
\text { NS }\end{array}$ & - & - & - & - & - & - & $\begin{array}{c}-0.14 \\
P=0.13\end{array}$ \\
\hline $\mathrm{C} 1 \mathrm{q}$ & $\begin{array}{c}-0.02 \\
\text { NS }\end{array}$ & $\begin{array}{c}-0.012 \\
\text { NS }\end{array}$ & $\begin{array}{c}0.04 \\
\text { NS }\end{array}$ & - & - & - & - & - & $\begin{array}{c}-0.18 \\
P=0.048\end{array}$ \\
\hline MBL & $\begin{array}{c}-0.04 \\
\text { NS }\end{array}$ & $\begin{array}{c}-0.04 \\
\text { NS }\end{array}$ & $\begin{array}{c}0.89 \\
P<0.0001\end{array}$ & $\begin{array}{l}-0.05 \\
\text { NS }\end{array}$ & - & - & - & - & $\begin{array}{c}-0.16 \\
P=0.09\end{array}$ \\
\hline $\mathrm{C} 4$ & $\begin{array}{l}0.01 \\
\text { NS }\end{array}$ & $\begin{array}{c}0.38 \\
P<0.0001\end{array}$ & $\begin{array}{c}0.000 \\
\text { NS }\end{array}$ & $\begin{array}{l}-0.08 \\
\text { NS }\end{array}$ & $\begin{array}{c}-0.07 \\
\text { NS }\end{array}$ & - & - & - & $\begin{array}{c}-0.06 \\
\text { NS }\end{array}$ \\
\hline $\mathrm{C} 2$ & $\begin{array}{c}0.51 \\
P<0.0001\end{array}$ & $\begin{array}{c}0.35 \\
P=0.0001\end{array}$ & $\begin{array}{c}-0.07 \\
\text { NS }\end{array}$ & $\begin{array}{l}0.02 \\
\text { NS }\end{array}$ & $\begin{array}{c}-0.04 \\
\text { NS }\end{array}$ & $\begin{array}{c}0.18 \\
P=0.07\end{array}$ & - & - & $\begin{array}{c}0.28 \\
P=0.0019\end{array}$ \\
\hline$f B$ & $\begin{array}{c}0.30 \\
P=0.001\end{array}$ & $\begin{array}{c}0.51 \\
P<0.0001\end{array}$ & $\begin{array}{l}0.03 \\
\text { NS }\end{array}$ & $\begin{array}{c}-0.13 \\
\text { NS }\end{array}$ & $\begin{array}{l}0.05 \\
\text { NS }\end{array}$ & $\begin{array}{c}0.39 \\
P<0.0001\end{array}$ & $\begin{array}{c}0.42 \\
P<0.0001\end{array}$ & - & $\begin{array}{c}0.27 \\
P=0.0027\end{array}$ \\
\hline C3 & $\begin{array}{l}0.02 \\
\text { NS }\end{array}$ & $\begin{array}{c}0.102 \\
\text { NS }\end{array}$ & $\begin{array}{l}0.17 \\
\text { NS }\end{array}$ & $\begin{array}{c}0.29 \\
P=0.002\end{array}$ & $\begin{array}{c}0.06 \\
\text { NS }\end{array}$ & $\begin{array}{c}0.31 \\
P=0.0012\end{array}$ & $\begin{array}{l}0.12 \\
\text { NS }\end{array}$ & $\begin{array}{c}0.14 \\
\text { NS }\end{array}$ & $\begin{array}{c}-0.33 \\
\mathbf{P}=\mathbf{0 . 0 0 0 2}\end{array}$ \\
\hline
\end{tabular}

Assessment of pathway activity in normal human serum samples using the complement kit

The complement kit for assessment of classical, alternative and MBL-induced lectin pathway activity was used according to the manufacturer's instructions. In brief, strips of wells for classical pathway (CP) evaluation were pre-coated with IgM, strips for alternative pathway (AP) determination were coated with LPS and MBL-induced lectin pathway (MBL-P) strips were coated with mannan. Sera were diluted 1/101 for the $\mathrm{CP}$ and MBL-P assay and 1/18 for the AP assay in specific buffers to ensure that activation of only one of the pathways occurred, and were incubated for $1 \mathrm{~h}$ at $37^{\circ} \mathrm{C}$. After washing the strips, alkaline phosphatase-conjugated anti-human C5b-9 was added before incubation at room temperature for $30 \mathrm{~min}$. Additional washing was performed, substrate was added and the wells were incubated for $30 \mathrm{~min}$. Finally, absorbance values were read at $405 \mathrm{~nm}$. In each assay standard positive and negative control sera, provided in the kit as lyophilised material and reconstituted with distilled water, were assessed. The positive standard serum was a pool of 5 sera from healthy individuals and the negative control consisted of sera heat-inactivated at $56^{\circ} \mathrm{C}$ for $20 \mathrm{~min}$. Complement activity was calculated using the following formula: Activity $=100 \% \mathrm{x}$ 


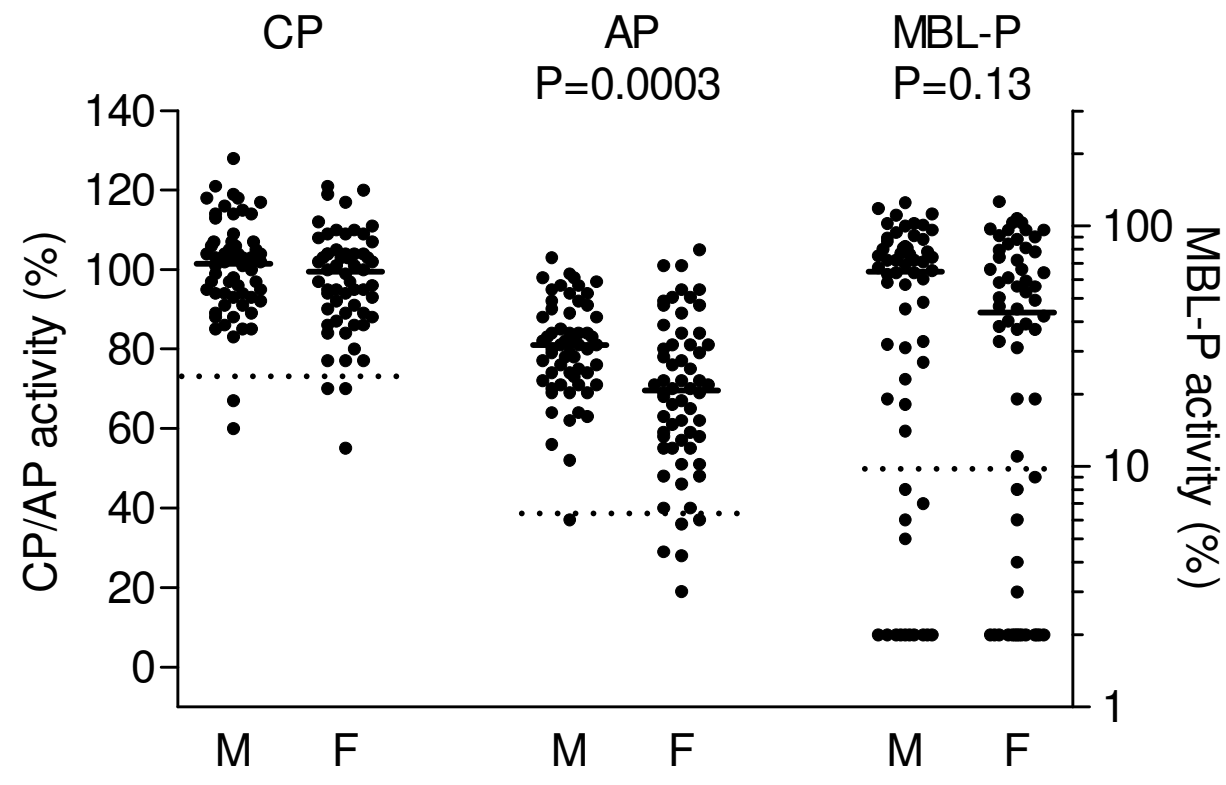

Figure 1. Complement activity and gender

The classical pathway activity, the alternative pathway activity and the MBL pathway activity were determined in 120 sera from both healthy men $(M)$ and females $(F)$. The solid lines indicate the median values of the samples tested and the dotted lines indicate the cut off values for normal pathway activity.

(mean A405 (sample) - mean A405 (negative control) / (mean A405 (standard serum) mean A405 (negative control). Samples as well as standard serum and negative control serum were tested in duplicate at a fixed dilution. Cut off values were defined as the mean minus two times the standard deviation of the complement activity of all samples for each pathway.

\section{Serum complement concentrations}

Assessment of MBL concentrations was performed as described previously ${ }^{14}$. C1q, C4 and C3 concentrations were assessed using radial immunodiffusion. C2 and factor B were measured using rocket-immunoelectrophoresis as described by Sjöholm et al. ${ }^{15}$

\section{Statistics}

The Mann Whitney test was used for statistical analysis. Correlation was evaluated using the Spearman Rank correlation coefficient $(\mathrm{R})$. P-values $<0.05$ were considered to be statistically significant. 

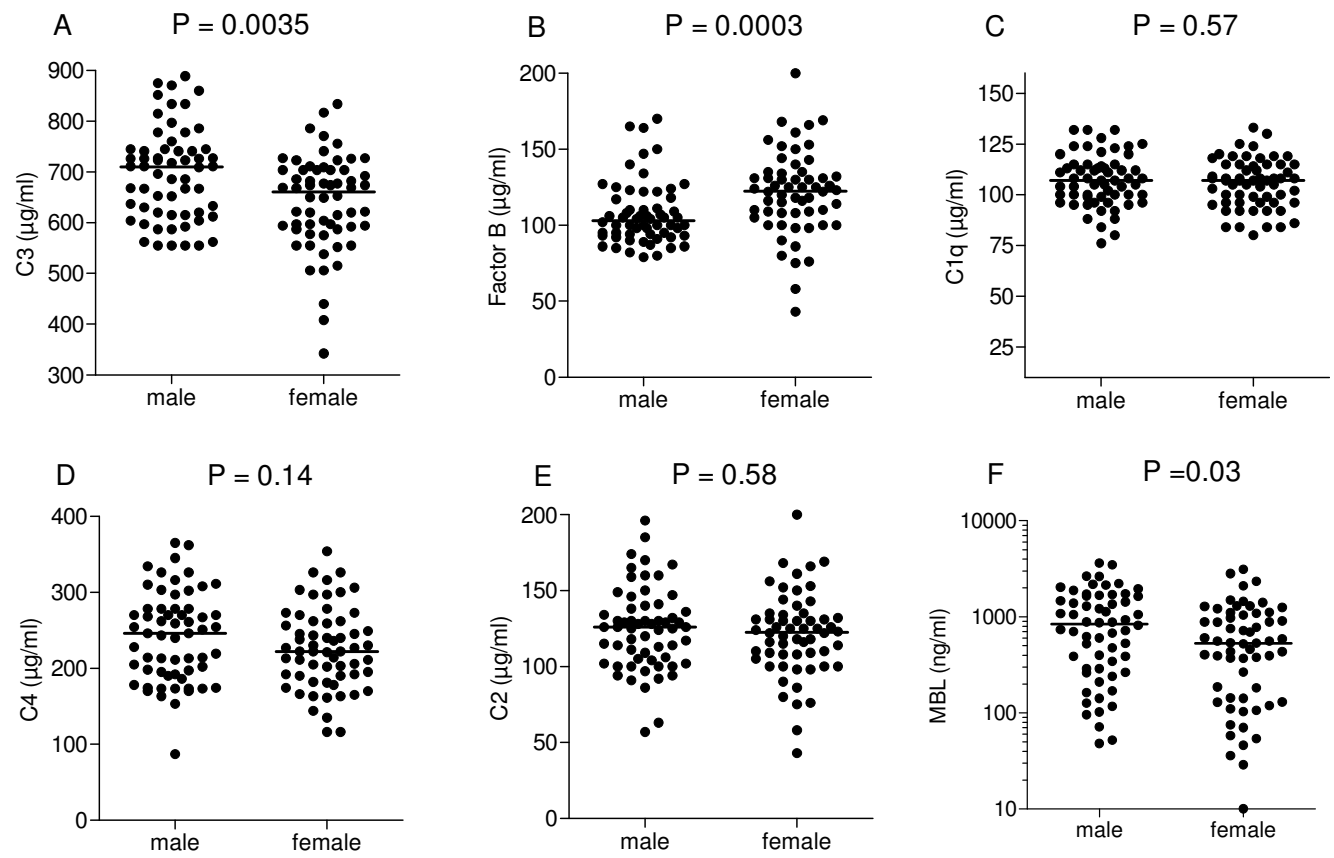

Figure 2. Complement concentration and gender

The concentration of $C 3(A)$, factor $(B), C 1 q(C), C 4(D), C 2(E)$ and factor $B(F)$ were assessed in all samples from males and females. The solid lines indicate the median values of the samples tested.

\section{Results}

\section{Complement pathway activity in females and males}

Classical pathway (CP), alternative pathway (AP) and MBL-induced lectin pathway (MBL-P) activity in serum samples from 60 males (mean age of 45.1 years, range 20-65 years) and 60 females (mean age of 44.7 years, range 20-69 years) were determined and analysed for differences between genders. CP activity and MBL-P activity were comparable between males and females (Fig 1). However, AP activity was significant lower for females. The median AP activity for females was $70 \%$ compared with $81 \%$ for males $(\mathrm{P}=0.0003)$ (Fig 1). Difference in AP activity could possibly be due to differences in concentration of one of the crucial factors of the AP namely, C3. The median C3 concentration for females was $661 \mathrm{ng} / \mathrm{ml}$ (range 342-834 ng/ml) compared to $710 \mathrm{ng} / \mathrm{ml}$ (range $555-889 \mathrm{ng} / \mathrm{ml}$ ) for males $(\mathrm{P}=0.0035)$ (Fig. 2A). To study differences in alternative pathway in more detail also factor B levels were assessed. Surprisingly, factor B levels were significantly enhanced in females compared to males $(\mathrm{P}=0.0003)$ (Fig $2 \mathrm{~B})$. $\mathrm{CP}$ activity was similar between genders, as well as serum levels for $\mathrm{C} 1 \mathrm{q}, \mathrm{C} 4$ and $\mathrm{C} 2$ (Fig. 2C-D). A trend for lower MBL pathway activity, however not significant, in females compared to males was found $(\mathrm{P}=0.13)$. Accordingly, MBL serum concentrations 

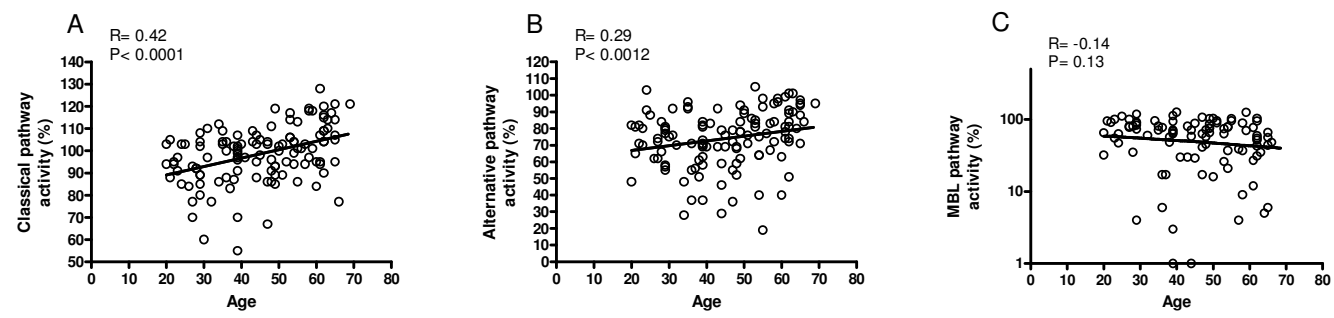

Figure 3 Complement activity and ageing

Correlations between age and the classical pathway activity $(A)$, between age and the alternative pathway activity $(C)$ and between age and the $M B L$ pathway activity were assessed. Statistical analysis was performed by Spearman Rank correlation test.

were significantly lower in females. The median MBL concentration for females was $533 \mathrm{ng} / \mathrm{ml}$ compared to $843 \mathrm{ng} / \mathrm{ml}$ for males ( $\mathrm{P}=0.03)$ (Fig.2F).

\section{Complement pathway activity at different ages}

The possible age-related changes in the CP activity, the AP activity, and the MBL-P activity were analysed (Fig 3 and Table 1). CP activity and AP activity were positively correlated with age (Fig $3 \mathrm{~A}$ and $3 \mathrm{~B}$ ). In contrast, a tendency for an age-related decline in MBL pathway activity was observed (Fig 3C). Only MBL-P activity of age group 20-29 years was significantly higher than MBL-P activity of age group 60-69 years $(\mathrm{P}=0.009)$. Serum concentrations of complement components of the $\mathrm{CP}$ as a possible explanation for the increase in CP activity with age were analyzed (Table 1). Serum concentrations of C1q and C3 showed an age-related decline. C4 levels remained stable with increasing age. However, $C 2$ levels were positively correlated with age $(R=0.28)$. Furthermore, $\mathrm{C} 2$ levels strongly correlated with $\mathrm{CP}$ activity ( $\mathrm{R}=0.51)$.

Consistent with the age-related increase in AP activity, factor B levels increased with ageing (Table 1). In addition, AP activity was strongly correlated with factor B levels $(\mathrm{R}=0.51)$.

In the present analysis the strongest correlation was found between MBL-P activity and MBL serum levels ( $\mathrm{R}=0.89$ ) (Table 1$)$. However, MBL concentrations were not correlated with age. Only comparison of MBL concentration in the youngest and oldest twenty individuals reached a significant difference $(\mathrm{P}=0.046)$ (data not shown), consistent with a lower MBL concentration in older people.

\section{Quantitative explanation of variation in complement activity}

In order to further explain the variation of complement activity in the present population, levels of individual complement components were correlated to the activity of the three complement pathways (Table 1). CP activity was correlated with AP activity ( $\mathrm{R}=$ $0.44), C 2$ levels $(R=0.51)$, and factor $B$ levels $(R=0.30)$. The correlation coefficients between AP activity and levels of factor $B, C 4$ and $C 2$ were $R=0.51, R=0.35$, and $R=$ 0.38 , respectively. The closest correlation was found between MBL-P activity and MBL 
concentrations, $\mathrm{R}=0.89(\mathrm{P}<0.0001)$. Complement levels of $\mathrm{C} 1 \mathrm{q}$ and $\mathrm{C} 3(\mathrm{R}=0.29), \mathrm{C} 4$ and factor $B(R=0.43), C 4$ and C3 $(R=0.34)$, and C2 and factor B levels $(R=0.42)$ were highly significantly correlated.

\section{Discussion}

The present study shows that ageing is associated with an enhanced functional activity of the classical pathway and the alternative pathway of the complement system. Although alternative pathway activity is significantly lower in females, the increase in alternative pathway activity with age is found for both genders. In contrast, ageing was associated with a decline in MBL pathway activity.

Much interest has been focused on the MBL pathway of the complement system in relation to infectious diseases and systemic diseases such as SLE, rheumatoid arthritis and diabetes mellitus. The importance of a functional MBL pathway in the defence against invading microorganisms is of major importance in young children before the development of a fully functional adaptive immunity. MBL concentrations rise swiftly before birth and are at the highest levels early after birth ${ }^{161718}$. However, at older age the MBL pathway activity might become again important in immune defence against microorganisms, because of a decline in functional adaptive immunity. In a recent paper by Ip et al. ${ }^{19}$ no age-related difference in the distribution of MBL2 haplotypes was found, although these authors detected a lower MBL concentration in the elderly. In the present study a mild decline in MBL pathway activity and MBL concentration with age was found. In contrast to MBL pathway activity the classical pathway activity and alternative pathway activity increased with age. The age-associated enhanced $\mathrm{CP}$ activity and AP activity might be a mechanism to compensate for the decline in adaptive immunity in the elderly for defence against microorganisms. Furthermore, reduced MBL pathway activity might be compensated by antibody-mediated activation of the classical pathway of complement ${ }^{20}$. Because a healthy population was studied, the decline in MBL pathway activity and MBL concentration with age could be in some way an advantage for longevity. Possibly the harmful role of MBL in the pathogenesis of atherosclerosis ${ }^{21}$ could contribute to longevity for those who have a reduced MBL function. In the study by Ip et al. ${ }^{19}$ the MBL genotype distribution was similar at different ages. Therefore, the decline in MBL pathway activity and MBL concentration with age is possibly dependent on environmental differences.

In contrast to the MBL-P, our study showed an age-related increase in activity of both the CP and AP. In earlier studies on classical pathway activity in healthy subjects aged between 20 and 79 years old, increased CH50 activity during ageing was observed, associated with increased levels of individual components of the classical pathway ${ }^{22}$. In the present study $\mathrm{C} 4$ concentration remained constant and to our surprise a decline in $\mathrm{C} 1 \mathrm{q}$ and $\mathrm{C} 3$ concentrations was found. However, $\mathrm{C} 2$ levels, the rate-limiting factor of the $\mathrm{CP}^{23}$, increased with age. In line with this, $\mathrm{C} 2$ levels were strongly correlated with CP activity. Furthermore, levels of factor B increased with age, and factor B levels 
also strongly correlated with AP activity. Interestingly also a correlation was found between $\mathrm{C} 4$ and factor $\mathrm{B}$ and between $\mathrm{C} 2$ and factor $\mathrm{B}$ concentration. Earlier reports on haemolytic activity of complement and C3, C4 and factor B levels in healthy children also showed correlations between $\mathrm{C} 4$ and Factor $\mathrm{B}^{24}$. This could be partially explained by the localisation of the genes encoding for $\mathrm{C} 4, \mathrm{C} 2$ and factor $\mathrm{B}$, close to each other in the MHC class 111 region on chromosome 6, which may be subjected to similar regulatory mechanisms. The association between AP activity and the classical pathway components $\mathrm{C} 4$ and $\mathrm{C} 2$, as well as the association between $\mathrm{CP}$ activity and factor $\mathrm{B}$ are possibly observed as a result of such a co-regulation of genes.

The present study shows a clear correlation between $\mathrm{CP}$ activity and AP activity ( $\mathrm{R}=$ $0.44, \mathrm{P}<0.0001)$. The correlation between the activities of both pathways could possibly be explained by a co-regulation of expression of $\mathrm{C} 2$, factor $\mathrm{B}$ and $\mathrm{C} 4$, as explained above, of which the former two determine activity of the $\mathrm{CP}$ and the $\mathrm{AP}$, respectively. Furthermore, an additional role of components of the terminal pathway, which are shared by all three complement activation pathways, can not be excluded. The components of the terminal pathway ( $\mathrm{C} 5, \mathrm{C} 6, \mathrm{C} 7, \mathrm{C} 8$ and $\mathrm{C} 9)$ were not quantified in the present study.

Sex hormones are well known to have influence on innate and adaptive immunity ${ }^{25}$. Hormonal differences between genders might result in a higher incidence of autoimmune diseases in females. Although the important role of complement in autoimmune diseases is well established, little is known about differences in functional activity and serum levels of complement between genders. In the present study a significantly lower AP pathway activity was found in females compared to males, whereas a tendency for lower MBL-P activity was found. Similar results are reported in earlier studies showing a reduced innate immune response in females assessed by reduced TNF production by blood cells after stimulation with LPS ${ }^{26}$. In the pathogenesis of autoimmune diseases, such as SLE, impaired clearance of apoptotic material is proposed to play an important role. Complement has been shown to participate in the clearance of apoptotic material. Therefore, reduced complement function in females might contribute to the increased incidence of SLE in females.

\section{In conclusion:}

Although an age-associated decline in innate immunity has been suggested this could not be confirmed for the functional activity of the complement system. Classical pathway activity and alternative pathway activity significantly increased with age. However, an age-associated decline in MBL-pathway activity was found. These data suggest that MBL is not necessarily important for longevity. Lower functional complement activity might contribute to increased frequency of autoimmune diseases in females. 


\section{Acknowledgements}

The authors like to thank the members of the EU consortium "Complement in disease" for helpful comments and discussions. Part of this work was supported by a grant from the European Union (QLGT-CT2001-01039) and by the Dutch Kidney Foundation (PC 95, C98-1763).

\section{References}

1. Walport, M. J. 2001. Complement. Second of two parts. N.Engl.J.Med. 344:1140-1144.

2. Walport, M. J. 2001. Complement. First of two parts. N.Engl.J.Med. 344:1058-1066.

3. Manderson, A. P., M. Botto, and M. J. Walport. 2004. The Role of Complement in the Development of Systemic Lupus Erythematosus. Annu.Rev.Immunol. 22:431-456.

4. Ruggenenti, P., M. Noris, and G. Remuzzi. 2001. Thrombotic microangiopathy, hemolytic uremic syndrome, and thrombotic thrombocytopenic purpura. Kidney Int. 60:831-846.

5. Trouw, L. A., M. A. Seelen, and M. R. Daha. 2003. Complement and renal disease. Mol.Immunol. 40:125-134.

6. Castle, S. C. 2000. Clinical relevance of age-related immune dysfunction. Clin.Infect.Dis. 31:578-585.

7. Linton, P. J. and K. Dorshkind. 2004. Age-related changes in lymphocyte development and function. Nat.Immunol. 5:133-139.

8. DeVeale, B., T. Brummel, and L. Seroude. 2004. Immunity and aging: the enemy within? Aging Cell 3:195-208

9. Plackett, T. P., E. D. Boehmer, D. E. Faunce, and E. J. Kovacs. 2004. Aging and innate immune cells. J.Leukoc.Biol. 76:291-299.

10. Fulop, T., Jr., A. Larbi, G. Dupuis, and G. Pawelec. 2003. Ageing, autoimmunity and arthritis: Perturbations of TCR signal transduction pathways with ageing - a biochemical paradigm for the ageing immune system. Arthritis Res.Ther. 5:290-302.

11. Turner, M. W. 2003. The role of mannose-binding lectin in health and disease. Mol.Immunol. 40:423429.

12. Peterslund, N. A., C. Koch, J. C. Jensenius, and S. Thiel. 2001. Association between deficiency of mannose-binding lectin and severe infections after chemotherapy. Lancet 358:637-638.

13. Hansen, T. K., L. Tarnow, S. Thiel, R. Steffensen, C. D. Stehouwer, C. G. Schalkwijk, H. H. Parving, and A. Flyvbjerg. 2004. Association between mannose-binding lectin and vascular complications in type 1 diabetes. Diabetes 53:1570-1576.

14. Roos, A., L. H. Bouwman, D. J. Gijlswijk-Janssen, M. C. Faber-Krol, G. L. Stahl, and M. R. Daha. 2001. Human IgA activates the complement system via the mannan-binding lectin pathway. J.Immunol. 167:2861-2868. 
15. Sjoholm, A. G. 1975. Complement components in normal serum and plasma quantitated by elec troimmunoassay. Scand.J.Immunol. 4:25-30.

16. Lau, Y. L., S. Y. Chan, M. W. Turner, J. Fong, and J. Karlberg. 1995. Mannose-binding protein in preterm infants: developmental profile and clinical significance. Clin.Exp.Immunol. 102:649-654.

17. Thiel, S., T. Bjerke, D. Hansen, L. K. Poulsen, P. O. Schiotz, and J. C. Jensenius. 1995. Ontogeny of human mannan-binding protein, a lectin of the innate immune system. Pediatr.Allergy Immunol. 6:20-23.

18. Aittoniemi, J., A. Miettinen, P. Laippala, E. Isolauri, J. Viikari, T. Ruuska, and E. Soppi. 1996. Agedependent variation in the serum concentration of mannan-binding protein. Acta Paediatr. 85:906909.

19. Ip, W. K., Y. F. To, S. K. Cheng, and Y. L. Lau. 2004. Serum mannose-binding lectin levels and mbl2 gene polymorphisms in different age and gender groups of southern Chinese adults.

Scand.J.Immunol. 59:310-314.

20. Roos, A., P. Garred, M. E. Wildenberg, N. J. Lynch, J. R. Munoz, T. C. Zuiverloon, L. H. Bouwman, N. Schlagwein, Fallaux van den Houten FC, M. C. Faber-Krol, H. O. Madsen, W. J. Schwaeble, M. Matsushita, T. Fujita, and M. R. Daha. 2004. Antibody-mediated activation of the classical pathway of complement may compensate for mannose-binding lectin deficiency. Eur.J.Immunol. 34:25892598.

21. Hegele, R. A., M. R. Ban, C. M. Anderson, and J. D. Spence. 2000. Infection-susceptibility alleles of mannose-binding lectin are associated with increased carotid plaque area. J.Investig.Med. 48:198202.

22. Nagaki, K., S. Hiramatsu, S. Inai, and A. Sasaki. 1980. The effect of aging on complement activity (CH50) and complement protein levels. J.Clin.Lab Immunol. 3:45-50.

23. Nielsen, H. E., S. O. Larsen, and T. Vikingsdottir. 1992. Rate-limiting components and reaction steps in complement-mediated haemolysis. APMIS 100:1053-1060.

24. Ferriani, V. P., J. E. Barbosa, and I. F. de Carvalho. 1999. Complement haemolytic activity (classical and alternative pathways), C3, C4 and factor B titres in healthy children. Acta Paediatr. 88:1062-1066.

25. Beagley, K. W. and C. M. Gockel. 2003. Regulation of innate and adaptive immunity by the female sex hormones oestradiol and progesterone. FEMS Immunol.Med.Microbiol. 38:13-22.

26. Moxley, G., D. Posthuma, P. Carlson, E. Estrada, J. Han, L. L. Benson, and M. C. Neale. 2002. Sexual dimorphism in innate immunity. Arthritis Rheum. 46:250-258. 


\section{Discussion}

Loss of immunologic tolerance is the main characteristic in the pathogenesis of SLE. As a consequence of the loss of tolerance, autoantibodies directed against a wide variety of antigens are present in serum from patients with SLE. These antibodies, even present before clinical onset of the disease, are thought to be involved in the initiation phase of SLE ${ }^{1}$. The important protective role of the complement system in the development of SLE is best illustrated by C1q knockout mice, who develop a lupus nephritis-like disease ${ }^{2}$. In man, deficiencies in early components of the classical pathway of the complement system are associated with the development of SLE ${ }^{3}$. Complement deficiency has been suggested to be involved in the loss of tolerance and generation of autoantibodies due to ineffective clearance of apoptotic material. Indeed, a role for complement components of the classical pathway in the clearance of apoptotic material has been demonstrated, both in vitro and in vivo ${ }^{4,6}$. Patients with SLE have increased numbers of circulating apoptotic cells. Ineffective clearance but also enhanced generation of apoptotic material in patients with SLE could explain the increased circulating amount of apoptotic cells. To demonstrate that apoptotic cells are able to generate an autoimmune response, mice have been injected with thymocytes rendered apoptotic by UV-radiation ${ }^{7}$. When large numbers of apoptotic cells are injected in healthy mice they indeed develop an autoimmune response. With lower numbers of apoptotic cells, an adjuvant is required to induce autoimmunity such as Freund's incomplete adjuvant or dendritic cells ${ }^{8}$. Results from these studies suggest that physiological quantities of apoptotic material, as found in every individual, are not sufficient to induce autoimmunity, but increased amounts are required. Furthermore, the requirement of a second hit supports the hypothesis that SLE can be induced by infections, establishing the necessary environment for pathophysiological levels of apoptotic material to induce autoimmunity.

As mentioned above, inefficient clearance of apoptotic material could enhance the level of circulating apoptotic material. The importance of complement in the clearance of apoptotic cells is well illustrated by the increased amount of apoptotic cells found in C1q-deficient mice ${ }^{2}$. Furthermore, C1q-deficient patients are at high risk to develop SLE. Also MBL participates in the recognition of apoptotic cells by phagocytes and patients with MBL-deficiency have an increased risk to develop SLE ${ }^{4 ; 6 ; 9}$. Abnormal clearance of apoptotic cells in MBL-deficiency has thus far not been reported in human or animal studies. To investigate whether ineffi an MBL-deficiency, can enhance autoreactivity, the presence of autoantibodies was assessed in SLE patients with or without an MBL-deficiency. In the present thesis autoantibodies against $\mathrm{C} 1 \mathrm{q}$ and cardiolipin were more frequently found in patients with MBL variant alleles, low MBL concentration or low MBL functional activity. Furthermore, anti-MBL autoantibodies were only found in patients with high serum MBL levels. This could indicate that only functionally active MBL can bind to apoptotic cells and be presented as autoantigen. A higher frequency of anti-MBL autoantibodies has been shown in patients with SLE. However, a pathogenic role for these antibodies has to be demonstrated. 
Taking these results together, MBL might play an important protective role in the onset of SLE by clearing apoptotic material and thereby preventing the formation of autoantibodies against molecules associated with apoptotic cells. However, when apoptotic material is insufficiently cleared because of other deficiencies than an MBL defect, MBL itself might be presented as autoantigen.

A functionally active MBL pathway is important for host defence against invading microorganisms. Activation of the complement cascade via MBL-binding to microorgamisms result in the formation of the membrane attack complex and causes cell lysis. Activation of the MBL pathway on self-structures however might cause tissue damage, as is also true for the other pathways of complement activation. Damage to renal tissue in lupus nephritis is associated with deposition of complement components of the classical pathway and consumption of serum complement components. Data presented in the present thesis suggest a similar down side for MBL, as previously has been demonstrated for C1q. Renal MBL deposition and lower MBL serum levels in a mouse model for lupus nephritis point to activation of the MBL pathway in renal tissue. Also in human renal biopsies deposition of MBL has been demonstrated (Roos and Pia Restaldi unpublished data). Therefore, a functional MBL pathway could be a disadvantage during the effector phase of the disease. Not only in SLE but also in diabetes type 1 and in ischaemia/reperfusion injury a functionally active MBL pathway might cause more damage than being protective ${ }^{10 ; 11}$. With these findings it is difficult to predict whether therapy by either restoration of MBL activity or inhibition of MBL activity with antibodies or proteins might be helpful in patients with SLE. Probably, young children with severe recurrent infections, because of MBL deficiency, benefit from MBL reconstitution therapy. But in patients with SLE this would be highly dependent on the stage of the disease. Infusion of MBL to enhance clearance of apoptotic cells would potentially be beneficial before generation of autoantibodies has started. However, no clinical markers are known to indicate whether apoptotic material is inefficiently cleared before the presence of autoantibodies. Infusion of MBL after onset of the disease might cause MBL deposits in tissue and activation of the complement system resulting in enhanced inflammation. Furthermore, binding of infused MBL to apoptotic material in patients with SLE who are not able to clear apoptotic material sufficiently, might induce production of anti-MBL autoantibodies.

The MBL pathway of complement activation plays a dual role in the initiating and effector phase of SLE. A functional MBL pathway is a disadvantage in SLE when MBL deposits in renal tissue and activates the complement system, resulting in renal damage. Furthermore, antibodies against $M B L$ are generated in patients with SLE. On the other hand a non-functional MBL pathway is associated with a higher risk to develop SLE, possibly involving autoantibody production as a consequence of inefficient clearance of apoptotic material.

Deficiency of MBL, a major initiator of the lectin pathway of complement, is frequently found in the general population due to point mutations in the coding sequence of the MBL2 gene. Genetic studies have shown that patients with MBL variant alleles are at risk for infectious diseases and for systemic diseases such as SLE and rheumatoid 
Table 1. Possible test results of the novel complement assay

\section{Complement Test result ELISA Frequently associated diseases deficiency}

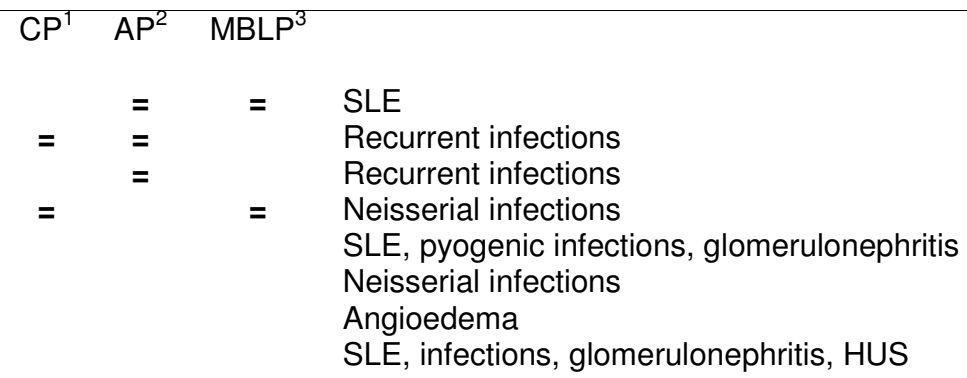

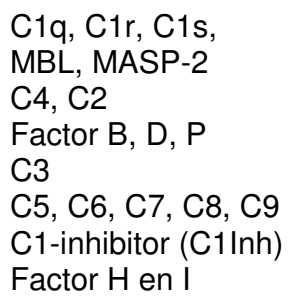

' Classical pathway (CP), ${ }^{2}$ Alternative pathway (AP), ${ }^{3} \mathrm{MBL}$ induced lectin pathway (MBLP)

arthritis ${ }^{9 ; 2 ; 13}$. In most of the studies a similar association was observed between low MBL serum concentrations and susceptibility to these diseases. The explanation given for the association between MBL and infectious diseases is that only functionally active MBL can bind to microorganisms efficiently and activate the complement system. Complement activation on the surface of microorganisms via the classical pathway, the alternative pathway or the lectin pathway result in opsonisation and formation of the membrane attack complex. Therefore, assessment of functional activity of the complement system is required in patients with recurrent infections. Also in other diseases, when a deficiency in innate immunity is suggested, or in diseases known to be associated with complement deficiency or complement consumption, information about the functional activity of the complement pathways is essential.

The functional activity of the classical and the alternative pathway can be measured by assessed of formation of the membrane attack complex on the surface of (sensitized) erythrocytes. The amount of cell lysis is used as measure of functional activity of the pathway. Such an assay is not available for the MBL pathway. MBL/MASP complex activity can be directly assessed but only informs about the binding ability of MBL to a ligand and the complement-activating capacity of the proteases associated with the MBL molecule ${ }^{14}$. A new complement assay developed to assess the functional activity of the total MBL pathway is described in the present thesis. The method is ELISAbased and formation of the terminal complex is assessed in parallel for the classical, alternative and MBL pathway. The advantage of this assay is the easy and reproducible way to detect deficiencies of complement components in any of the three pathways. Furthermore, reduced functional activity of the pathways in diseases with complement consumption can be detected. With the results of the functional activity of the three different pathways it is simply to determine, which of the complement component(s) in a given serum is (are) deficient. In table 1 the possible test results are shown in relation to certain complement deficiencies. To determine a single comple- 
ment component deficiency responsible for the reduced pathway activity, further analysis is required.

Age-related changes in innate and adaptive immunity in the elderly are a topic of much interest. Research for changes in innate immunity has been focused on the cellular compartment ${ }^{15}$. With the use of the new complement assay it is now possible to study the age-related changes in functional activity of the complement system. In the present thesis the functional activity of the MBL pathway was reduced in elderly. Given that the samples were taken from healthy individuals, a reduced functional activity of the MBL pathway is not required for good health in elderly. Possibly antibodymediated activation of the classical pathway of complement possibly compensate for reduced MBL pathway activity ${ }^{16}$. In a previously reported study in large Danish population it was shown that MBL deficiency was not a major risk factor for morbidity or death ${ }^{17}$. Taken together, it can be concluded that the MBL pathway is not important for longevity in relation to infectious diseases in the Caucasian population.

Regulation of innate and adaptive immunity is different between genders. Women are reported to mount a more vigorous immune response compared to men ${ }^{18}$. The role of sex hormones on regulation of immunity is best illustrated with the changes in activity of autoimmune disease during pregnancy. Furthermore, the incidence of autoimmune diseases is higher in women than in men. The results in the present thesis show a lower MBL pathway activity in the female population. This result, in perspective of the role of MBL in the development of SLE as presented in the thesis, might possibly suggest that lower MBL pathway activity in females partially explains the higher incidence of SLE in females. Furthermore, in earlier studies a role for the alternative pathway and MBL pathway in the pathogenesis of IgA nephropathy has been suggested ${ }^{19 ; 21}$. Lower AP activity and MBL-P in females, demonstrated in the present thesis, might contribute to the lower incidence of $\operatorname{IgA}$ nephropathy in females compared to males.

An age-related enhanced complement pathway activity for the $C P$ and the AP might protect the elderly against infections when adaptive immunity declines. In females lower functional complement activity might predispose to (auto)immune mediated diseases. 


\section{References}

1. Arbuckle, M. R., M. T. McClain, M. V. Rubertone, R. H. Scofield, G. J. Dennis, J. A. James, and J. B. Harley. 2003. Development of autoantibodies before the clinical onset of systemic lupus erythematosus. N.Engl.J.Med. 349:1526-1533.

2. Botto, M., C. Dell'Agnola, A. E. Bygrave, E. M. Thompson, H. T. Cook, F. Petry, M. Loos, P. P. Pandolfi, and M. J. Walport. 1998. Homozygous C1q deficiency causes glomerulonephritis associated with multiple apoptotic bodies. Nat.Genet. 19:56-59.

3. Pickering, M. C., M. Botto, P. R. Taylor, P. J. Lachmann, and M. J. Walport. 2000. Systemic lupus ery thematosus, complement deficiency, and apoptosis. Adv.Immunol. 76:227-324.

4. Nauta, A. J., N. Raaschou-Jensen, A. Roos, M. R. Daha, H. O. Madsen, M. C. Borrias-Essers, L. P. Ryder, C. Koch, and P. Garred. 2003. Mannose-binding lectin engagement with late apoptotic and necrotic cells. Eur.J.Immunol. 33:2853-2863.

5. Taylor, P. R., A. Carugati, V. A. Fadok, H. T. Cook, M. Andrews, M. C. Carroll, J. S. Savill, P. M. Henson, M. Botto, and M. J. Walport. 2000. A hierarchical role for classical pathway complement proteins in the clearance of apoptotic cells in vivo. J.Exp.Med. 192:359-366.

6. Ogden, C. A., A. deCathelineau, P. R. Hoffmann, D. Bratton, B. Ghebrehiwet, V. A. Fadok, and P. M. Henson. 2001. C1q and mannose binding lectin engagement of cell surface calreticulin and CD91 initiates macropinocytosis and uptake of apoptotic cells. J.Exp.Med. 194:781-795.

7. Mevorach, D., J. L. Zhou, X. Song, and K. B. Elkon. 1998. Systemic exposure to irradiated apoptotic cells induces autoantibody production. J.Exp.Med. 188:387-392.

8. Bondanza, A., V. S. Zimmermann, G. Dell'Antonio, E. D. Cin, G. Balestrieri, A. Tincani, Z. Amoura, J. C. Piette, M. G. Sabbadini, P. Rovere-Querini, and A. A. Manfredi. 2004. Requirement of dying cells and environmental adjuvants for the induction of autoimmunity. Arthritis Rheum. 50:1549-1560.

9. Garred, P., A. Voss, H. O. Madsen, and P. Junker. 2001. Association of mannose-binding lectin gene variation with disease severity and infections in a population-based cohort of systemic lupus ery thematosus patients. Genes Immun. 2:442-450.

10. Collard, C. D., A. Vakeva, M. A. Morrissey, A. Agah, S. A. Rollins, W. R. Reenstra, J. A. Buras, S. Meri, and G. L. Stahl. 2000. Complement activation after oxidative stress: role of the lectin complement pathway. Am.J.Pathol. 156:1549-1556.

11. Hansen, T. K., L. Tarnow, S. Thiel, R. Steffensen, C. D. Stehouwer, C. G. Schalkwijk, H. H. Parving, and A. Flyvbjerg. 2004. Association between mannose-binding lectin and vascular complications in type 1 diabetes. Diabetes 53:1570-1576.

12. Eisen, D. P. and R. M. Minchinton. 2003. Impact of mannose-binding lectin on susceptibility to infectious diseases. Clin.Infect.Dis. 37:1496-1505.

13. Garred, P., H. O. Madsen, H. Marquart, T. M. Hansen, S. F. Sorensen, J. Petersen, B. Volck, A. Svejgaard, N. A. Graudal, P. M. Rudd, R. A. Dwek, R. B. Sim, and V. Andersen. 2000. Two edged role of mannose binding lectin in rheumatoid arthritis: a cross sectional study. J.Rheumatol. 27:26-34.

14. Petersen, S. V., S. Thiel, L. Jensen, R. Steffensen, and J. C. Jensenius. 2001. An assay for the mannanbinding lectin pathway of complement activation. J.Immunol.Methods 257:107-116.

15. Pawelec, G., R. Solana, E. Remarque, and E. Mariani. 1998. Impact of aging on innate immunity. J.Leukoc.Biol. 64:703-712. 
16. Roos, A., P. Garred, M. E. Wildenberg, N. J. Lynch, J. R. Munoz, T. C. Zuiverloon, L. H. Bouwman, N. Schlagwein, Fallaux van den Houten FC, M. C. Faber-Krol, H. O. Madsen, W. J. Schwaeble, M. Matsushita, T. Fujita, and M. R. Daha. 2004. Antibody-mediated activation of the classical pathway of complement may compensate for mannose-binding lectin deficiency. Eur.J.Immunol. 34:25892598 .

17. Dahl, M., A. Tybjaerg-Hansen, P. Schnohr, and B. G. Nordestgaard. 2004. A Population-based Study of Morbidity and Mortality in Mannose-binding Lectin Deficiency. J.Exp.Med. 199:1391-1399.

18. Beagley, K. W. and C. M. Gockel. 2003. Regulation of innate and adaptive immunity by the female sex hormones oestradiol and progesterone. FEMS Immunol.Med.Microbiol. 38:13-22.

19. Roos, A., L. H. Bouwman, D. J. Gijlswijk-Janssen, M. C. Faber-Krol, G. L. Stahl, and M. R. Daha. 2001. Human IgA activates the complement system via the mannan-binding lectin pathway. J.Immunol. 167:2861-2868.

20. Russell MW, Kilian M, and Lamm ME. 1999. Biological activity of IgA. In Mucosal Immunology. Ogra PLO and Mestecky J, eds. Academic Press, San Diego, p. 225.

21. Stad, R. K., J. A. Bruijn, D. J. Gijlswijk-Janssen, L. A. van Es, and M. R. Daha. 1993. An acute model for IgA-mediated glomerular inflammation in rats induced by monoclonal polymeric rat $\operatorname{IgA}$ antibodies. Clin.Exp.Immunol. 92:514-521. 


\section{Summary}

Mannose-binding lectin, one of the initiating components of most recently described pathway of complement activation, the lectin pathway, has been suggested to play a protective role in patients with SLE. MBL deficiency is a risk factor for acquiring SLE. Furthermore, patients with SLE who are homozygous carriers of MBL variant alleles have an increased risk for complications such as arterial thrombosis, infections, and renal involvement. Autoantibodies, generated in patients with SLE, are thought to play an important role in most of the complications and tissue damage.

The principal idea of the generation of autoantibodies in patients with SLE is a defective waste disposal mechanism. An important role in clearance of apoptotic material for complement components i.e., C1q but also MBL, has been demonstrated. However, the role of C1q in SLE has been described as a two-edged sword, necessary for clearance of immune complexes and apoptotic material but damaging when binding to deposited immune complexes in tissue. In parallel with the findings for $\mathrm{C} 1 \mathrm{q}$ a potential dual role for MBL in patients with SLE was investigated.

\section{Chapter 2. Does MBL play a role in tissue damage in lupus nephritis?}

Activation of the complement system is one of the major causes of organ damage in SLE patients with active disease. In renal tissue from patients with lupus nephritis the characteristic finding of a full house immunofluorescence with the presence of $\mathrm{C} 1 \mathrm{q}$ and C3 is used as a diagnostic criterion. Also a relation between organ damage and decreased serum levels of components of the classical and alternative pathway has been reported. MBL deposition in renal tissue from patients with active lupus nephritis has been demonstrated but no details about a pathogenic role for MBL has been reported. To study the role of the MBL pathway in lupus nephritis MRL +/+ mice and MRL-lpr mice were used. These mice spontaneously develop an autoimmune disease resembling SLE. However, in MRL-lpr mice the disease is more aggressive and signs of organ damage occur at earlier age. In renal tissue from these mice deposition was observed of C1q, MBL-A, MBL-C and C3. These depositions were more pronounced with increasing age. Furthermore, serum levels of MBL-A, MBL-C, C1q and C3 decreased with age of these mice. Also a reduced classical pathway activity was found during ageing. Alternative pathway and MBL pathway activity remained constant. Elevated BUN levels and proteinuria demonstrated the development of renal damage in these mice. These results support the hypothesis that the MBL pathway is involved in tissue damage in lupus nephritis.

\section{Chapter 3. Do patients with SLE have auto-reactivity against MBL?}

The presence of a wide variety of autoantibodies is a characteristic finding in SLE. Autoantibodies against nuclear proteins, such as anti-nuclear and anti-double stranded DNA antibodies, are used as diagnostic markers in SLE. In earlier studies anti-C1q antibodies in sera from patients with SLE are found in almost all patients with severe renal involvement. Recently, anti-C1q antibodies are reported to be pathogenic to the kidney in the context of C1q-deposition on IgG in glomerular immune complex disea- 
se. MBL deposition has been demonstrated in renal tissue in lupus nephritis. A similar possible role for anti-MBL antibodies as the pathogenic role of anti-C1q antibodies in SLE could be hypothesized. Anti-MBL autoantibodies were demonstrated in sera from patients with SLE. The antigenic specificity of these autoantibodies was demonstrated. Also anti-C1q antibodies were found in sera from these patients, in association with renal involvement and disease activity. No association between clinical characteristics or disease activity and the presence of anti-MBL antibodies could be demonstrated. The presence of anti-MBL autoantibodies was associated with reduced MBL/MASP complex activity. Therefore, anti-MBL autoantibodies are possibly able to interfere with the functional activity of MBL, which could thereby lead to impaired MBLmediated clearance of apoptotic material and impaired protection against microorganisms.

\section{Chapter 4. Does MBL deficiency play a role in the generation of autoantibodies in SLE?}

An impaired "waste-disposal" mechanism is one of the current theories on the pathophysiology of SLE. The complement system plays an important role in clearance of apoptotic material. Impaired clearance of apoptotic material might lead to presentation of proteins from this apoptotic material, by antigen presenting cells, as autoantigens and subsequently, to generation of autoantibodies. Autoantibodies are already found in very early stages of SLE, even before clinical onset. These autoantibodies are mostly directed against antigens present on apoptotic material. Since MBL has been postulated to play a role in the clearance of apoptotic material, the presence of autoantibodies in SLE patients in relation to MBL gene polymorphisms and MBL functional activity was studied.

The results from this study indicated that expression of MBL variant alleles in SLE patients was not only associated with reduced MBL concentrations but also with impaired MBL complex activity and impaired MBL pathway activity. Furthermore, it is demonstrated that MBL gene polymorphisms, low MBL concentration and impaired functional activity of the MBL pathway are significantly associated with the presence of anti-cardiolipin and anti-C1q antibodies in patients diagnosed with SLE. In addition, SLE disease activity was higher in patients with lower MBL-pathway activity.

This study supports the hypothesis that MBL deficiency or dysfunction might play a role in the onset and severity of SLE, possibly caused by insufficient clearance of apoptotic debris, leading to increased production of autoantibodies against persisting self antigens.

\section{Conclusion}

In MBL deficient patients with SLE enhanced autoantibody production has been demonstrated, which might indicate that the MBL pathway of complement activation plays a protective role in SLE by clearance of apoptotic material. However, activation of the MBL pathway might aggravate organ damage in SLE. In addition, autoantibodies against MBL, generated in patients with SLE might interfere with the functional activity of MBL. 


\section{Chapter 5. Assessment of mannose-binding lectin pathway activity.}

A compromised innate immune system resulting from defective activation of complement can be caused by genetically determined deficiencies of any of the complement components. Furthermore, decreased or undetectable pathway activity may also be caused by acquired complement deficiencies due to consumption.

A functional innate immune system is essential for primary defence against invading microorganisms and the complement system plays a major role in such immunity. Deficiencies in one of the components of the complement system can cause severe and recurrent infections, systemic diseases such as systemic lupus erythematosus (SLE) and renal disease. Haemolytic assays to assess the functional activity of the classical and the alternative pathways of complement activation have been available for many years. However, for the MBL pathway no comparable assay exists. A simple ELISAbased format for the evaluation of three pathways of complement activation is described. The assays are based on specific coatings for each pathway in combination with specific buffer systems. The degree of activity is assessed on the basis of the amount of C5b-9 that is generated and bound in ELISA wells. These assays are standardised and cut off values to detect complement deficiencies at the different levels of the complement system are defined. Furthermore, the assays are validated for the detection of genetic and acquired complement deficiencies associated with all three activation pathways. The results demonstrate the value of these ELISA-based procedures for the functional assessment of complement deficiencies in clinical practice. Screening the sera of patients for genetic complement deficiencies or any other functional defect in the complement system can now be performed with one simple assay format for the three pathways analysed in parallel.

\section{Chapter 6. Age-related changes in functional activity of complement and differen- ces between genders}

Much attention has been focused on changes in complement activity in early childhood. Defence against microorganisms in the time period after immune protection by maternal antibodies, are based on an adequate innate immune response, followed by the development of protective adaptive immunity. However, in the elderly a decline in adaptive immunity has been demonstrated. A functionally active innate immune system is important for immune protection against microorganisms. However, the functional activity of the cellular compartment of the innate immune system also declines with age. Age-related changes in complement activity are scarcely investigated. The results from the present study show a significantly increase in classical pathway (CP) activity and alternative pathway (AP) activity with age. The increase in these pathways might be a tool to compensate for the decline in other immune mechanisms with age. However, an age-dependent decrease in MBL pathway activity was observed. A possible advantage of lower MBL pathway activity could be the reduced harmful effect of MBL on (ischaemic) vascular injury. The increase in CP and AP activity could be explained by enhanced concentrations of, $\mathrm{C} 2$ and factor $\mathrm{B}$, respectively, with age. Lower MBL pathway activity was caused by lower MBL serum concentrations with age. Between genders a significantly lower AP activity was found in females. 
Lower C3 levels in females could possibly explain the difference in alternative pathway activity between genders. In the present study we show an enhanced innate immunity with age in relation to $\mathrm{CP}$ activity and AP activity. MBL pathway activity declined with age. Gender-associated differences in pathway activity and serum concentrations were also observed. Differences in functional activity of the complement pathways between genders may have consequences for the incidence of (auto) immune diseases.

\section{Conclusion}

Enhanced functional activity of the $\mathrm{CP}$ and $\mathrm{AP}$ with ageing is demonstrated and might be important for protection against infectious diseases in elderly when adaptive immunity declines. The difference in complement activity between genders is suggested to play a role in the incidence of development of (auto) immune diseases. 


\section{Samenvatting}

De integriteit van het menselijk lichaam wordt dagelijks op de proef gesteld door het ons omringend milieu. Het aangeboren en verworven afweersysteem moet het lichaam beschermen tegen invasieve pathogene micro-organismen. Vooral bij het herkennen en opruimen van deze micro-organismen speelt het aangeboren afweersysteem een belangrijke rol. Behalve inzake dit lichaamsvreemde materiaal is het aangeboren afweersysteem ook van essentieel belang voor het opruimen van lichaamseigen materiaal dat, door al dan niet geprogrammeerde (apoptotische) celdood, zijn functie heeft verloren.

Eén van de belangrijkste onderdelen van het aangeboren afweersysteem is het complementsysteem. Het speelt in het opruimen van micro-organismen en lichaamseigen materiaal een cruciale rol. Deficiënties in het complementsysteem kunnen leiden tot recidiverende infecties, systeemziekten zoals 'systemische lupus erythematosus' (SLE) en nierziekten.

Het complementsysteem bestaat uit meerdere routes die op verschillende manieren in werking gesteld kunnen worden. Welke route geactiveerd wordt, hangt af van de structuur die door één van de complementfactoren wordt herkend. De klassieke route wordt geactiveerd door $\mathrm{C} 1 \mathrm{q}$ nadat het aan o.a. antistoffen en dode cellen gebonden is.

De alternatieve route wordt na het binden van spontaan geactiveerd C3 aan bijvoorbeeld celwandbestanddelen van bacteriën in werking gesteld. De lectine route wordt geactiveerd door het binden van bijvoorbeeld mannose-bindend lectine (MBL) aan verschillende suikers. Wanneer één van deze routes geactiveerd wordt zal, na een cascade van enzymatisch geactiveerde complementcomponenten, een eiwitcomplex (het "membrane attack complex") gevormd worden. Dit eiwitcomplex is onder andere in staat micro-organismen te doden. Tijdens de activatie van complementfactoren ontstaan er fragmenten van complementcomponenten die er voor zorgen dat ontstekingscellen aangetrokken worden naar de plaats van complementactivatie. Dit proces zal ertoe leiden dat het micro-organisme gedood en vervolgens opgeruimd wordt door cellen van het afweersysteem. Wordt het complementsysteem echter geactiveerd op lichaamseigen cellen en/of weefsel, en volgt hetzelfde proces als hierboven beschreven, dan zal dit leiden tot schade aan het gezonde weefsel. Zo kan het complementsysteem dus een beschermende functie hebben, maar ook de integriteit van de organen doorbreken.

Het functioneren van het complementsysteem als een aan twee kanten snijdend zwaard, kan goed geillustreerd worden aan de hand van complementdeficiënties en het gevolg daarvan. Patiënten met een deficiëntie voor $\mathrm{C} 1 \mathrm{q}$, de eerste factor van de klassieke route, presenteren zich bijna allemaal met de ziekte systemische lupus erythematosus (SLE). Echter, bij patiënten met SLE zónder een C1q deficiëntie zal de schade, die bijvoorbeeld ontstaat in de nieren van deze patiënten, voor een groot deel veroorzaakt worden door activatie van de klassieke route van het complementsysteem. 
Om deze twee facetten te begrijpen moeten we rekening houden met het feit dat bij het ontstaan en het beloop van een ziekte (in dit geval SLE) niet dezelfde mechanismen een rol hoeven te spelen. C1q blijkt een belangrijke rol te spelen in het opruimen van immuuncomplexen. Wanneer immuuncomplexen efficient worden opgeruimd kunnen zij niet in de nier neerslaan en daarom geen aanleiding kunnen geven tot een ontstekingsreactie. Slaan immuuncomplexen, ondanks de aanwezigheid van $\mathrm{C} 1 \mathrm{q}$, wel neer in de nier, dan kan, door het binden van C1q aan deze immuuncomplexen, het complementsysteem lokaal geactiveerd worden en er schade aan de nier ontstaan.

MBL, de complementfactor die na het binden aan een suiker de lectine route activeert, heeft structurele en functionele eigenschappen die lijken op die van C1q. Of MBL ook een dubbele rol, zoals C1q, kan vervullen in het ontstaan en beloop van SLE is echter niet duidelijk.

MBL lijkt een beschermende rol te spelen bij het ontstaan van SLE. Uit studies is gebleken dat het hebben van een MBL-deficiëntie een risicofactor is voor het ontwikkelen van SLE. Ook hebben patiënten met SLE én een MBL-deficiëntie een toegenomen risico op het krijgen van complicaties zoals trombose en infecties. Tevens zou MBL een rol kunnen spelen in de ontwikkeling van autoantistoffen bij patiënten met SLE. Eén van de huidige theorieën omtrent de ontwikkeling van autoantistoffen in SLE duidt op een niet goed functionerend systeem voor de verwerking van apoptotisch materiaal. Zoals al eerder genoemd lijkt het complementsysteem, met name de complementcomponenten $\mathrm{C1q}$ en MBL, een belangrijke rol bij het opruimen van dit celafval te spelen. Zo zou het kunnen dat, wanneer iemand een MBL-deficiëntie heeft, het apoptotisch materiaal niet goed geklaard wordt hetgeen kan leiden tot de productie van autoantistoffen.

Of MBL ook een schadelijke rol speelt bij het ontstaan of in het beloop van SLE is onduidelijk. Aanwijzingen voor een mogelijke rol van MBL in het veroorzaken van schade, zijn de aanwezigheid van zowel C1q als MBL in de nierbiopten van patiënten met SLE.

Of MBL inderdaad functioneert als een aan twee kanten snijdend zwaard, is in de huidige studie verder onderzocht.

\section{Hoofdstuk 2. Speelt MBL een rol bij het ontstaan van weefselschade in nierontste- king bij SLE patiënten?}

In het mechanisme dat leidt tot weefsel- en orgaanschade bij patiënten met SLE gedurende een actieve periode van hun ziekte, speelt de activatie van het complementsysteem een belangrijke rol. De aanwezigheid van zowel antistoffen als complement bij microscopisch onderzoek van een nierbiopt wordt gebruikt als één van de criteria bij het stellen van de diagnose SLE. Eveneens is er een relatie aangetoond tussen orgaanschade en verlaagde serumwaarden van componenten van de klassieke en alternatieve route.

MBL-neerslag in nierbiopten van SLE patiënten met actieve nierziekte ("lupus nefritis") is aangetoond, maar verder zijn er geen gegevens bekend voor een mogelijk pathogene rol van MBL in de nier. Om de rol van de MBL-route in "lupus nefritis" te bestuderen hebben wij gebruik gemaakt van MRL-lpr and MRL +/+ muizen. Beide 
muizen ontwikkelen spontaan een auto-immuunziekte die lijkt op SLE. MRL-lpr muizen ontwikkelen echter een veel sneller en ernstiger verlopende ziekte dan MRL +/+ muizen. In nierweefsel van deze muizen werd een neerslag gevonden van C1q, MBL$\mathrm{A}, \mathrm{MBL}-\mathrm{C}$ en C3. De mate van neerslag van deze componenten nam toe met de leeftijd. De serumconcentratie van C1q, C3, MBL-A en MBL-C nam in alle muizen af gedurende het ouder worden. Binnen de verschillende routes nam met het toenemen van de leeftijd alleen de routeactiviteit van de klassieke route af. De activiteit van de alternatieve en MBL-route bleef gelijk. Dat de muizen daadwerkelijk een nierziekte ontwikkelen werd vastgesteld aan de hand van een toegenomen serum ureum concentratie en sterk verhoogde albumine excretie in de urine bij hogere leeftijd. Met deze bevinding werd de betrokkenheid van de MBL route in het ontstaan van weefselschade bij "lupus nefritis" waarschijnlijk geacht.

\section{Hoofdstuk 3. Hebben patiënten met SLE autoreactiviteit tegen MBL?}

De aanwezigheid van autoantistoffen gericht tegen veel verschillende antigenen is een karakteristieke bevinding bij SLE. De aanwezigheid van autoantistoffen in het serum van patiënten met SLE gericht tegen kerneiwitten en DNA wordt gebruikt als criterium om de diagnose SLE te stellen. Anti-C1q antistoffen worden bijna altijd aangetoond in het serum van patiënten met ernstige lupus nefritis. Anti-C1q antistoffen kunnen een pathogene rol spelen in de nier wanneer $\mathrm{C} 1 \mathrm{q}$ gebonden is aan $\operatorname{IgG}$ deposities in de glomeruli. Omdat ook de aanwezigheid van MBL in de nier van patiënten met lupus nefritis is gevonden, zou een vergelijkbaar mechanisme, als recent aangetoond voor anti-C1q antistoffen, voor anti-MBL antistoffen kunnen gelden.

Inderdaad vonden wij in patiënten met SLE naast anti-C1q antistoffen ook anti-MBL antistoffen in het serum. De antigeen-specifieke binding van anti-MBL antistoffen voor MBL werd vastgesteld.

Zoals al eerder beschreven is, werd ook in de huidige studie een verhoogde spiegel van anti-C1q antistoffen bij patiënten met actieve ziekte gevonden. Voor anti-MBL antistoffen werd geen verhoogde spiegel aangetoond. De associatie tussen anti-C1q antistoffen en lupus nefritis werd in deze studie bevestigd. Voor de aanwezigheid van anti-MBL antistoffen werd geen associatie gevonden met de betrokkenheid van een specifiek orgaan.

Het is bekend dat SLE patiënten met een MBL-deficiëntie vaker infectieuze complicaties doormaken. Mogelijk veroorzaakt een niet goed functionerende MBL route een inadequate lysis van bacteriën. Helaas waren er geen klinische gegevens beschikbaar omtrent infectieuze complicaties. Wel werd er een verminderde activatie van C4 door het MBL molecuul vastgesteld in aanwezigheid van anti-MBL antistoffen. Anti-MBL antistoffen zouden dus de functionele activiteit van de MBL route kunnen verstoren wat zou kunnen leiden tot inefficiënt opruimen van dode cellen en verminderde bescherming tegen bacteriën. 


\section{Hoofdstuk 4. Leidt MBL deficiëntie tot toename van productie van autoantistoffen in SLE?}

Eén van de huidige concepten over de pathofysiologie van SLE, beschrijft een niet goed functionerend mechanisme voor het verwerken van apoptotisch materiaal, het "waste disposal" mechanisme. In het opruimen van apoptotisch materiaal speelt het complementsysteem een belangrijke rol. Wanneer het apoptotisch materiaal niet goed geklaard wordt, ontwikkelen patiënten met SLE autoantistoffen gericht tegen antigenen die zich aan het oppervlak van dit apoptotisch materiaal bevinden. Deze autoantistoffen kunnen al in het serum aangetroffen worden voordat het volledige klinische beeld van SLE zich ontwikkeld heeft. Omdat van MBL is aangetoond dat het een rol speelt bij het opruimen van apoptotisch materiaal, werd de aanwezigheid van autoantistoffen in SLE-patiënten met een MBL-dysfunctie onderzocht.

In deze studie is aangetoond dat de aanwezigheid van MBL genpolymorfismen niet alleen geassocieerd is met een verlaagde MBL-concentratie maar ook met verminderde MBL-functie. Tevens werd gevonden dat MBL-gen polymorfismen, MBL-concentratie en MBL-dysfunctie geassocieerd is met de aanwezigheid van autoantistoffen tegen componeneten vn dode cellen. Daarnaast werd er gevonden dat de ernst van de ziekteactiviteit geassocieerd is met verminderde MBL route activiteit. De resultaten van deze studie ondersteunen dan ook de hypothese dat MBL dysfunctie een rol kan spelen bij de ontwikkeling en het beloop van SLE, hetgeen mogelijk verklaard kan worden door een verminderd opruimen van apoptotisch materiaal en daardoor een verhoogde productie van autoantistoffen.

\section{Conclusie}

Een beschermende rol van de MBL-route van complement activatie, door middel van het opruimen van apoptotisch materiaal, lijkt waarschijnlijk gezien de verminderde aanwezigheid van autoantistoffen in patienten met een goede MBL functie. Echter, activatie van de MBL-route kan ook tot verergering van orgaanschade leiden. Daarnaast kan de complementactiverende functie van het MBL verminderd worden door de autoantistoffen gericht tegen MBL. Deze autoantistoffen worden in het serum van patienten met SLE gevonden.

Voor patiënten bij wie een immuundeficiëntie wordt vermoed, is het vaststellen van een mogelijke complementdeficiëntie van belang voor het stellen van een diagnose. Bovendien kan de mate van complementactivatie van belang zijn om de ziekteactiviteit te vervolgen en de effectiviteit van de behandeling te evalueren. De functionele activiteit van de complementeactivatieroutes wordt, voor de klassieke en de alternatieve route, bepaald door het meten van complementafhankelijke lysis van erythrocyten. Er is recent een methode ontwikkeld om de activiteit van alle drie de routes te bepalen door middel van ELISA. Met behulp van voor iedere route specifieke activatoren en condities wordt selectief de activiteit van elke route gemeten. De uiteindelijke vorming van het "membrane attack complex" (C5b-9) bepaalt de mate van activiteit van één van de routes.

Met deze methode is het voor het eerst mogelijk om de activiteit van de hele MBL- 
route in serum te bepalen en om tegelijkertijd de klassieke en de alternatieve routeactiviteit op eenvoudige wijze te meten. De resultaten van het onderzoek, uitgevoerd binnen een Europese samenwerking, omtrent de verschillen in functionele activiteit van de complementroutes tussen mannen en vrouwen én de verandering hiervan met toename van de leeftijd, zijn in dit proefschrift beschreven.

\section{Hoofdstuk 5. Standaardisering en validatie van een nieuwe methode om de functionele activiteit van complementroutes te meten.}

Om de toepasbaarheid van deze nieuwe meetmethode te testen is de activatie van de drie verschillende routes gemeten in 120 sera van gezonden individuen. Deze bepalingen zijn gedaan in drie verschillende laboratoria in Europa. Dit onderzoek heeft laten zien dat de meetmethode goed vergelijkbaar is tussen verschillende laboratoria. Met behulp van de testuitslagen werd voor elk van de drie routes de ondergrens van normale routeactiviteit vastgesteld. Om de bruikbaarheid van de meetmethode te testen voor het detecteren van complementdeficiënties werden sera met al eerder vastgestelde erfelijke deficiënties getest. Op deze manier werd aangetoond dat deze methode goed bruikbaar is om sera te screenen voor aangeboren complementdeficiënties. Ook werd er aangetoond dat deze meetmethode bruikbaar is om complementconsumptie vast te stellen in sera van patiënten met verschillenden ziekten waarvan bekend is dat er complementverbruik plaatsvindt. Met deze nieuwe meetmethode is het mogelijk geworden om de drie routes van het complementsysteem te screenen op deficiënties en ook om complementverbruik vast te stellen.

\section{Hoofdstuk 6. Verschil in de functionele activiteit van complementactivatieroutes tussen mannen en vrouwen en de verandering hiervan met het toenemen van de leeftijd.}

Veel aandacht is er besteed aan de veranderingen in complementactivatie bij jonge kinderen. Bij jonge kinderen is de afweer tegen microorganismen, na de periode van de beschermende antistoffen van de moeder, afhankelijk van een goed functionerend aangeboren afweersysteem. Ook op oudere leeftijd, wanneer de verworven immuniteit minder wordt, zou het aangeboren afweersysteem een belangrijke rol kunnen spelen. Echter, het cellulaire deel van de aangeboren afweer neemt in functie af met het toenemen van de leeftijd. Leeftijdsafhankelijke veranderingen in complementactiviteit, zoals in dit onderzoek beschreven, werden eerder nauwelijks onderzocht.

De resultaten van deze studie laten een significante toename zien van de klassieke en alternatieve routeactiviteit met het toenemen van de leeftijd. Deze toename in routeactiviteit zou een manier kunnen zijn waardoor de afgenomen immuniteit bij ouderen gecompenseerd kan worden. Echter, een afname van de MBL route werd gevonden bij toename van de leeftijd. Een mogelijk voordeel van afname van MBL routeactiviteit zou het ongunstig effect van MBL op vaatschade kunnen zijn. In overeenstemming met de klassieke routeactiviteit werd er een toename van de C2 concentratie gevonden; voor de alternatieve route werd er een toename van factor B concentratie gevonden. De lagere MBL routeactiviteit was sterk gecorreleerd met afgenomen MBL serumconcentraties. In vergelijking met mannen, werd er bij vrouwen een lagere alternatieve 
routeactiviteit gevonden. Lagere C3 concentratie in het serum bij vrouwen zou mogelijk een verklaring kunnen zijn voor de verminderde alternatieve route activiteit.

In de studie wordt een toegenomen activiteit van het aangeboren afweersysteem gevonden voor de klassieke route en alternatieve route met het ouder worden. Daarentegen werd een afgenomen MBL route activiteit vastgesteld bij ouderen. Het verschil in incidentie van sommige (auto-) immuunziekten tussen mannen en vrouwen kan mogelijk deels verklaard kan worden door het verschil in functionele activiteit van de complementroutes.

\section{Conclusie}

De klassieke route en alternatieve route van het complementsysteem nemen in functionele activiteit toe met toename van leeftijd, hetgeen van belang kan zijn in de bescherming tegen infectieziekten bij ouderen, bij wie de verworven immuniteit afgenomen is. Het verschil in functionele activiteit van het complementsysteem tussen mannen en vrouwen speelt mogelijk een rol in het verschil van voorkomen van (auto) immuunziekten in beide geslachten. 


\section{Nawoord}

Zonder de hieronder genoemde personen zou mijn werk er de afgelopen vier jaar anders hebben uitgezien. In de meeste gevallen ben ik hen dankbaar.

Collega's en secretariële medewerkers van de afdeling Nierziekten

Medewerkers van het laboratorium Nierziekten

Verplegend personeel van de afdeling Nierziekten

Zonder de volgende personen zou mijn leven er de afgelopen vier jaar anders uit hebben gezien. Ik ben hen hiervoor dankbaar.

Mariken, Dominique en Wouter

Familie en vrienden 


\section{Curriculum vitae}

De auteur vandit proefschrift werd geboren te Delft op 20 maart 1967. Aansluitend op het behalen van zijn eindexamen aan het Gymnasium Haganum in Den Haag, is hij in 1985 begonnen met zijn studie Geneeskunde aan de Universiteit Leiden. Tijdens het doorlopen van zijn co-assistentschappen is hij zijn wetenschappelijk onderzoek begonnen in het Laboratorium Nierziekten onder leiding van Prof. Dr. M.R. Daha. Na het behalen van het artsexamen in 1993, heeft hij zijn onderzoek gecontinueerd in het Hammersmith Hospital in London bij prof.dr. M Walport. Vanaf 1994 tot 2000 is hij opgeleid tot specialist in de Interne Geneeskunde door Prof. Dr. E.A. Meinders en Dr. P.H.E.M.de Meijer in het LUMC. In 2001 keerde hij terug naar de Vakgroep Nierziekten, nu om zijn opleiding Nierziekten (opleider: Prof. Dr. L.A. Paul) te volgen en om het onderzoek te verrichten wat geleid heeft tot dit proefschrift. Vanaf januari 2005 is hij werkzaam zijn binnen de afdeling Nierziekten van het Universitair Medisch Centrum Groningen. 


\section{Publications}

Seelen MA, Roos A, Wieslander J, Mollnes TE, Sjöholm AG, Wurzner R, Loos M, Tedesco F, Sim RB, Garred P, Alexopoulos E, Turner MW, Daha MR. Functional analysis of the classical, alternative, and MBL pathways of the complement system: standardization and validation of a simple ELISA. J of Immunol Methods 2005: 187-198

Trouw LA, Seelen MA, Duijs JMGJ, Wagner S, Loos M, Bajema IM, van Kooten C, Roos A, Daha MR. Activation of the lectin pathway in murine lupus nephritis. Mol immunol 2005:731-740

Seelen MA, van der Bijl EA, Trouw LA, Zuiverloon TCM, Munoz JM, Fallaux-van den Houten FC, Daha MR, Huizinga TWJ, Roos A. A role for mannose-binding lectin dysfunction ingeneration of autoantibodies in systemic lupus erythematosus. Reumatology 2005: 111-119

Trouw LA, Groeneveld TWL, Seelen MA, Duijs JMGJ, Bajema IM, Prins FA, Kishore U, Salant DJ, Verbeek JS, van Kooten C, Daha MR. Anti-C1q autoantibodies deposit in glomeruli but are only pathogenic in combination with glomerular C1q-containing immune complexes. J. Clin. Invest. 2004: 679-688.

Seelen MA, Trouw LA, Daha MR, Roos A. Immuniteit tegen infecties en de rol van het complementsysteem: Klinische toepassing en interpretatie van een nieuwe eenvoudige meetmethode. Ned Tijdschr Geneeskd. 2004: Dutch

Castellano G, Woltman AM, Nauta AJ, Roos A, Trouw LA, Seelen MA, Schena FP, Daha MR, Van Kooten C. Maturation of dendritic cells abrogates C1q production in vivo and in vitro. Blood. 2004:15

Trouw LA, Seelen MA, Visseren R, Duijs JM, Benediktsson H, De Heer E, Roos A, Van Kooten C, Daha MR. Anti-C1q autoantibodies in murine lupus nephritis. Clin Exp Immunol. 2004:41-8.

Seelen MA, Trouw LA, van der Hoorn JW, Fallaux-van den Houten FC, Huizinga TW, Daha MR, Roos A. Autoantibodies against mannose-binding lectin in systemic lupus erythematosus. Clin Exp Immunol. 2003:335-43.

Seelen MA, Trouw LA, Daha MR. Diagnostic and prognostic significance of anti-C1q antibodies in systemic lupus erythematosus. Curr Opin Nephrol Hypertens. 2003:61924.

Trouw LA, Seelen MA, Daha MR. Complement and renal disease. Mol Immunol. 2003:125 34 . 
Trouw LA, Seelen MA, Duijs JM, Benediktsson H, Van Kooten C, Daha MR. Glomerular deposition of $\mathrm{C} 1 \mathrm{q}$ and anti-C1q antibodies in mice following injection of antimouse C1q antibodies. Clin Exp Immunol. 2003:32-9.

Seelen MA, de Meijer PH, Posthuma EF, Meinders AE. Myelofibrosis and idiopathic thrombocytopenic purpura. Ann Hematol. 1997:129-31.

Seelen MA, de Meijer PH, Arnoldus EP, van DuinenSG, Meinders AE. A patient with multiple myeloma presenting with severe polyneuropathy caused by necrotizing vasculitis. Am J Med. 1997

Seelen MA, de Meijer PH, Meinders AE. Serotonin reuptake inhibitor unmasks a pheochromocytoma. Ann Intern Med. 1997:333.

Seelen MA, de Meijer PH, Braun J, Swinkels LM, Waanders H, Meinders AE, Meijer PH. [Hypertension caused by licorice consumption]. Ned Tijdschr Geneeskd. 1996:2632-5. Dutch.

Berger SP, Seelen MA, Hiemstra PS, Gerritsma JS, Heemskerk E, van der Woude FJ, Daha

MR. Proteinase 3, the major autoantigen of Wegener's granulomatosis, enhances IL-8 Production by endothelial cells in vitro. J Am Soc Nephrol. 1996:694-701.

Seelen MA, Athanassiou P, Lynn WA, Norsworthy P, Walport MJ, Cohen J, Davies KA. The anti-lipid A monoclonal antibody E5 binds to rough gram-negative bacteria, fixes C3, and facilitates binding of bacterial immune complexes to both erythrocytes and monocytes. Immunology. 1995:653-61.

Seelen MA, Brooimans RA, van der Woude FJ, van Es LA, Daha MR. IFN-gamma mediates stimulation of complement $\mathrm{C} 4$ biosynthesis in human proximal tubular epithelial cells. Kidney Int. 1993:50-7. 
